\author{
Universidade de São Paulo \\ Instituto de Física
}

\title{
Matéria de quarks (strangelets) de origem astrofísica e sua detecção por experimentos terrestres
}

\author{
Laura Paulucci Machado
}

Orientador: Prof. Dr. Jorge Ernesto Horvath

Co-orientadora: Profa. Dra. Frederique Grassi

Tese de doutorado apresentada ao

Instituto de Física para a obtenção

do título de Doutor em Ciências

Banca examinadora:

Prof. Dr. Jorge Ernesto Horvath (orientador - IAG/USP)

Profa. Dra. Marina Nielsen (IFUSP)

Prof. Dr. Carlos Ourívio Escobar (UNICAMP)

Prof. Dr. Marcelo Chiapparini (UERJ)

Prof. Dr. Sérgio José Barbosa Duarte (CBPF)

São Paulo 

Ao meu avô José, in memoriam. 

"Tho' much is taken, much abides; and tho' We are not now that strength which in old days Moved earth and heaven, that which we are, we are;

One equal temper of heroic hearts, Made weak by time and fate, but strong in will To strive, to seek, to find, and not to yield."

Ulysses Lord Alfred Tennyson 



\section{Resumo}

A hipótese de que a matéria estranha de quarks (um plasma composto por quarks up, down e strange em quantidades aproximadamente iguais) é estável à pressão nula vem sendo considerada há mais de vinte anos, tanto teoricamente quanto em experimentos específicos para sua eventual detecção.

Se a matéria estranha é de fato estável, então poderia haver importantes implicações para a Astrofísica. Entre as mais estimulantes destas implicações está a possibilidade de conversão da matéria nuclear ordinária em matéria estranha no interior das estrelas de nêutrons devido às altíssimas densidades ali encontradas.

Processos tais como coalescência em binárias de estrelas de nêutrons e as próprias supernovas, eventos responsáveis pelo nascimento destas estrelas, poderiam ejetar estruturas finitas de matéria estranha, chamadas strangelets (equivalentes aos núcleos), no meio interestelar. Desta forma, strangelets estariam presentes entre os primários de raios cósmicos e seriam sujeitas a processos elementares análogos aos núcleos ordinários.

Nesta Tese, as strangelets são estudadas desde os prováveis sítios para sua produção astrofísica, passando por interações com a matéria do meio interestelar, até a chegada às imediações terrestres. Estima-se o fluxo de strangelets de baixa energia que poderia ser mantido aprisionado na magnetosfera da Terra, bem como são estudados os processos de suas interações com componentes da atmosfera, com vistas às assinaturas observacionais então resultantes. Desta forma, são determinadas as características relevantes para a identificação destes exóticos por experimentos que testam o fluxo de raios cósmicos, ajudando na melhor compreensão das propriedades da matéria nuclear em alta densidade bariônica e baixa temperatura. 



\begin{abstract}
The strange quark matter hypothesis, which states that a plasma composed of quarks up, down and strange in roughly equal amounts is absolutely stable at zero pressure, has been studied for more than twenty years, both theoretically and during searches for its detection in specific experiments.

If strange quark matter is indeed stable, then there could be important implications for the field of Astrophysics. Among the most stimulating ones is the possibility of conversion of ordinary nuclear matter in strange quark matter in the interior of neutron stars due to the extremely high densities reached in the core of these compact objects.

Processes such as the merger in neutron star binaries systems and supernovae themselves, responsible for the birth of these stars, may eject lumps of strange quark matter, termed strangelets, in the interstellar medium. In this way, strangelets may be present among the cosmic ray flux and be subjected to elementary processes much in the same way as ordinary nuclei.

In this Thesis, strangelets are studied from their likely astrophysical production sites, passing through the interstellar medium until they reach the Earth neighborhood. Estimates of the low energy flux of strangelets that could be trapped in the terrestrial magnetosphere are given. Also, the interaction of these particles with components in the Earth atmosphere are studied with the aim of providing better understanding of the resulting observational signatures. It allows the determination of the relevant characteristics for the identification of these exotics by experiments testing the cosmic ray flux, helping to better understand the properties of nuclear matter at high densities and low temperatures.
\end{abstract}





\section{Agradecimentos}

A minha mãe, ao meu pai e a minha irmã por sempre me apoiarem, pelos anos de carinho, amor, dedicação. Sem vocês eu não teria alçado tão alto vôo.

Ao meu grande amor, Franci, pela confiança e pela motivação, fundamentais.

Ao orientador e amigo Jorge, pelos ensinamentos, pelo incentivo, pelas inúmeras conversas e risadas e, especialmente, por acreditar que a ciência está acima de corporativismos.

Aos professores Frederique Grassi, pela co-orientação, Edilson Crema, pelo incentivo e atenção, e Gustavo Medina-Tanco, pela paciência, apoio, colaboração e amizade, o meu muito obrigada.

À Bel, pela amizade incondicional.

Ao grande amigo Julian, por desde o primeiro instante ter sido esta pessoa com quem posso contar e que já perdi a conta de quantas vezes me ajudou com seu bom-humor infinito.

Ao amigo Rone que, mais do que dividir uma sala de trabalho, partilhou comigo pensamentos, anseios, dúvidas, respostas e muitos cafés.

Aos amigos da graduação, Ulisses, Feng e Rafaello, e às amizades mais recentes, mas não menos importantes, Silas e Marcelos. Vocês por muitas vezes mandaram para longe as chateações, transformando momentos difíceis em alegrias e divertidas memórias.

Aos amigos de grupo, Douglas e Marcio, pela imensa disposição em ajudar e por tantas aventuras juntos.

Ao amigo Eduardo Ratinho, por ser essa pessoa incrível e estar ao meu lado desde tempos imemoriáveis.

Aos amigos Gabi, Danilo, Helder e Masayuki. Também ao Gabriel, por sempre ter uma palavra amiga e tornar a convivência em nossa pequena sala tão agradável.

À Fapesp pelo financiamento. 



\section{Conteúdo}

Motivação

1 Fundamentos teóricos 6

1.1 A hipótese da matéria estranha . . . . . . . . . . . . . . 10

1.2 Matéria estranha em ambientes astrofísicos . . . . . . . . . . . . . . . . 14

1.3 Os cenários de injeção de strangelets no meio interestelar . . . . . . . . . . . . 19

1.4 A procura por strangelets $\ldots \ldots \ldots \ldots$

2 Matéria estranha à temperatura finita $\quad 30$

2.1 Janelas de estabilidade . . . . . . . . . . . . . . . . . . 31

2.2 Strangelets . . . . . . . . . . . . . . . . . . . . . . . 34

2.2.1 A carga elétrica . . . . . . . . . . . . . . . 43

3 A passagem de strangelets pelo meio interestelar 48

3.1 Estados de ionização de strangelets . . . . . . . . . . . . . . . . . . . 48

3.2 Interações hadrônicas . . . . . . . . . . . . . . . . . . . 52

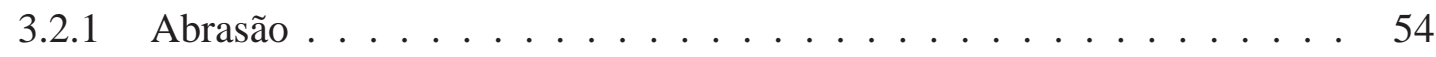

3.2 .2 Fusão . . . . . . . . . . . . . . . . . . . . . . . 59

3.2 .3 Fissão . . . . . . . . . . . . . . . . . . 61

3.2 .4 Excitação .............................. 61

3.2 .5 Desexcitação . . . . . . . . . . . . . . . . . 64

3.3 Cálculos numéricos . . . . . . . . . . . . . . . . . 67

4 A possível detecção de strangelets por experimentos terrestres $\quad 78$ 
4.1 Strangelets na magnetosfera terrestre . . . . . . . . . . . . 78

4.1 .1 O cone de perda atmosférico . . . . . . . . . . 85

4.1.2 Condições de captura . . . . . . . . . . . . . . . . . . . . 87

4.1 .3 A população aprisionada . . . . . . . . . . . . . . . 93

4.2 Strangelets na atmosfera terrestre . . . . . . . . . . . . . 100

4.2.1 Análise dos processos de interação hadrônica . . . . . . . . . . . . . 103

4.2.2 Considerações sobre chuveiros atmosféricos . . . . . . . . . . . . . . 109

5 Conclusões

A Espectro de fragmentação da matéria estranha 116

A.1 O modelo de multifragmentação estatística . . . . . . . . . . . . . . . 117

A.2 Minimização da informação . . . . . . . . . . . . . . . . 123

A.3 Construção do diagrama de fases pelo critério de Gibbs . . . . . . . . . . . 124

B Análise do evento AMS-01: contínuo versus modelo de camadas 127

B.1 Efeitos de camada . . . . . . . . . . . . . . . . . . 127

B.2 O evento AMS-01 como strangelet . . . . . . . . . . . . . . 131

Referências $\quad 141$ 


\section{Lista de Figuras}

1 Diagrama de fases esquemático da QCD . . . . . . . . . . . . . 2

1.1 Representação esquemática do equilíbrio de pressões no modelo de sacola . . . 9

1.2 Representação esquemática da diferença de energia entre a matéria de quarks $u$ e $d$ e matéria estranha . . . . . . . . . . . . . . . . . . . . 10

1.3 Representação esquemática do processo de criação de strangelets de origem cosmológica . . . . . . . . . . . . . . . . . . . 13

1.4 Diagramas massa-raio para diferentes equações de estado possíveis para estrelas de nêutrons . . . . . . . . . . . . . . . . . . 16

1.5 As possíveis composições do interior de uma estrela de nêutrons . . . . . . . . 18

1.6 Representação esquemática da magnestofera de um pulsar estranho . . . . . . . 25

2.1 Janela de estabilidade para a SQM sem emparelhamento à temperatura finita . . 34

2.2 Janela de estabilidade para a SQM no estado CFL à temperatura finita . . . . . 35

2.3 Energia por unidade de número bariônico para strangelets sem emparelhamento de quarks como função de $A \ldots \ldots$. . . . . . . . . . . . . . 37

2.4 Energia por unidade de número bariônico para strangelets CFL como função de $A, B, m_{s}, \Delta$ e temperatura. . . . . . . . . . . . . 38

2.5 Energias de superfície e curvatura para strangelets CFL como função de $m_{s}$. . . 39

2.6 Energias de superfície e curvatura para strangelets CFL como função de $\Delta$. . . 39

2.7 Energias total por unidade de número bariônico, de superfície e de curvatura para strangelets CFL como função de $A$ calculadas para $\Delta=\Delta(T) \quad \ldots$. . . . 40

2.8 Energias de superfície e curvatura como função de $A$ para strangelets sem emparelhamento de quarks . . . . . . . . . . . . . . . . . . 42 
2.9 Carga elétrica de strangelets como função do número bariônico . . . . . . . . . 45

3.1 Carga efetiva versus número bariônico para strangelets de energia $1 \mathrm{GeV} / \mathrm{A}$ após interação com elétrons no meio interestelar. . . . . . . . . . . . . 50

3.2 Representação pictórica do processo de abrasão. . . . . . . . . . . . . . . . . 55

3.3 Representação esquemática para colisões centrais e periféricas. . . . . . . . . . 57

3.4 Representação pictórica da formação de clusters em strangelets. . . . . . . . . . 58

3.5 Visão esquemática do processo de avaliação da interação de uma strangelet com prótons. . . . . . . . . . . . . . . . . . . . . 69

3.6 Comparação dos processos de interação hadrônica como função da energia para strangelets com prótons para diferentes frações de clusters de bárions. . . . . . 72

3.7 Probabilidade de fusão como função da energia para strangelets no meio interestelar para diferentes $A \ldots \ldots \ldots \ldots \ldots \ldots$

3.8 Quantidade de matéria que sofre abrasão como função da energia para strangelets no meio interestelar. . . . . . . . . . . . . . . 73

3.9 Energia de ativação para a fissão de strangelets e energia de excitação devido à fusão. . . . . . . . . . . . . . . . . . . . . . . 74

3.10 Temperatura após interação hadrônica como função da energia para strangelets no meio interestelar. . . . . . . . . . . . . . . . . . . 75

3.11 Temperatura necessária para a emissão de nêutrons por strangelets. . . . . . . . 76

4.1 Ilustração do movimento feito por um íon aprisionado no campo geomagnético

4.2 Representação gráfica das linhas dipolares do campo geomagnético e do ângulo

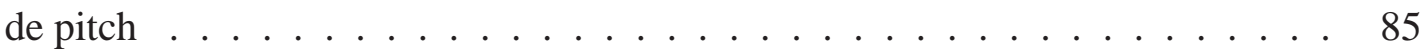

4.3 Cone de perda para strangelets no campo geomagnético. . . . . . . . . . . . 87

4.4 Curvas de restrição ao aprisionamento estável de strangelets sem emparelhamento de quarks para $L=2 \ldots \ldots \ldots$. . . . . . . . . . . 89

4.5 Curvas de restrição ao aprisionamento estável de strangelets CFL para $L=2$. . 90

4.6 Forma da função de distribuição para strangelets aprisionadas no campo geomagnético como função de $L \ldots \ldots$. . . . . . . . . . . . . . . . 95 
4.7 Exemplo esquemático da geração de um chuveiro atmosférico por um núcleo ordinário . . . . . . . . . . . . . . . . . . . 102

4.8 Comparação dos processos de interação hadrônica como função da energia para strangelets com nitrogênio atmosférico para diferentes frações de clusters de bárions. . . . . . . . . . . . . . . . . . . . . . 104

4.9 Probabilidade de fusão como função da energia para strangelets na atmosfera. 105

4.10 Probabilidade de fissão como função da energia para strangelets na atmosfera para $A=100 \ldots \ldots \ldots \ldots \ldots \ldots \ldots$

4.11 Quantidade de matéria que sofre abrasão como função da energia para strangelets na atmosfera.

4.12 Temperatura para strangelets após interação hadrônica como função da energia na atmosfera.

4.13 Rigidez de cutoff geomagnético como função da latitude magnética. . . . . . . . 110

4.14 Rigidez de strangelets como função da energia. . . . . . . . . . . . . . . . . . 111

4.15 Evolução da massa de uma strangelet que penetra a atmosfera terrestre em função da densidade de coluna atravessada.

A.1 Diagrama de fases da matéria estranha calculado com o formalismo do modelo de multifragmentação estatística . . . . . . . . . . . . . . . . 118

A.2 Máximo da função de distribuição no formalismo de multifragmentação estatística.

A.3 Exemplo do pico relevante da função de distribuição para o modelo de multifragmentação estatística com introdução explícita da contribuição de $B$.

A.4 Número atômico para o qual a função de distribuição dos fragmentos atinge seu máximo na fase mista para o modelo de multifragmentação estatístico com introdução da contribuição de $B$.

B.1 Comparação entre a energia de strangelets no modelo de camadas e de gás de Fermi 


\section{Lista de Tabelas}

4.1 Fluxo médio de partículas para uma população estacionária de strangelets calculado com o fluxo "padrão". . . . . . . . . . . . . . . . . . . . . . . . 96

4.2 Fluxo médio de partículas para uma população estacionária de strangelets calculado com o fluxo "detalhado". . . . . . . . . . . . . . . . . . . . . 96 


\section{Motivação}

O diagrama de fases da matéria nuclear em regiões de altas densidades e/ou altas temperaturas é pouco conhecido. Os desenvolvimentos teóricos recentes ajudam a prever o comportamento da matéria sob estas condições extremas mas de maneira ainda aproximada. A propriedade de liberdade assintótica da QCD indica que a temperaturas ou densidades suficientemente altas, $\left(T>>\Lambda_{Q C D}, n>>\Lambda_{Q C D}^{-3}\right)$, a realidade é qualitativamente diferente do regime no qual se encontram os hadrons. Em baixas densidades de energia, os quarks e gluons encontram-se confinados em bárions e mésons, enquanto que em altas densidades de energia, eles devem encontrar-se num estado de plasma.

Alguns eventos sabidamente poderiam elucidar pontos sobre as regiões de transição de fase para a matéria bariônica: certamente durante a evolução do Universo primordial houve uma transição de fase da matéria na região de altas temperaturas e relativamente baixa densidade bariônica (ver figura 1); no entanto, não é possível obter dados relativos à época na qual se estima que o Universo tinha aproximadamente $10^{-5} \mathrm{~s}$. As colisões de íons em aceleradores, que conseguem atingir cada vez energias mais elevadas em centro de massa, poderiam testar uma região intermediária na qual a temperatura é alta e a densidade um pouco mais elevada que aquela da transição do Universo primordial. No entanto, a região ainda mais especulativa está nas relativamente baixas temperaturas e altas densidades.

No extremo de altas temperaturas, os recentes avanços e mais modernas previsões vêm dos cálculos em QCD na rede (para uma recente revisão, veja [2]). Mas mesmo com este método, ainda não foi possível resolver a questão da ordem da transição de fase para o caso cosmológico relevante, ou seja, quando o potencial químico vai a zero e há dois quarks leves $(u, d)$ e um de massa intermediária $(s)$.

Apesar dos enormes avanços nas análises da QCD na rede, estes cálculos não se encontram 


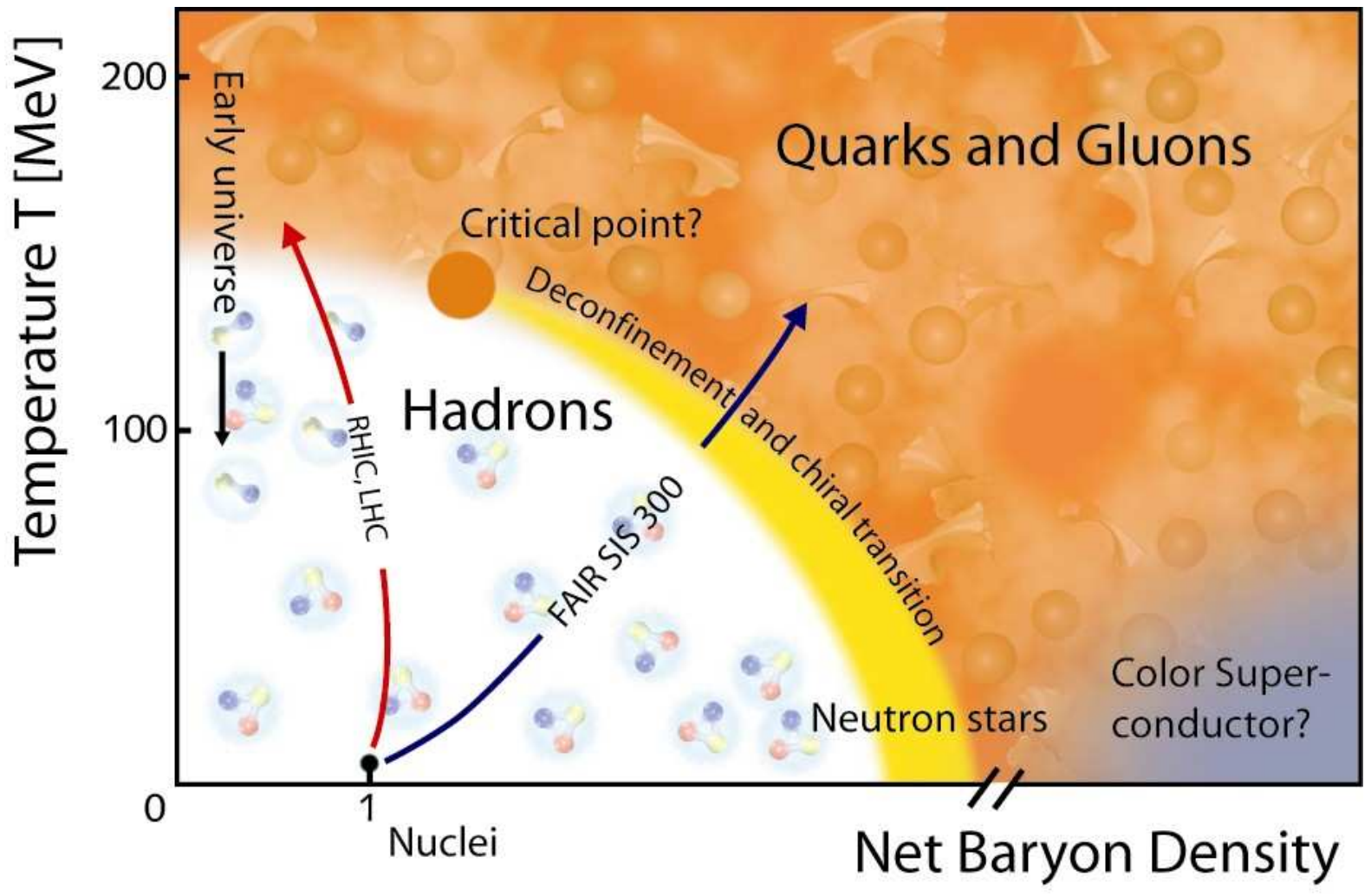

Figura 1: Visão esquemática do que se espera do diagrama de fases da QCD, retirado da referência [1]. Cálculos em QCD na rede indicam que é provável que a transição de fases sofrida pelo universo primordial seja do tipo crossover. Na região de altas densidades e baixas temperaturas, espera-se uma transição de fases de primeira ordem, possivelmente para uma matéria de quarks supercondutora. No entanto ainda não é possível prever com exatidão o ponto no qual esta última ocorre e nem, conseqüentemente, se as densidades encontradas no centro das estrelas de nêutrons são suficientes para que a matéria em seu interior sofra a transição para o plasma de quark e gluons. 
estendidos ao domínio das altas densidades, sendo necessário o desenvolvimento de modelos teóricos que englobem as características pertinentes à matéria nuclear sob tais condições para proceder-se ao estudo desta região do diagrama de fases.

Numa estrela de nêutrons, a densidade em seu centro excede a densidade de saturação nuclear. Quais partículas elementares ocorrem ali e quais as suas propriedades coletivas não são conhecidas com precisão para prever a equação de estado da matéria que compõe as estrelas de nêutrons.

A possibilidade mais trivial é que a matéria seja simplesmente muito rica em nêutrons em tão altas densidades. Mesmo se é este o caso, as densidades altíssimas no interior das estrelas de nêutrons poderiam causar os fenômenos de superfluidez e supercondutividade. Entretanto tem sido sugerido que no núcleo de estrelas de nêutrons podem dominar estados mais exóticos da matéria. Estes incluem condensados de Bose-Einstein de partículas subatômicas como píons e kaons e matéria de quarks (matéria estranha) [3, 4].

Por haver incerteza sobre o comportamento das interações nucleares no regime de alta densidade que deve existir no interior das estrelas de nêutrons, hoje é impossível dizer com precisão o estado da matéria no interior desses objetos.

Uma maneira de elucidar este ponto é obter restrições no espaço de parâmetros permitidos para uma dada equação de estado que condizem com as medidas observacionais das estrelas de nêutrons. Em particular, obter a relação massa-raio para estes objetos seria determinar a equação de estado da matéria nuclear acima da densidade de saturação, ou pelo menos excluir uma série de propostas, que vão desde equações muito duras até bastante moles. No entanto, esta relação é incerta dadas as grandes dificuldades em medir-se parâmetros de objetos de raios da ordem de $10 \mathrm{~km}$ a distâncias de muitos parsecs.

A composição de uma estrela de nêutrons depende primariamente da natureza da interação forte. Estes objetos podem, portanto, ser uma importante janela de estudo para se desvendar o comportamento das interações da matéria nuclear densa e fria. Apesar de algumas limitações que já podem ser impostas às equações de estado permitidas, ainda há muita especulação sobre a composição do interior destes objetos. Espera-se que com o avanço crescente nas técnicas de observação e um maior número de objetos estudados, em breve possamos dizer do que é de fato composta uma estrela de nêutrons. 
Uma das propostas que vem sendo estudada já há mais de duas décadas é a de que as estrelas de nêutrons sejam, na verdade, compostas de um plasma de quarks up, down e strange, formando o que é chamado de matéria estranha de quarks $[5,6,7,8]$. Se a matéria estranha é de fato estável, a presença de "gotículas" desta matéria, chamada de strangelets, vagando no meio interestelar é prevista. Alguns mecanismos de injeção destas têm sido propostos e levam a uma abundância mensurável em meio aos raios cósmicos. De fato, alguns experimentos julgam ter detectado possíveis componentes exóticas $[9,10,11,12]$, ainda que estes dados sejam discutíveis.

Assim sendo, uma maneira simples e, principalmente, direta de se testar a hipótese de matéria estranha como componente do interior de estrelas de nêutrons seria detectar a presença de strangelets por experimentos terrestres, em solo ou em órbita, provenientes do meio interestelar. Nesta Tese, estudamos a injeção, propagação e conseqüente interação destas partículas nas imediações terrestres de modo a prever as assinaturas observacionais destes eventos que possam distingui-los e os identificar com segurança como um teste à equação de estado da matéria bariônica a baixas temperaturas e altas densidades.

Esta Tese está estruturada da seguinte maneira:

O Capítulo 1 introduz conceitos básicos da Cromodinâmica Quântica e apresenta a hipótese da presença de matéria estranha em ambientes astrofísicos. É dada ênfase aos aspectos relevantes aos estudos desta Tese. É discutida a possível existência de matéria de quarks no interior das estrelas de nêutrons e os mecanismos pelos quais strangelets poderiam ser ejetadas no meio interestelar para formar uma componente exótica em meio ao fluxo de raios cósmicos. São também brevemente discutidos os eventos que apresentam características geralmente associadas a evidências para detecção da matéria estranha.

No Capítulo 2, apresentamos uma análise de estabilidade da matéria estranha à temperatura finita. Este constitui um assunto importante quando se consideram os processos de fragmentação da matéria em bulk, na aceleração de strangelets em fontes astrofísicas, para a estabilidade contra o decaimento por emissão de bárions na interação de strangelets com matéria nuclear ordinária e também na possível produção desses exóticos em colisões de íons pesados.

No Capítulo 3, são estudados os processos de interação de strangelets com prótons no 
meio interestelar com especial atenção ao reprocessamento do espectro de massa inicial produzido nas fontes. São considerados os processos de espalação, fusão, fissão, espalhamento e desexcitação através da emissão de píons, fótons, bárions e neutrinos. São brevemente discutidas as implicações destes resultados nos cálculos existentes na literatura.

No Capítulo 4, voltamos nossa atenção aos possíveis modos de detecção de strangelets por experimentos terrestres. Foram estudados dois sítios. Primeiro, a possibilidade de que strangelets de baixo número bariônico e energia sejam ser aprisionadas pelas linhas de campo geomagnético formando um cinturão de radiação exótico em regiões específicas da magnetosfera. Este estudo foi feito considerando-se os critérios para penetração no campo geomagnético e aprisionamento adiabático. A possível interação de strangelets com partículas da atmosfera resultando na sua remoção do fluxo aprisionado e o mecanismo de difusão radial para dentro foram utilizados para determinar a localização da região na qual a densidade de strangelets deve ser máxima. Também a passagem de strangelets pela atmosfera terrestre, na qual strangelets poderiam sofrer alterações em seu número bariônico gerando uma assinatura de emissão de partículas que poderia ser usada para sua identificação, foi estudada. Foram considerados os mesmos mecanismos de interação que pela passagem de strangelets pelo meio interestelar com o objetivo de verificar se estes exóticos podem ser considerados como primários de eventos anômalos reportados na literatura. 


\section{Capítulo 1}

\section{Fundamentos teóricos}

Na década de 1960, experimentos de espalhamento de elétrons de alta energia em prótons no Stanford Linear Accelerator Center (SLAC) começaram a desvendar a estrutura dos nucleons. O espalhamento de elétrons com alta transferência de momento sugeria que o próton continha centros de espalhamento discretos no seu interior. Também as distribuições em ângulo e energia dos elétrons espalhados sugeriam que os centros de espalhamento não possuíam estrutura interna (ou que ainda não havia resolução para distingui-la até as maiores energias atingíveis) *, fenômeno conhecido como invariância de escala. Hoje há evidências convincentes de que os hadrons são compostos de uma substrutura de partículas chamadas quarks.

Prótons e nêutrons não são, portanto, partículas fundamentais, mas sim formados por partons: os gluons (bósons de calibre sem massa, de carga elétrica nula e responsáveis pela força forte) e quarks (férmions de spin 1/2 carregados eletricamente). De fato, todos os hadrons podem ser compreendidos como uma composição de quarks, sendo necessários três para se formar os bárions e dois (um quark e um antiquark) para formar os mésons.

Os quarks são encontrados em seis sabores: up, down, strange, charm, top e bottom. Os partons possuem um número quântico adicional chamado de cor, sendo que os quarks assumem três valores para a cor (azul, verde e vermelho) e os gluons, oito. Um quark pode acoplar-se com um anti-quark e um gluon, resultando em nove possíveis misturas de cor. Em particular, uma delas é um singleto de cor, ou seja, o estado final é simétrico com relação às permutações de cor; os oito gluons acoplam-se aos quarks com uma intensidade medida pela "constante" de

\footnotetext{
${ }^{*}$ Hoje sabe-se que as partículas elementares não têm estrutura interna até os limites de $10^{-18}-10^{-19} \mathrm{~m}$.
} 
acoplamento $\alpha_{S}$. É possível, então, construir uma teoria de campos das interações fortes na qual quarks portadores da carga de cor trocam gluons coloridos de forma análoga à eletrodinâmica quântica (QED), onde férmions com carga elétrica acoplam-se aos fótons, com a diferença de que o próprio campo de calibre também é portador da cor. Esta teoria das interações fortes é chamada de Cromodinâmica Quântica (QCD).

$\mathrm{Na}$ QCD, existem dois efeitos que afetam a intensidade da constante de acoplamento forte, $\alpha_{S}$ : um quark (uma carga de cor isolada) cerca-se de uma nuvem de pares virtuais quarkantiquark coloridos, de modo análogo à polarização do vácuo por uma carga elétrica isolada que se cerca de uma nuvem de pares elétron-pósitron virtuais. No entanto, como já apontamos, os gluons também carregam carga de cor (em contraste com o fóton eletricamente neutro na QED). Então, um gluon pode acoplar-se com um par de gluons e o quark também pode cercarse de pares de gluons. A carga de cor predominante dos gluons perto do quark é a mesma do quark em si. O resultado é que a carga do quark parece estar "espalhada" no espaço, e a carga efetiva diminui conforme aproxima-se do quark. Como a nuvem de gluons virtuais espalha a carga de cor, a força forte entre dois quarks não aumenta tão rápido quanto à força eletromagnética quando a distância entre as partículas é reduzida (efeito de anti-blindagem da carga de cor). Isso tende a fazer com que $\alpha_{S}$ decaia a distâncias pequenas.

O número de gluons virtuais em torno de um quark é maior que o número de quarks virtuais, de modo que a influência dos gluons é a mais forte. O efeito final é fazer com que a constante de acoplamento da QCD, $\alpha_{S}$, decresça a pequenas distâncias, tendendo assintoticamente a zero. Isto implica que, na região de momento elevado ou, equivalentemente, curta distância, a constante de acoplamento torna-se muito pequena e os quarks parecerão quase livres, ou seja, a teoria é assintoticamente livre.

Se quarks de fato comportam-se como partículas livres e têm massas relativamente pequenas, a questão crítica é: por que não se vêem quarks livres como estado final? É um fato empírico que quarks e cor estão confinados no interior dos hadrons. Como regra geral, acreditase que a natureza proíba a existência de partículas "coloridas" como sistemas isolados. Há evidências de cálculos em QCD na rede de que o confinamento é uma propriedade dinâmica da teoria, proveniente dos acoplamentos fortes e não lineares dos gluons.

Conforme a separação entre os quarks aumenta, a força entre estas partículas também au- 
menta, sendo que diagramas nos quais os gluons fragmentam e se recombinam podem contribuir. Estas topologias não têm análogo na QED onde apenas um fóton existe, ao contrário das oito cores para gluons na QCD. Assim, ao tentar separar dois quarks, o campo de cor é "esticado" de tal modo que passa a acumular energia com o aumento da distância. A partir de um dado ponto, a energia necessária para separar as duas partículas excede aquela necessária para a produção de um par quark-antiquark, sendo, portanto, energeticamente mais favorável a criação do par. Isto resulta no que se chama da propriedade de confinamento da cor, levando à existência apenas de estados que são singletos de cor com massas finitas.

Comparando-se a supercondutividade em QED com o confinamento de cor nesta interpretação fenomenológica da QCD, quando mudamos da QED para a QCD, substitui-se o campo magnético $\vec{H}$ pelo campo elétrico de cor $\vec{E}$, o supercondutor pelo vácuo da QCD e o vácuo da QED pelo interior dos hádrons. No primeiro, o campo magnético é expelido do supercondutor, enquanto que no último o campo elétrico de cor é "puxado" para o interior dos hadrons, levando ao confinamento dos quarks (ou cor).

Assim, a complexidade decorrente da existência da multiplicidade de cores faz com que a QCD tenha duas propriedades importantes: o confinamento e a liberdade assintótica. Encontrar soluções exatas para a QCD apresenta problemas diversos. Devido à não-linearidade da teoria, ainda não é possível realizar cálculos completos de fenomenologia hadrônica. As simulações de QCD na rede ainda não proporcionaram respostas precisas a densidades bariônicas finitas. O que tem sido feito, então, é a construção de modelos não-perturbativos que enfatizam um ou outro aspecto da QCD e que, proporcionando visão física, servem de guia para trabalhos futuros. Estes modelos podem ser divididos em: modelos fenomenológicos, nos quais os quarks possuem massa fixa e o confinamento é obtido através da introdução de uma constante de sacola (ou potencial); modelos dinâmicos; e modelos que solucionam a equação de Dyson-Schwinger nos quais as propriedades da matéria são determinadas de maneira auto-consistente.

\section{O modelo de sacola do MIT}

Os modelos mais simples são os chamados modelos de sacola. Eles são construídos com base em três características principais da QCD: os bárions têm números quânticos de sistemas 


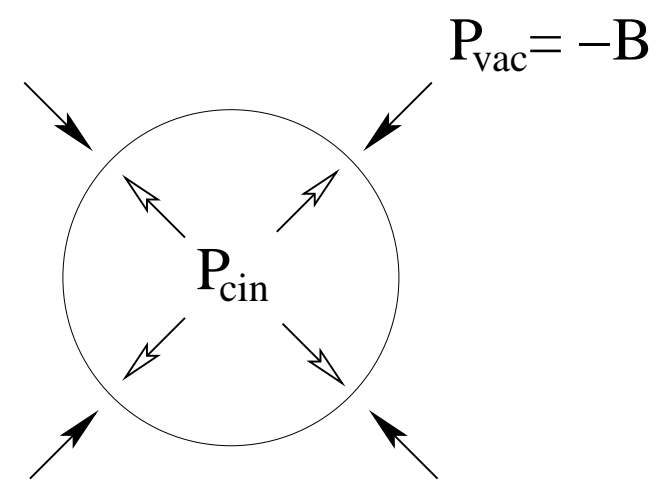

Figura 1.1: Representação esquemática do equilíbrio de pressões no modelo de sacola. O confinamento dos quarks é resultado da pressão externa exercida pelo vácuo. Por sua vez, a bolha torna-se estável através do equilíbrio desta pressão externa com a pressão interna resultante da energia cinética dos quarks presentes em seu interior.

com três quarks e os mesons, de um quark e um antiquark; cor e as forças coloridas encontramse confinadas no interior dos hadrons; e a QCD é assintoticamente livre.

Em particular, o modelo de sacola do MIT [13] considera que bárions são compostos de três quarks relativísticos não interagentes (com os números quânticos corretos) e trata a interação de troca de um gluon como uma perturbação (liberdade assintótica). Esses três quarks encontramse dentro de uma bolha no vácuo de raio $R$ (confinamento). Assume-se que é preciso uma quantidade positiva de densidade de energia para criar-se esta bolha no vácuo, $(E / V)_{v a c}=+B$, ou seja, o confinamento ocorre devido a uma pressão externa, como exemplificado esquematicamente na figura 1.1.

O hadron, então, aparece como uma bolha de gás imersa em um meio, o vácuo. Nesta analogia, como o meio exerce uma "pressão" sobre a bolha, há uma energia volumétrica associada a ela. Também há uma energia cinética associada aos quarks no interior da bolha. O colapso da bolha é evitado devido à energia cinética dos quarks. Por outro lado, esta não se expande livremente devido à tensão de superfície e à pressão do vácuo.

Para um bárion, com os três quarks no estado fundamental representados por espinores relativísticos, a energia cinética é dada por $E_{c i n}=2.04 \times 3 / R$, onde $R$ é o raio da partícula. A idéia da sacola pode ser naturalmente estendida para descrever um grande número de quarks (na aproximação de um gás de Fermi). Embora este modelo seja bastante simples e, sabidamente, descreva a matéria apenas de maneira aproximada, nesta Tese será apenas discutida a hipótese 


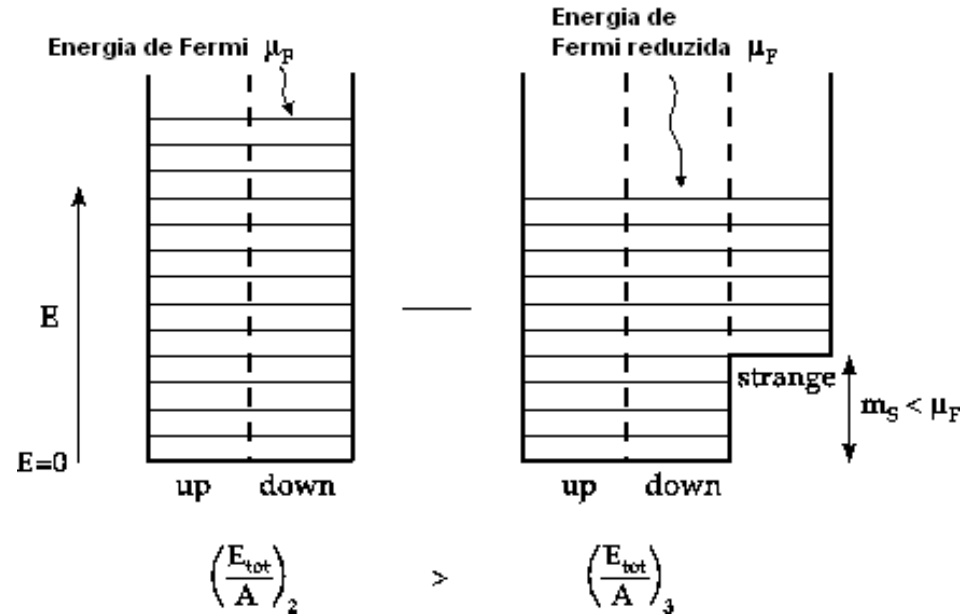

Figura 1.2: Representação esquemática da diferença de energia entre a matéria de quarks $u$ e $d$ e matéria estranha. A introdução do quark $s$ mais massivo poderia ser compensada pelo aparecimento do mar de Fermi associado a este sabor extra. Figura adaptada da referência [14].

de estabilidade da matéria estranha nas bases do modelo de sacola do MIT, sendo esta uma escolha natural para proporcionar simplicidade no tratamento analítico (inclusive quando se consideram as incertezas dos parâmetros que caracterizam a matéria bariônica) e direcionar trabalhos futuros.

\subsection{A hipótese da matéria estranha}

Há quase trinta anos, foi proposto que um gás de Fermi desconfinado composto por quarks up, down e strange, denominado matéria estranha (SQM, da sigla em inglês strange quark matter), poderia ser estável à pressão nula $[5,6,7,8]$. A questão da estabilidade depende se seria ou não possível diminuir a energia de um sistema composto apenas de quarks $u$ e $d$, convertendo aproximadamente um terço de seus componentes no muito mais massivo quark $s$. Como o momento de Fermi da matéria de quarks $u$ e $d$ é da ordem de $300 \mathrm{MeV}$ na região de coexistência com a matÃ (Cria hadrônica em $T=0$, ou seja, maior que a massa estimada para o quark strange, então seria energeticamente favorável a conversão de uma parcela dos quarks não strange deste sistema em quarks $s$ por interações fracas, devido à introdução deste terceiro mar de Fermi (como mostrado esquematicamente na figura 1.2).

Este cenário de estabilidade é viável para um amplo espaço de parâmetros da SQM em 


\subsection{A HIPÓTESE DA MATÉRIA ESTRANHA}

bulk nas bases do modelo de sacola do MIT [15]. Cálculos também indicam que a SQM pode ser estável em outras abordagens, por exemplo, no modelo de camadas, no qual os diferentes níveis de energia na sacola são preenchidos de acordo com o princípio de Pauli [16]. Mais recentemente, estudos indicam que este cenário de estabilidade é ainda mais favorável se a matéria estranha está no estado de color flavor locking (CFL), no qual há emparelhamento de quarks, em processo semelhante à formação dos pares de Cooper em supercondutividade $[17,18,19,20,21]$, devido à diminuição da energia do sistema pela formação do condensado. No entanto, ainda há controvérsias quando se consideram modelos mais elaborados, como o Nambu-Jonas-Lasinio [22].

A análise das propriedades de emparelhamento para a matéria estranha como um supercondutor de cor, não é trivial devido à variedade de sabores, cores e massas dos quarks, além da necessidade de manter-se a matéria em bulk neutra com relação à carga elétrica e de cor e em equilíbrio químico entre os três sabores [18]. Se a massa do quark $s$ é muito pequena, então a matéria estranha deve apresentar emparelhamento dos três sabores de quarks. Se a massa do quark strange for muito elevada, então se espera que apenas os quarks $u$ e $d$ sofram emparelhamento, configurando o estado 2SC (two-flavor superconducting) [23]. O diagrama de fases da QCD está sendo explorado com grande interesse (veja [24] e referências aí citadas). Outros estados de emparelhamento diferentes são possíveis para o supercondutor de cor, dependendo dos valores de $m_{s}, \mu$ e a densidade de carga elétrica, entre eles os estados CFL-K ${ }^{0}, \mathrm{CFL}-\mathrm{K}^{+}$, $\mathrm{CFL}-\pi^{0,-}$, gCFL (gapless CFL), 1SC (single-flavor pairing), CSL (color-spin locked) e LOFF (crystalline pairing).

O fato de observarmos em nosso dia-a-dia núcleos ordinários não contradiz a hipótese de estabilidade da matéria estranha. Se a matéria estranha é mais estável que os núcleos ordinários, o fato deles não decaírem espontaneamente está relacionado com a altíssima ordem da interação fraca necessária para fazer com que aproximadamente um terço dos quarks $u$ e $d$ que compõem os nucleons sejam convertidos simultaneamente em quarks strange. Então, núcleos com $A \gtrsim 6$ seriam estáveis por mais de $10^{60}$ anos, já que a probabilidade para a transição é de ordem $G_{F}^{2 A}$, onde $G_{F}$ é a constante de acoplamento eletrofraca de Fermi. Para valores menores de $A$, efeitos de superfície e curvatura são importantes e desestabilizam a matéria estranha [15].

Inicialmente, foi sugerido que a estabilidade da matéria estranha poderia implicar na existên- 
cia de "relíquias" cosmológicas se a transição de fase associada aos efeitos da QCD no Universo primordial tiver sido uma transição de primeira ordem [5]. Se esta transição ocorresse sem consideráveis desvios do equilíbrio, a percolação de bolhas hadrônicas surgidas no plasma de quarks e gluons durante a expansão do Universo resultaria em um cenário inverso àquele correspondente ao início da transição: haveria bolhas da fase de alta temperatura em um substrato de matéria hadrônica, como mostrado esquematicamente na figura 1.3. Ainda nesta análise, se o esfriamento por emissão de neutrinos dominasse a emissão de bárions, então, a medida que estas bolhas esfriassem, elas se tornariam mais ricas em conteúdo bariônico (perdendo energia para $A$ quase fixo). Se estas regiões densas pudessem sobreviver aos dias de hoje, então seriam candidatas naturais à componente da matéria escura do Universo. No entanto, trabalhos subseqüentes mostraram que a sobrevivência destas relíquias cósmicas até a atualidade é difícil, já que a evaporação de bárions desde o momento de formação teria exaurido seu conteúdo bariônico [25, 26, 27, 28], a menos que o emparelhamento impeça a evaporação total [29]. Além disso, cálculos de QCD na rede indicam que a transição de fase quark-hadron no Universo primordial teria sido um crossover $^{\dagger}$ e não uma transição de primeira ordem (veja [19] e referências aí citadas). Se este for o caso, então as bolhas de SQM sequer seriam formadas durante este período.

Apesar destes resultados, se de fato a matéria estranha é o estado fundamental da matéria bariônica densa e fria, ainda poderia haver importantes implicações astrofísicas, por exemplo, o interior das estrelas de nêutrons poderia ser composto por esta matéria exótica, seja na forma de uma estrela híbrida ou de uma estrela estranha [4, 30, 31, 32, 33]. A existência de estrelas estranhas implicaria na presença de strangelets, porções finitas de matéria estranha, entre os primários de raios cósmicos (vide abaixo). Strangelets seriam objetos com massas variando, em princípio, desde poucas dezenas em número bariônico a $A \sim 2 \times 10^{57}$, adequado para a descrição de uma estrela estranha instável gravitacionalmente. Sua relação carga-massa seria muito menor do que aquela verificada para núcleos ordinários, mas em valores absolutos, poderiam alcançar valores para carga atômica muito maiores do que as dos núcleos.

A descrição da matéria estranha em bulk sem emparelhamento (também referida nesta tese

\footnotetext{
${ }^{\dagger} \mathrm{Na}$ região de crossover, a física muda suavemente e os comprimentos de correlação não divergem (não há fronteira bem definida entre as fases).
} 


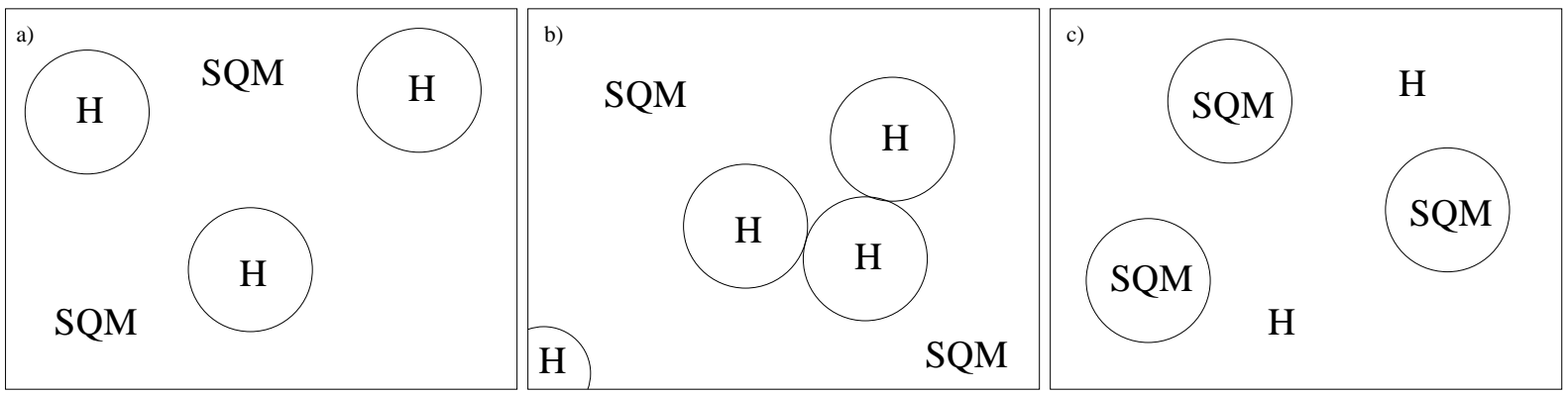

Figura 1.3: Representação esquemática do processo de criação de strangelets de origem cosmológica, de acordo com a referência [5]. a) inicialmente, quando o sistema atinge a temperatura crítica para a transição de fase, surgem bolhas isoladas da fase de menor temperatura (no caso, hadrons, indicada por $H$ ) na fase de alta temperatura (matéria estranha, indicada por $S Q M$ ); $b$ ) as bolhas em expansão encontram-se e percolam; $c$ ) ao fim da transição, há bolhas isoladas de matéria estranha (strangelets) em fase de encolhimento num substrato da fase de baixa temperatura.

como "normal" e através da sigla NSQM) não é complicada: supõe-se que esta contém quarks $u, d$ e $s$ e elétrons (ou pósitrons) para manter a neutralidade de carga elétrica. O equilíbrio químico é mantido pelas interações fracas,

$$
\begin{gathered}
d \leftrightarrow u+e^{-}+\bar{\nu}_{e}, \\
s \leftrightarrow u+e^{-}+\bar{\nu}_{e}, \\
\quad u+s \leftrightarrow d+u .
\end{gathered}
$$

Os neutrinos em geral escapam do sistema, não sendo, portanto, associado a eles um potencial químico. As equações de equilíbrio podem ser resolvidas sem dificuldades.

O estado de supercondutividade de cor para a matéria de quarks é possível devido à interação fortemente atrativa entre os quarks em alguns canais. Neste estado, a simetria local de cor será quebrada com a formação dos pares, já que estes não são brancos. Se a SQM encontra-se no estado CFL, no qual os quarks de todos os sabores e cores perto da superfície de Fermi formam pares, por simetria, existe um número igual para os três sabores e a mistura em bulk é automaticamente neutra [34]. Neste caso, a condição para os potenciais químicos é dada pela igualdade do momento de Fermi para os quarks $u, d$ e $s$. Sendo o momento de Fermi para cada componente $i$ escrito como $\nu_{i}=\sqrt{\mu_{i}^{2}-m_{i}^{2}}$ e o potencial químico comum da fase, 
$3 \mu=\mu_{u}+\mu_{d}+\mu_{s}$, obtém-se

$$
\nu=2 \mu-\left(\mu^{2}+m_{s}^{2} / 3\right)^{1 / 2}
$$

As soluções são um pouco mais complexas do que no caso sem emparelhamento de quarks mas perfeitamente tratáveis. Retornaremos explicitamente a este assunto no capítulo 2.

\subsection{Matéria estranha em ambientes astrofísicos}

Já mencionamos que a produção contemporânea de SQM leva naturalmente à consideração do interior das estrelas compactas como "laboratórios" de alta densidade. Os objetos compactos astrofísicos estão classificados em três categorias: buracos negros, estrelas de nêutrons e anãs brancas. Estes constituem o estágio final da evolução de estrelas de massa maiores que $1 M_{\odot}$, onde $M_{\odot}$ representa a massa do Sol. Anãs brancas e estrelas de nêutrons são estrelas suportadas pela pressão de degenerescência dos férmions que as constituem, enquanto que um buraco negro é um objeto formado quando a pressão de degenerescência das partículas que o constituem não conseguiu impedir o colapso completo da estrela que o originou, o que resulta na formação de uma região do espaço-tempo desconectada do resto do Universo.

A idéia de uma estrela suportada pela pressão de degenerescência dos nêutrons surgiu em 1934, pouco depois da descoberta desta partícula, com a hipótese de Landau (numa carta que nunca foi publicada) e com o trabalho de Baade e Zwicky [35]. Esta seria uma estrela de pequeno raio e alta densidade, sendo mais ligada gravitacionalmente que as estrelas ordinárias. Seguiu-se, então, o cálculo de Oppenheimer e Volkoff [36], utilizando-se das equações relativísticas de equilíbrio hidrostático, de um modelo no qual a estrela seria composta por um gás ideal de nêutrons livres.

Somente em 1962 houve a primeira detecção de uma fonte de raios-X consistente com a idéia de um objeto nas bases daquele proposto por Baade e Zwicky. Mais tarde, em 1967, o primeiro pulsar foi detectado, sendo prontamente associado a uma estrela de nêutrons em rotação. As descobertas dos pulsares de Vela e Caranguejo, situados em remanescentes de supernovas, forneceram a conexão entre as explosões de supernovas e a formação de estrelas de nêutrons. 
As observações de estrelas de nêutrons indicam que não é possível compatibilizar muitas das massas inferidas para estes objetos com a massa máxima permitida em um modelo no qual as estrelas seriam compostas somente por nêutrons livres (que suportariam uma massa máxima de $0.7 M_{\odot}$, enquanto que a maioria das massas destas estrelas detectadas está em torno de $1.4 M_{\odot}$ ). Supor um modelo de gás ideal para uma mistura de prótons, nêutrons e elétrons não interagentes produz resultados para a massa máxima, raio e densidades centrais similares ao caso de ter-se simplesmente nêutrons. Assim, faz-se necessária a introdução das interações entre os nucleons aos modelos. A equação de estado que descreve a matéria hadrônica em densidades superiores à densidade de saturação nuclear é bastante incerta e esta incerteza é refletida nas propriedades esperadas para as estrelas de nêutrons.

Desta forma, diversas equações de estado são propostas para a descrição da matéria hadrônica a elevadas densidades. Estas diferem basicamente quanto à composição exata da matéria (nêutrons, prótons, elétrons, nuclídeos, $\Lambda$ 's, $\Delta$ 's...), no modelo de interação (interação entre dois e três nucleons, por troca de píons, teoria de campo médio...) e na teoria para muitos corpos utilizada para determinar a equação de estado (método variacional com vínculos, aproximação relativística de campo médio, modelo de gota líquida, etc) ${ }^{\ddagger}$. Estas diferenças produzem significativa mudança na dependência da pressão com a densidade no interior destes objetos compactos.

Para um dado modelo de equação de estado, $P(\rho)$, as propriedades macroscópicas, massa e raio, para as estrelas compactas são então calculadas utilizando-se as equações de estrutura estelar (as equações Tolmann-Oppenheimer-Volkoff que descrevem objetos autogravitantes, esfericamente simétricos e sem rotação ). Quando dispostas em um diagrama massa-raio, produzem o resultado mostrado na figura 1.4. As observações de estrelas de nêutrons devem ser, portanto, comparadas às previsões de diferentes equações de estado para verificar-se qual melhor representa a composição do seu interior (ou pelo menos quais não representam).

Além de encontrar equações de estado que sejam compatíveis com as observações no diagrama massa-raio, há também uma série de fenômenos que devem ser explicados. Num conjunto de pulsares, foram observados glitches, mudanças súbitas na frequiência rotacional, que requerem origem em algum tipo de superfluido presente na estrutura interna dessas estrelas, como

\footnotetext{
${ }_{\dagger}^{\ddagger}$ Veja, por exemplo, [24] e referências aí citadas.
} 

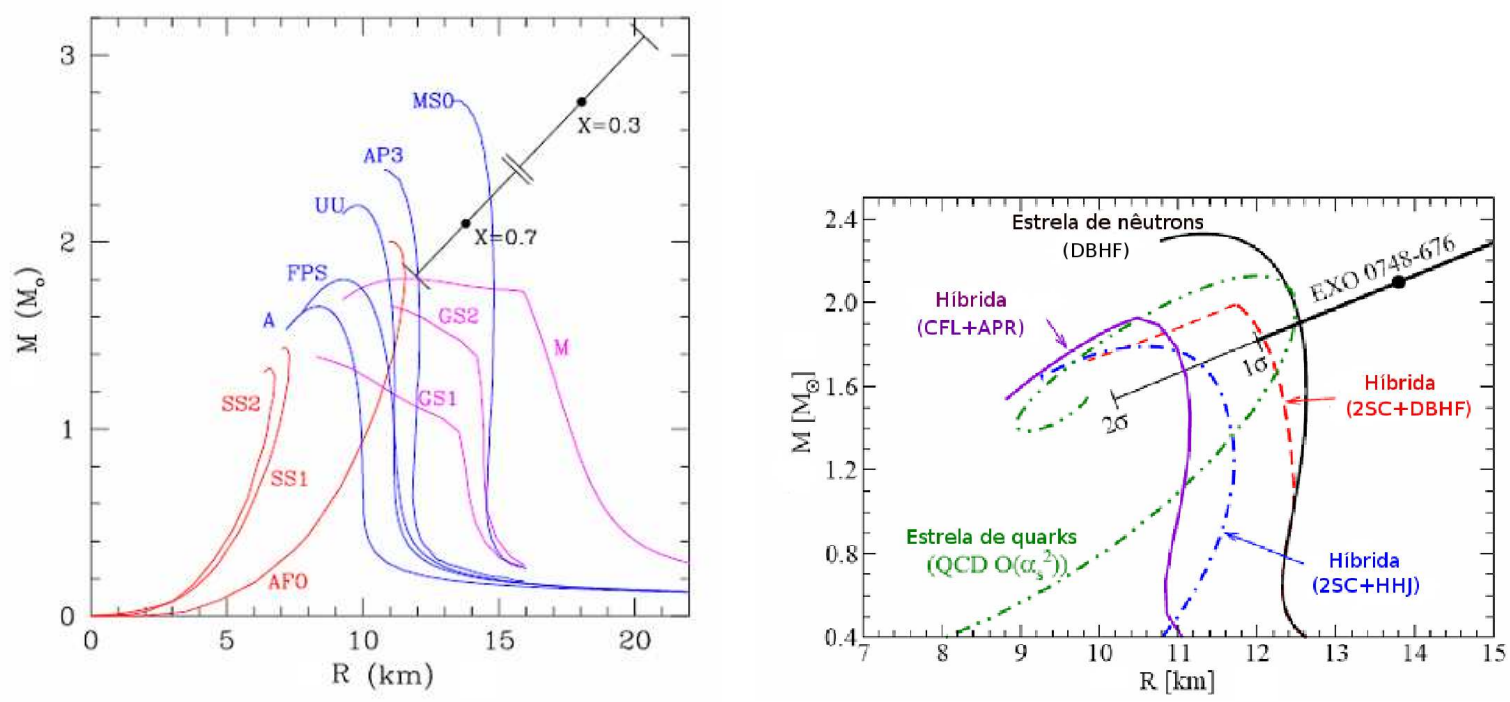

Figura 1.4: Diagrama massa-raio para diferentes equações de estado possíveis para estrelas de nêutrons, adaptado das referências [37, 38]. Vemos o comportamento típico das baseadas na composição do interior de matéria nuclear ordinária naquelas identificadas pelas siglas FPS, $U U, A P 3, M S O$ e $D B H F$. As que pressupõem a existência de condensados podem ser vistas em $G S 1, G S 2$ e $M$. As equações de estado para a matéria desconfinada apenas no caroço ou dominando quase totalmente o interior da estrela, têm comportamento das curvas $S S 1$, SS2, AFO, estrela de quark e híbridas.

sugerido pelos tempos macroscópicos de relaxação ao estado rotacional original. Também as erupções (bursts) de raios-X (aumento repentino no fluxo de raios-X em fontes de raios-X) e a conexão da colisão de duas estrelas de nêutrons com uma dada classe de erupções de raios gama devem depender da composição desses objetos compactos, bem como seu esfriamento. Enfim, toda a fenomenologia de pulsares deve ser bem compreendida e explicada pelos modelos de estrutura para essas estrelas.

Cerca de três décadas atrás, foi sugerido que, devido às altíssimas densidades alcançadas no interior das estrelas de nêutrons (da ordem de $10^{14} \mathrm{~g} / \mathrm{cm}^{3}$ ), os constituintes hadrônicos no interior destas estrelas poderiam passar a uma fase desconfinada (ou seja, cruzar a linha de transição de fase ao longo do eixo $T=0$ mostrada no diagrama da figura 1), resultando em um núcleo de matéria de quark para estes objetos.

Ainda nem os experimentos de altas energias nem as simulações de QCD na rede puderam fornecer de maneira conclusiva a densidade na qual a transição de fase para a matéria de quarks deve ocorrer ao longo do eixo $T=0$. Uma estimativa baseada em argumentos geométricos 
mostra que os nucleons começam a se tocar em densidades da ordem de aproximadamente $\left(4 \pi r_{N}^{3} / 3\right)^{-1} \simeq 0.24 \mathrm{fm}^{-3}$, onde $r_{N} \simeq 1 \mathrm{fm}$ é o raio do nucleon. Este valor está abaixo de duas vezes a densidade de saturação nuclear, $\rho_{0}=0.16 \mathrm{fm}^{-3}$ [39]. Acima desta densidade, parece então concebível que os hadrons "dissolvam-se" de modo que os quarks não permaneçam confinados em seus interiores (resultado da propriedade de liberdade assintótica da QCD). Dependendo da massa da estrela, densidades da ordem de três ou mais vezes $\rho_{0}$ são facilmente alcançadas em seu interior, de modo que os prótons e nêutrons poderiam ser dissolvidos em quarks pela força da gravidade [40, 41]. Além disso, os quarks up e down de alta energia seriam rapidamente convertidos em quarks strange aproximadamente na mesma densidade na qual ocorre o desconfinamento [42, 43], resultando em um núcleo de matéria estranha.

A conversão de um pequeno volume de matéria hadrônica em matéria de quarks no núcleo de uma estrela de nêutrons, causaria uma onda de conversão da matéria circundante (ainda na forma de nucleons) até que o equilíbrio entre as duas fases da matéria seja alcançado e o processo de conversão pare.

Desta forma, há uma enorme variedade de possíveis composições para as chamadas estrelas de nêutrons, conforme mostrado esquematicamente na figura 1.5. As propostas vão desde a conservadora possibilidade de que essas estrelas sejam compostas de uma mistura de prótons, nêutrons e elétrons em seu interior até a possível existência de matéria de quarks ou condensados.

Se a hipótese da estabilidade da matéria estranha for de fato válida, então estrelas de nêutrons seriam, na verdade, estrelas estranhas. Em princípio, essas duas classes de estrelas compactas (estranhas e de matéria nuclear ordinária) poderiam coexistir. No entanto, se a SQM é o estado fundamental da matéria bariônica fria e densa, então as galáxias devem estar contaminadas com strangelets que, dependendo das suas energias [44], poderiam converter estrelas de nêutrons em estrelas estranhas [45, 46, 47]. Então, fatalmente todas as estrelas de nêutrons seriam convertidas em algum período de sua existência em estrelas estranhas.

Outra consequiência da estabilidade da matéria estranha seria a possível existência de "anãs brancas estranhas", ou seja, anãs brancas que poderiam conter núcleos de matéria de quark inertes mantidos separados do envelope de matéria nuclear ordinária por um campo elétrico superficial [4, 43]. Ou ainda, a existência de MACHOS (da sigla em inglês, massive compact 


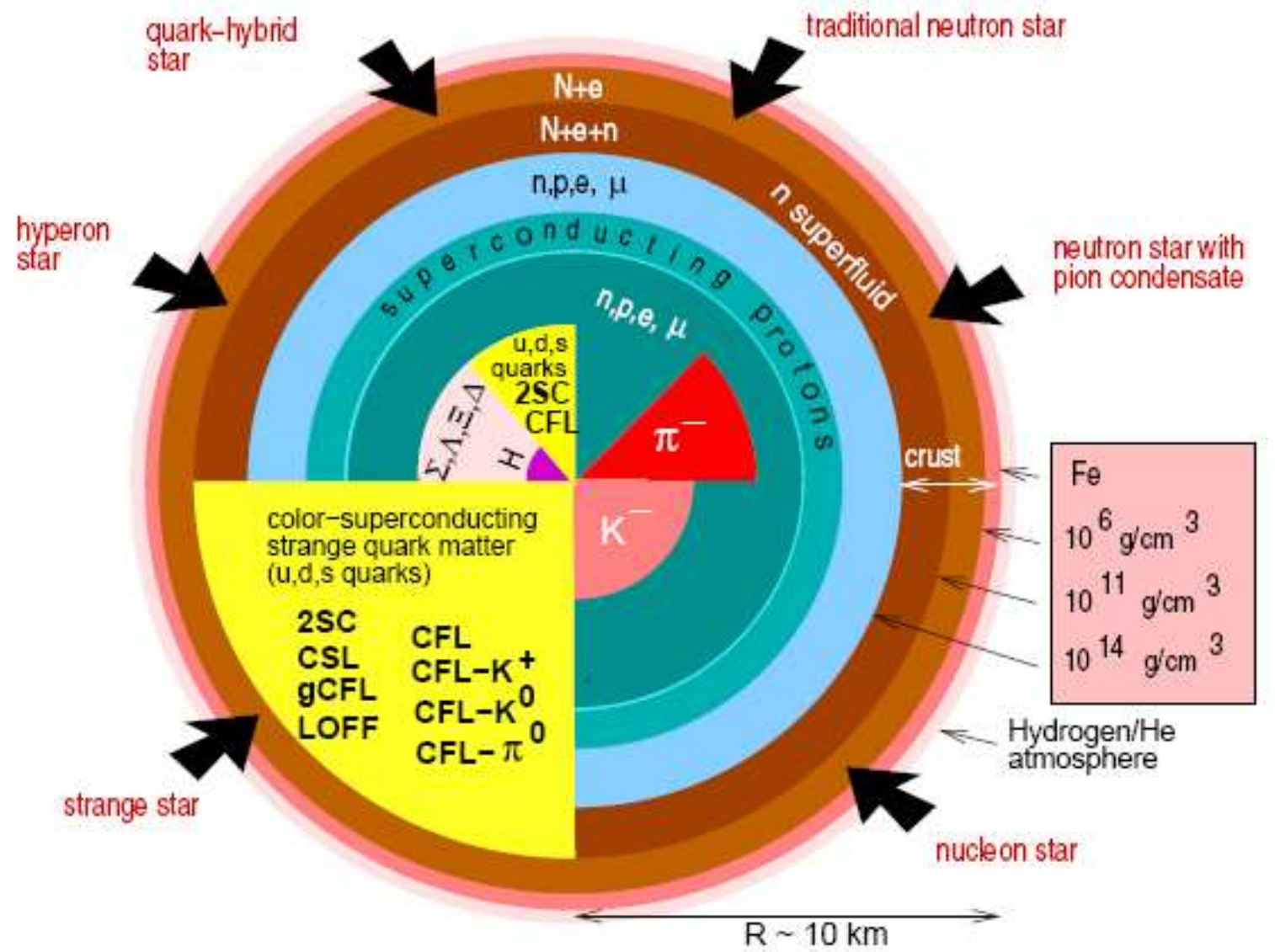

Figura 1.5: As possíveis propostas para a composição do interior de uma estrela de nêutrons vão desde as mais antigas, com composição de matéria nuclear ordinária, passando pela existência de condensados de píons e kaons, o aparecimento de hadrons mais pesados como $\Lambda$ 's, até o desconfinamento completo da matéria hadrônica em quarks, seja apenas no caroço ou dominando quase totalmente o interior da estrela. Figura extraída da referência [24]. 
halo objects) estranhos que poderiam contabilizar uma fração da matéria escura da galáxia e poderiam ser detectados por experimentos de microlentes gravitacionais dependendo da sua abundância $[48]^{\S}$

\subsection{Os cenários de injeção de strangelets no meio interestelar}

Três diferentes cenários astrofísicos de injeção de strangelets no meio interestelar têm sido propostos: a coalescência (processo de merger) de estrelas estranhas, a formação de matéria estranha em supernovas tipo II e a injeção e aceleração de strangelets na magnetosfera de pulsares. Um breve resumo destes servirá para contextualizar a possível presença de strangelets no fluxo de raios cósmicos, objeto de estudo desta Tese.

\section{Coalescência de estrelas estranhas}

Witten [5] já havia sugerido que a coalescência de estrelas estranhas poderia ser uma fonte de strangelets para o fluxo de raios cósmicos devido à quase inevitável ejeção de matéria nestes eventos. Em princípio, o espectro de injeção e a massa total na Galáxia podem ser calculados a partir da ocorrência desses eventos e da massa total ejetada em cada um deles.

A taxa de coalescência galáctica para binárias de estrelas de nêutrons é de aproximadamente uma colisão na Galáxia a cada 3000 a 60000 anos e simulações indicam que a massa liberada por evento é da ordem $10^{-5}$ a $10^{-2} M_{\odot}$. Isto levaria a uma massa total liberada na Galáxia de $10^{-10}$ a $3 \times 10^{-6} M_{\odot}$ por ano. Estas estimativas, no entanto, são um pouco incertas tendo em vista que recentemente foi revisado o número de sistemas binários de estrelas de nêutrons, resultando em um aumento do mesmo [49], enquanto que estudos numéricos sugerem que a massa total ejetada nesses eventos pode ser menor do que aquela previamente esperada, pelo menos em coalescências de estrelas estranhas e buracos negros [50, 51]. Ainda não há simulações completas para um sistema de duas estrelas estranhas, que só foi parcialmente estudado em [52] com interesses outros que não a análise da ejeção de matéria para o meio interestelar nestes eventos.

\footnotetext{
$\S$ Os MACHOS são corpos astronômicos que poderiam explicar a aparente presença de matéria escura nos halos galácticos. Entre as propostas de MACHOS encontram-se as estrelas de nêutrons, buracos negros, anãs brancas velhas, anãs marrons entre outros tipos de corpos não-luminosos.
} 
Conforme as estrelas espiralam em direção uma a outra, devido à perda de energia por emissão de ondas gravitacionais, há uma fase de disrupção por forças de maré antes da colisão final. Analisando-se o balanço entre as forças de maré e a tensão de superfície da matéria estranha, espera-se que, durante este estágio, os pedaços de matéria estranha extraídos do sistema sejam macroscópicos, tipicamente de número bariônico da ordem de $10^{38}$. Uma grande fração desta matéria extraída deve ficar orbitando o sistema com velocidades típicas de $0,1 c$, onde $c$ é a velocidade da luz. Colisões subseqüentes devem diminuir seu número de massa. Considerandose que toda a energia cinética resultante dessas colisões é usada para compensar as energias de superfície e curvatura necessárias para a formação de strangelets de menor massa, acredita-se que a distribuição de strangelets encontre-se majoritariamente na faixa de $A \approx 10^{2}-10^{4}$ [53].

Além da análise numérica apresentada em [54], estimativas do fluxo de strangelets na Galáxia foram dadas por Madsen [55]. Considera-se que todas as strangelets liberadas na coalescência apresentam o mesmo número bariônico $A$, uma incrível aproximação que se faz necessária já que ainda não foi possível o cálculo do espectro de massa resultante da fragmentação da matéria estranha (ver apêndice A). Desta forma, o fluxo total obtido é válido como um limite inferior para uma massa total fixa ejetada se strangelets apresentarem uma distribuição de massa com número bariônico menor que o $A$ adotado como espectro inicial.

Como as escalas de tempo características para aceleração, perda de energia, espalação (reação nuclear na qual um núcleo bombardeado ejeta diferentes partículas) e escape da Galáxia de strangelets são muito menores que a idade da Via Láctea, considera-se distribuição estacionária para as partículas. Os termos considerados na resolução da equação de propagação são descritos brevemente nos ítens abaixo:

- Termo de fonte: strangelets de número bariônico $A$ são produzidas a uma taxa de $10^{-10}$ $M_{\odot} /$ ano e espalhadas igualmente pela Galáxia. São aceleradas pelo mecanismo de Fermi em remanescentes de supernovas o que resulta em um espectro de lei de potência para a distribuição em rigidez $R(R=p c / Z e$, onde $p$ e $Z$ são o momento e carga elétrica da partícula e $c$ e $e$, a velocidade da luz e a carga do elétron, respectivamente);

- Difusão e escape da Galáxia: descreve a difusão dos raios cósmicos e eventual escape do campo magnético que os confina na Galáxia; 
- Perda de energia: considera as perdas por ionização do hidrogênio neutro do meio interestelar e por produção de píons através de colisões inelásticas em energias relativísticas $(\gamma \geq 1,3)$

- Espalação: considera-se que o processo destrói as strangelets, o que leva a subestimar o fluxo;

- Reaceleração : devido à passagem de strangelets por novos remanescentes de supernovas.

É possível encontrar três regimes para a propagação de strangelets no meio interestelar: a baixas energias, as perdas de energia dominam sobre os outros processos, enquanto que a médias e altas energias, os processos dominantes são espalação e escape da Galáxia, respectivamente.

Assim, neste cenário, o fluxo total de strangelets no meio interestelar (ISM, da sigla em inglês interstellar medium) que atinge a Terra, conforme estimado por Madsen [55] no mecanismo de injeção por coalescência de estrelas estranhas, é dado por

$$
F \approx 2 \times 10^{5} \mathrm{~m}^{-2} \mathrm{yr}^{-1} s r^{-1} A^{-0,467} Z^{-1,2} \max \left[R_{S M}, R_{G C}\right]^{-1,2} \Lambda,
$$

onde $R_{S M}$ e $R_{G C}$ são a modulação solar e a rigidez para o cutoff geomagnético, respectivamente, e $\Lambda$ é um parâmetro de incerteza que se adota como sendo de $\mathcal{O}(1)$ e expressa a incerteza associada à normalização do fluxo de strangelets com a massa total ejetada. Este é um fluxo perfeitamente passível de ser detectado por experimentos já existentes e por aqueles que estão programados para entrar em operação [56].

\section{Explosões de supernovas}

Outro cenário proposto para a produção de strangelets de origem astrofísica está relacionado a um modelo de explosões de supernovas tipo II, Ib e Ic, ou seja, supernovas resultantes do colapso gravitacional de estrelas massivas, devido à conversão matéria nuclear $\rightarrow$ matéria estranha no caroço da estrela em colapso [31,32]. Este modelo veio propor uma explicação 
ao fato de que há muitas dificuldades nas simulações computacionais que visam explicar o processo de ejeção de uma grande quantidade de massa e energia na fase final de evolução dessas estrelas. Neste cenário seria possível emitir strangelets junto com as camadas exteriores da estrela.

Supernovas são eventos astrofísicos que ocorrem quando estrelas massivas, com massas de $8-70 M_{\odot}$, exaurem todo o seu combustível nuclear, não sendo mais possível o balanço entre a atração gravitacional e a pressão térmica que estabiliza a matéria que as compõem. Estas estrelas evoluem através da queima termonuclear de combustíveis cada vez mais pesados, desenvolvendo, então, um núcleo de ferro suportado pela pressão de degenerescência dos elétrons. No entanto, quando este núcleo de ferro atinge a massa de Chandrasekhar ${ }^{\Uparrow}, M_{C h} \simeq 1,4 M_{\odot}$, o núcleo torna-se instável e se inicia o colapso gravitacional. Inicialmente, em escalas de tempo dinâmicas, ocorre a fotodissociação parcial dos núcleos de ferro, diminuindo a pressão da matéria. Conforme o colapso continua, a densidade aumenta, elevando o potencial químico eletrônico, o que permite o processo de neutronização do núcleo estelar. Os neutrinos produzidos nessa região por captura eletrônica ficam aprisionados devido à densidade muito elevada do meio $\left(n \sim 3 n_{0}=0,48 \mathrm{fm}^{-3}\right)$.

Conforme a densidade em seu interior aumenta, o colapso é freado no núcleo devido à pressão de degenerescência dos nucleons. As camadas da estrela exteriores ao núcleo continuam a deslocar-se em direção ao centro a velocidades supersônicas. Como resultado, quando esta matéria atinge a superfície do núcleo, que agora não mais sofre colapso gravitacional, originase uma onda de choque radialmente para fora com energia de algumas vezes $10^{51}$ ergs (prompt shock). No entanto, esta energia é drenada na dissociação nuclear da matéria nas camadas exteriores em colapso e na dissipação de neutrinos. Efetivamente, a frente de choque mantémse a uma distância de algumas centenas de quilômetros do centro e as camadas de matéria que alcançam esta região são comprimidas e aquecidas por esta frente e se acomodam sobre a proto-estrela compacta.

Os neutrinos aprisionados no núcleo da estrela, na verdade, difundem-se lentamente e esca-

\footnotetext{
"A massa de Chandrasekhar é a máxima massa que pode ser suportada contra o colapso gravitacional pela pressão de degenerescência dos elétrons. O valor numérico para este parâmetro é dependente da fração de elétrons presente na matéria que compõe a estrela.
} 
pam em escalas de segundos, sendo que uma parte deles são absorvidos pelo manto de matéria que atingiu a região da frente de choque, aquecendo-o. Este processo (neutrino heating) deve criar as condições necessárias para a explosão de supernova.

Até o momento, apenas uma simulação computacional conseguiu sucesso em obter as condições necessárias para a explosão em supernova de uma estrela massiva com massa inicial de $11 M_{\odot}$ [57]. No entanto, estes programas são extremamente complexos já que precisam incorporar efeitos de relatividade geral, efeitos de turbulência e de convecção em simulações mutidimensionais. Ainda se espera que outras simulações venham a confirmar estes resultados, inclusive para estrelas de massas mais elevadas.

Foi frente a estas controvérsias que o modelo de supernova impulsionado pelo aparecimento da matéria estranha no interior da estrela em colapso foi proposto. O mecanismo responsável pela explosão nesse caso seria considerar que a emissão de neutrinos prevista no modelo de neutrino heating previne o recolapso mas que seria incapaz de ejetar as camadas externas da estrela.

O núcleo da estrela alcançaria, então, densidades nas quais seria possível o desconfinamento da matéria nuclear rica em nêutrons em matéria estranha. Se a matéria estranha é mais estável que a matéria nuclear ordinária, a discontinuidade da pressão entre as duas fases resultaria em uma onda de choque movendo-se radialmente para fora [58]. Esta onda de choque converteria a matéria na forma de nêutrons que se encontra à frente, no modo de detonação. Cada nucleon convertido em matéria estranha liberaria uma quantidade de energia que impulsionaria a onda de choque. Sendo este um processo espontâneo, a detonação corresponderia à mínima quantidade de entropia produzida por um processo de detonação e a velocidade da frente teria o valor da velocidade do som no meio (neste caso, $1 / \sqrt{3}$ ).

A detonação iria proceder até que a densidade da matéria nuclear à frente fosse menor que $\rho_{c} \sim 1,8 \rho_{0}$. Deste ponto em diante, o fluido evoluiria como uma onda de choque padrão em direção à borda da estrela compacta [59]. Como o número de Reynolds é grande tanto para a matéria nuclear quanto para a estranha (da ordem de $\sim 10$ ), deve haver uma região turbulenta atrás da frente de detonação. Conforme a frente de onda se propaga, matéria estranha poderia ser misturada por efeitos de turbulência [60] à matéria nuclear e ser ejetada junto com ela, impulsionando strangelets com $v \sim 0,1 c$ e gerando, assim, uma abundância não nula no ISM. 
Cabe aqui apontar que as supernovas de colapso são de uma dezena a uma centena de vezes mais freqüentes que a coalescência de estrelas de nêutrons já discutida, podendo, portanto, contribuir de modo significativo à ejeção de strangelets na Galáxia se o mecanismo de explosão discutido aqui se mostrar viável.

Adotando um perfil de densidade constante em uma massa de $M \simeq 1,6 M_{\odot}$ e desconsiderando interações gravitacionais, a quantidade de energia estimada que seria carregada na forma de movimento hidrodinâmico é da ordem de $10^{51} \mathrm{erg}$, magnitude de energia esperada para os eventos de supernova tipo I. Esta onda de detonação teria energia suficiente para ejetar as camadas exteriores da estrela.

\section{Injeção e aceleração por pulsares}

Se o cenário de estabilidade da matéria estranha é favorável à existência de estrelas estranhas, então é possível que a superfície destes objetos seja, na verdade, composta por strangelets de carga elétrica positiva e massas da ordem de $A \sim 10^{3}$ em um substrato uniforme de elétrons $[61,62]$.

A magnetosfera de um pulsar " apresenta uma região na qual as linhas de campo magnético co-rotacionam com a estrela. Esta região estende-se até a localização do chamado cilindro de luz, um cilindro imaginário com eixo ao longo do eixo de rotação do pulsar e com raio que se estende até o ponto no qual a velocidade de co-rotação é igual a velocidade da luz. A partir deste ponto afastando-se da estrela, aparece uma componente de campo toroidal formada pelas linhas de campo magnético abertas que passam pelo cilindro de luz e são defletidas de volta (ver figura 1.6). Partículas carregadas na magnetosfera poderiam, então, ser aceleradas por linhas de campo magnético na região interna ao cilindro de luz, seguindo o movimento de rotação do pulsar. Estas partículas relativísticas poderiam ser "ejetadas" pelas linhas de campo abertas perto do cilindro de luz, gerando a radiação de alta freqüência observada em pulsares.

Assim, strangelets poderiam também ser extraídas da superfície de pulsares e aceleradas por fortes campos elétricos gerados na magnetosfera destes objetos devido a sua rotação [63]. Duas regiões seriam responsáveis pela aceleração das strangelets a energias relativísticas por causa

\footnotetext{
"Sem perdas de generalidade, vejamos o caso no qual o momento de dipolo e o eixo de rotação da estrela estão alinhados.
} 


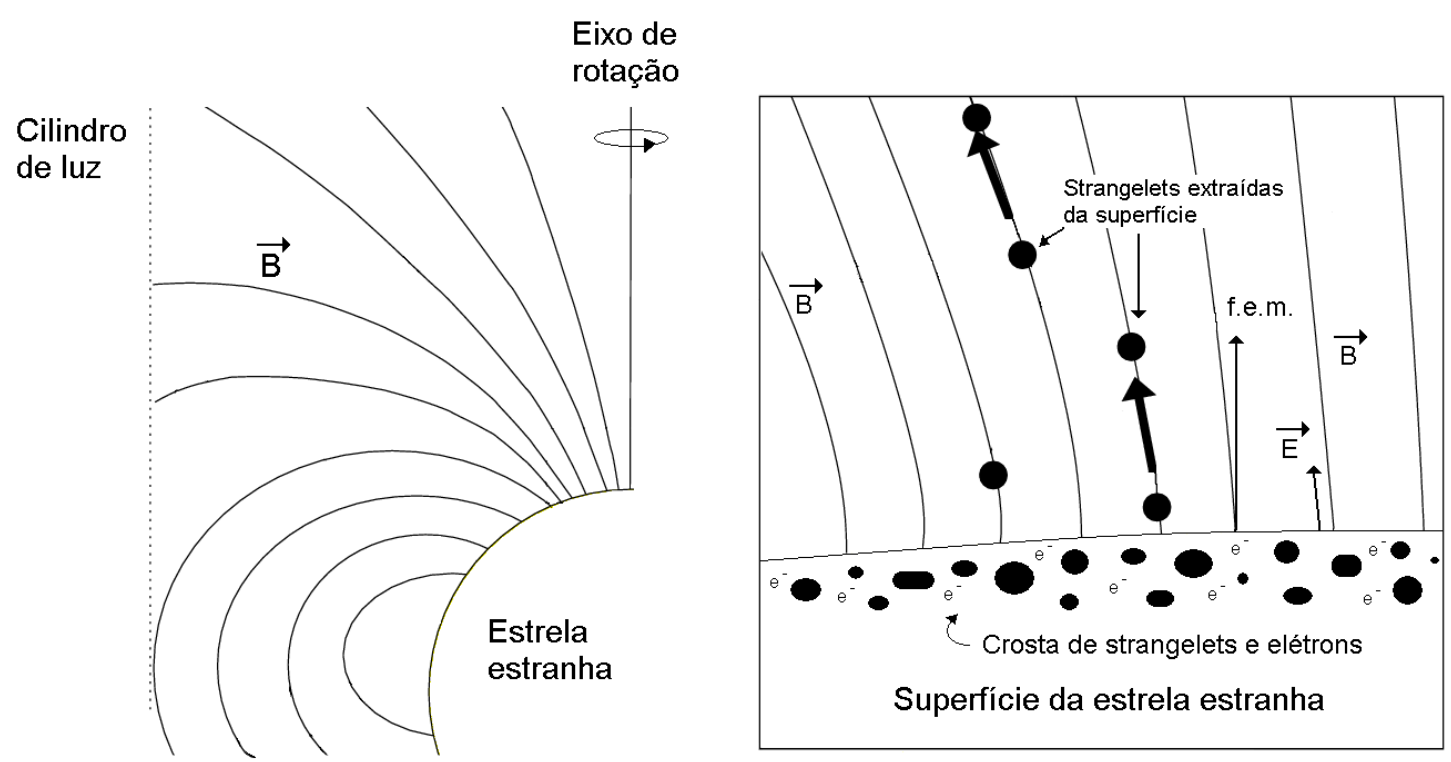

Figura 1.6: Representação esquemática da magnetosfera de um pulsar estranho com a localização do cilindro de luz (painel à esquerda). No painel à direita, a representação gráfica da superfície deste pulsar, com destaque para a fragmentação da matéria estranha em strangelets distribuídas em um substrato de elétrons. Estas strangelets poderiam ser extraídas pelos fortes campos elétricos e aceleradas pela magnetosfera. 
dos intensos campos magnéticos: os pólos e o cilindro de luz.

As regiões polares seriam capazes de acelerar strangelets com energias típicas de $\sim 3 \times$ $10^{14}\left(Z / 10^{2}\right)$ eV e resultaria em um fluxo dessas partículas com $A \simeq 10^{3}$ duas ordens de grandeza menor do que aquele estimado por Madsen (equação 1.5).

A região próxima ao cilindro de luz consegue acelerar de modo eficiente apenas nos pulsares jovens, com períodos de rotação entre 0,1 e 0,3 segundos. Nestes casos, partículas provenientes das regiões polares poderiam ser também aceleradas nas regiões próximas ao cilindro de luz, resultando em strangelets com energias típicas de $\sim 3 \times 10^{16}\left(Z / 10^{2}\right) \mathrm{eV}$.

Para energias da ordem de $\sim 10^{14}-10^{15} \mathrm{eV}$, o fluxo esperado para strangelets aceleradas nas regiões polares é

$$
F \simeq 25 \Lambda\left(\mathrm{m}^{2} \text { sterad ano }\right)^{-1}
$$

onde $\Lambda$ é um fator próximo da unidade dado por

$$
\Lambda=\left(Z / 10^{2}\right)^{-1}\left(I / 10^{45} \mathrm{~g} / \mathrm{cm}^{2}\right)\left(R / 10^{6} \mathrm{~cm}\right)^{-3}\left(B_{p} / 10^{12} G\right)^{-1},
$$

sendo $I, R$ e $B_{p}$ o momento de inércia, o raio e a intensidade do campo magnético no pólo da estrela estranha, respectivamente, e $Z$ a carga elétrica da strangelet.

Para strangelets aceleradas na região do cilindro de luz, com energias de $\sim 10^{16}-10^{17} \mathrm{eV}$, o fluxo esperado é de $F \simeq 0,1 \Lambda\left(\mathrm{m}^{2} \text { sterad ano }\right)^{-1}$.

Apesar destes valores para o fluxo serem muito menores do que aquele estimado por Madsen (equação 1.5), este processo também poderia contribuir de maneira não desprezível à abundância de strangelets no meio interestelar, mais uma vez, devido à freqüência muito maior destes eventos quando comparados à coalescência de estrelas de nêutrons.

\subsection{A procura por strangelets}

A prova definitiva sobre se a hipótese de (meta-) estabilidade da matéria estranha é válida ou não deve vir das medidas experimentais. A procura por strangelets começou há mais de 20 anos 
e foram revisadas recentemente em [64]. Três principais nichos para a pesquisa desses exóticos são explorados: $i$ ) a produção direta de strangelets em colisões de íons pesados [65, 66]; e a sua existência entre os primários de raios cósmicos que poderiam ser detectados $i i$ ) diretamente; ou iii) pela sua interação com o material presente na Terra (registro de meteoritos anômalos, Earth quakes, procura de traços em mica, meteoritos ou detectores de raios cósmicos, entre outras possibilidades) $[67,68,69,70]$.

Ao longo de várias décadas de trabalho, os experimentos em raios cósmicos indicam a possível presença de primários exóticos $[9,10]$. Inicialmente, os eventos Centauro, detectados por câmaras de emulsão em um experimento localizado no topo do monte Chacaltaya, Bolívia, por uma colaboração nipo-brasileira [71], apresentaram características que os fizeram ser interpretados como possível evidência para a existência de strangelets entre os raios cósmicos. Entre suas assinaturas observacionais, destacam-se a sua alta penetração na atmosfera e o grande número de hadrons carregados e pouquíssimos (ou nenhum) fótons e elétrons resultantes da interação. Este último mostra-se peculiar porque em colisões de alta energia, píons neutros que decaem em fótons são sempre produzidos. Explicar esses eventos como a fragmentação de um núcleo ordinário não justificaria a altitude da interação, cerca de 50 a 500 metros acima do detector, já que este deveria ter se fragmentado no topo da atmosfera.

Outros eventos, como os registrados pelo experimento HECRO-81 [9, 11], evento Price [72] e o reportado por Miyamura [73], registraram uma relação carga/massa inferida extremamente baixa para o primário, e em $[74,75]$ são apresentados eventos com caraterísticas que remetem aos eventos Centauros. Mais recentemente, pelo menos um evento reportado pelo experimento AMS-01 (Alpha Magnetic Spectrometer) [12], um espectrômetro de massa a bordo da nave Discovery durante um vôo de 10 dias em 1998, tem sido considerado como uma possível detecção de uma strangelet. No entanto, os efeitos de camada, que aumentam a complexidade das análises, ainda tornam duvidosas as tentativas de indentificação desses primários com strangelets [76]. Ainda não é claro até que ponto esses eventos anômalos podem ser originados por primários ordinários ou requerem necessariamente origem exótica.

Também foi proposto que os raios cósmicos de ultra-alta energia (UHECR) sejam resultado da interação de uma strangelet com partículas da atmosfera [77]. Interações com a radiação cósmica de fundo devem suprimir fortemente o fluxo de raios cósmicos ordinários acima de 
energias de $10^{19}-10^{20} \mathrm{eV}$ (conhecido com corte Greisen-Zatsepin-Kuzmin, ou corte GZK) através da produção de píons e pares. Para núcleos pesados, a desintegração na interação com os fótons também se torna relevante. Por ainda não haver consenso sobre a existência do corte, algumas propostas têm sido apresentadas para explicar o possível fluxo além do corte GZK. Entre elas, fontes próximas (o que deveria levar a uma anisotropia do fluxo) e física nova (decaimento de partículas supersimétricas).

Devido às altas cargas elétricas que podem ser suportadas por strangelets, mas baixa relação carga-massa, as energias atingidas por estas partículas por aceleração nos campos magnéticos que permeiam o meio interestelar podem ser ordens de magnitude maiores do que aquelas atingidas por prótons e outros núcleos ordinários. Devido ao menor raio de giro no campo magnético galáctico, strangelets podem atingir as energias requeridas em fontes menores do que aquelas necessárias para a aceleração de núcleos a mesma energia.

Além disso, strangelets estariam menos suscetíveis a interações com a radiação cósmica de fundo, já que a energia cinética mínima para a produção de píons, criação de pares e fotodesintegração nestes casos é proporcional a $A$. Desta forma, strangelets de alta massa não devem ser afetadas por estes processos nas energias de interesse.

No entanto, os chuveiros atmosféricos resultantes dos UHECR são consistentes com prótons e núcleos ordinários. Objetos com maior massa parecem ser inconsistentes com os dados. Também a caracterização da componente nucleônica gerada deve ser bastante diferente e o fluxo de strangelets em energias menores que $\sim 10^{20} \mathrm{eV}$ deveria ser relativamente grande. Ainda, para que este cenário seja viável, o primeiro requisito é a existência de estrelas estranhas, assunto sobre o qual, definitivamente, não há um consenso.

O espectrômetro de massa AMS-02 [56] está sendo construído e deve estar a bordo da Estação Espacial Internacional nos próximos anos. Este será um detector de partículas com aproximadamente $0,5 \mathrm{~m}^{2}$ sterad de aceitação com um magneto supercondutor de campo magnético de 0,86 Tesla. Outros aparatos farão parte do sistema de detecção como um detector de traços de silício e um de tempo de vôo, um calorímetro e contadores de radiação Cherenkov e de anti-coincidência. Com tempo de operação previsto para no mínimo três anos e sendo sensível a strangelets numa ampla região de massas e cargas elétricas, na região de rigidez de GV-TV, espera-se que este detector possa ajudar na identificação destes primários exóticos e 
testar, assim, a validade de conjuntura de Bodmer-Witten-Terazawa. 


\section{Capítulo 2}

\section{Matéria estranha à temperatura finita}

A questão da estabilidade da matéria estranha depende dos valores assumidos pelos parâmetros que caracterizam a interação forte e das propriedades das partículas que sofrem sua influência. Até o momento só foi possível introduzir vínculos experimentais para algumas dessas componentes como, por exemplo, para a massa do quark strange. Também a existência de diferentes modelos que visam explicar o comportamento da matéria bariônica pode levar a conclusões ambígüas. Assim sendo, a pergunta sobre qual o estado fundamental da matéria regida pelas interações fortes na região de baixas temperaturas e altas densidades, atualmente não pode ser respondida com precisão.

Desta forma, para avaliar-se a viabilidade da proposta de estabilidade para a SQM, é preciso estudar o espaço de parâmetros possível para as variáveis que a caracterizam, como feito, por exemplo, em [15, 21, 78, 79]. Apesar de a temperatura envolvida nos processos astrofísicos de interesse para a injeção de strangelets no meio interestelar ser muito menor que o potencial químico da matéria estranha (da ordem de um décimo), a temperatura não nula pode influenciar de maneira significativa os cálculos de fragmentação da matéria em bulk, além de ser relevante para as propostas de produção de strangelets em colisões de íons pesados em aceleradores de alta energia $[65,66]$. Assim, estudaremos a seguir as condições para a estabilidade da SQM a $T \neq 0$ na aproximação de gota líquida.

Um estudo detalhado de strangelets deve basear-se nos cálculos de modelo de camada. No entanto, foi demonstrado que o comportamento dos parâmetros que caracterizam os sistemas com elevado conteúdo de quarks pode ser bem aproximado pelo modelo de gota líquida 
incluindo-se os termos volumétrico, de superfície e curvatura [16, 78]. Sendo estes cálculos muito mais diretos, a estrutura de strangelets pode ser estudada de maneira mais clara, permitindo generalizações para sistemas a temperaturas finitas.

\subsection{Janelas de estabilidade}

Considerando-se um sistema de quarks leves com confinamento forçado a uma esfera de raio $\mathrm{R}$, conforme $R \rightarrow \infty$, um sistema desconfinado de quarks livres emerge (sistema em bulk).

Para a matéria estranha em bulk sem emparelhamento de quarks, os potenciais termodinâmicos que a descrevem são os correspondentes ao gás de Fermi com $\alpha_{c}=0$ * dados por [15]

$$
\Omega_{i}=\mp T \int_{0}^{\infty} d k g_{i} \frac{k^{2}}{2 \pi^{2}} \ln \left[1 \pm \exp \left(-\frac{\epsilon_{i}(k)-\mu_{i}}{T}\right)\right]
$$

onde o sinal superior corresponde a férmions e o inferior aos bósons, $\mu$ e $T$ são o potencial químico e temperatura, $k$ e $\epsilon_{i}$ o momento e a energia da partícula, respectivamente, $i=$ quarks $\mathrm{u}, \mathrm{d}$, s, elétrons e gluons, e o fator $g_{i}$ é o peso estatístico para os quarks e gluons (6 para quarks e antiquarks e 16 para gluons). A integração é feita além do momento de Fermi já que a temperatura finita provoca o alargamento da distribuição de Fermi-Dirac.

Considerando o equilíbrio de carga elétrica e interações fracas (ver equações 1.1 a 1.3), tem-se os potenciais químicos obedecendo às seguintes relações

$$
\mu_{d}=\mu_{s}=\mu_{u}+\mu_{e^{-}}
$$

E assim o modelo é definido por $\Omega_{S Q M}=\sum \Omega_{i}+B$.

Se considerarmos a matéria CFL em bulk, os potenciais termodinâmicos para o sistema até ordem $\Delta^{2}$ levam a $[34,80]$

${ }^{*}$ Quando se considera a constante de acoplamento forte, $\alpha_{c}$, finita foi demonstrado [15] que este efeito pode ser absorvido através de uma redução efetiva no valor da constante de sacola $B$. 


$$
\Omega_{C F L}=\sum_{i} \Omega_{i}-\frac{3}{\pi^{2}} \Delta^{2} \mu^{2}+B
$$

onde $\Delta$ é o gap de emparelhamento e o termo extra dependente deste parâmetro representa a energia de ligação do condensado de diquark. O termo $\Omega_{\text {livre }}=\sum_{i} \Omega_{i}$, apesar de análogo a $\Omega_{S Q M}$, representa um estado fictício sem emparelhamento no qual todos os quarks têm um momento de Fermi comum (dado pela equação 1.4) e $i$ vale para quarks $u, d, s$ e gluons (lembrando que não há elétrons no estado CFL). Assim, a energia desse estado é construída através de um "modelo de brinquedo" sem emparelhamento mais a energia proveniente da existência do condensado.

A densidade de partículas é dada por $n_{i}=-\partial \Omega_{i} / \partial \mu_{i}$, e a densidade total de energia, $E=\sum_{i}\left(\Omega_{i}+n_{i} \mu_{i}\right)-3 \Delta^{2} \mu^{2} / \pi^{2}+B+T S$, onde $S=-(\partial \Omega / \partial T)_{V, \mu}$ é a entropia do sistema.

Ainda que a maior parte da análise para a SQM no estado CFL tenha sido feita considerandose um valor constante para $\Delta=\Delta_{0}$, o gap de emparelhamento é, na verdade, dependente da temperatura na qual se encontra o sistema. Usando como referência os estudos de supercondutividade eletrônica [81], escrevemos esta dependência como ${ }^{\dagger}$

$$
\begin{array}{r}
\Delta(T)=\Delta_{0} \sqrt{1-\left(\frac{T}{T_{c}}\right)^{2}}, \\
T_{c}=0.57 \Delta(T=0) \equiv 0.57 \Delta_{0},
\end{array}
$$

onde $T_{c}$ é a temperatura crítica do sistema supercondutor acima do qual o emparelhamento entre os quarks não pode mais ser sustentado.

As "janelas de estabilidade" (regiões no plano $m_{s}-B$ para as quais a matéria estranha pode ser estável à pressão nula) para a matéria estranha obtidas por nós com e sem emparelhamento de quarks nas bases do modelo de sacola do MIT são mostradas nas figuras 2.1 e 2.2. O valor mínimo para a constante de sacola, $B^{1 / 4}=145 \mathrm{MeV}$, deriva do fato que um valor menor de $B$ faria com que um núcleo de ${ }^{56} \mathrm{Fe}$ decaísse espontaneamente para matéria com dois sabores de quarks (quarks $u$ e $d$ ), em profundo desacordo com o que é observado. Também se deve

\footnotetext{
${ }^{\dagger}$ Estudos recentes indicam que a relação entre $T_{c}$ e $\Delta_{0}$ pode ser diferente [82]
} 
ter $E / A<939 \mathrm{MeV}$, ou a matéria é instável por emissão de nucleons. Como esperado, a matéria é menos estável a temperatura finita, seja ela supercondutora ou não. Isto também é verificado no caso CFL para aproximação de gap de emparelhamento constante ou dependente da temperatura.

O caso mais realista de $\Delta$ dependente da temperatura, $\Delta=\Delta(T)$, mostra uma característica interessante quando são consideradas as janelas de estabilidade. Neste caso, ao invés de haver uma desestabilização adicional do sistema devido a uma redução efetiva no gap de emparelhamento, há de fato um aumento na região de estabilidade quando comparado aos cálculos com um valor de $\Delta$ constante. A razão para este comportamento pode ser identificada com dois efeitos quando são comparados os casos $\Delta=\Delta_{0}$ e $\Delta=\Delta(T)$ para um dado conjunto de massa do quark $s$, constante de sacola e gap de emparelhamento à temperatura nula: primeiro, há uma mudança no $\mu$ comum da fase CFL (e, consequentemente, de todos os quarks), que aumenta em até $4 \%$ quando $\Delta=\Delta(T)$. Isto faz com que a soma dos potenciais termodinâmicos dos quarks e gluons diminua (se torne mais negativa) em até 10\%. Em segundo lugar, o aparecimento de um termo extra na entropia relacionado com $\partial \Delta^{2} / \partial T$ causa uma diminuição na entropia de mais de 50\%, o que, por sua vez, se manifesta em uma contribuição na energia total proporcional a $-\Delta_{0}^{2}\left(T / T_{c}\right)^{2}$. A densidade bariônica não sofre mudança significativa (menos de $2 \%$ ). Assim, a efetiva redução no gap de emparelhamento é "compensada" pelo decréscimo em $\sum_{i} \Omega_{i}$ e também na entropia do sistema quando comparado ao caso de $\Delta$ fixo. Esta conclusão mostra-se válida ainda que o sistema se encontre bastante próximo à temperatura crítica para emparelhamento dos quarks.

Concluímos que para a matéria em bulk, quando se consideram temperaturas finitas, a matéria estranha torna-se menos estável devido a um aumento na densidade de energia devido à excitação térmica de seus componentes, como esperado. No entanto, o estado CFL ainda apresenta um amplo espaço de parâmetros que permite a estabilidade da matéria, dependendo do valor do gap de emparelhamento, e mesmo para o caso em que os quarks não formam pares, a estabilidade pode ser alcançada para temperaturas tão elevadas quanto $T=30 \mathrm{MeV}$, dependendo dos valores de $m_{s}$ e $B$. Inclusive, verificamos que no caso de um $\Delta$ dependente da temperatura, este cenário de estabilidade para temperaturas não nulas é ligeiramente mais favorável para a matéria em bulk. 


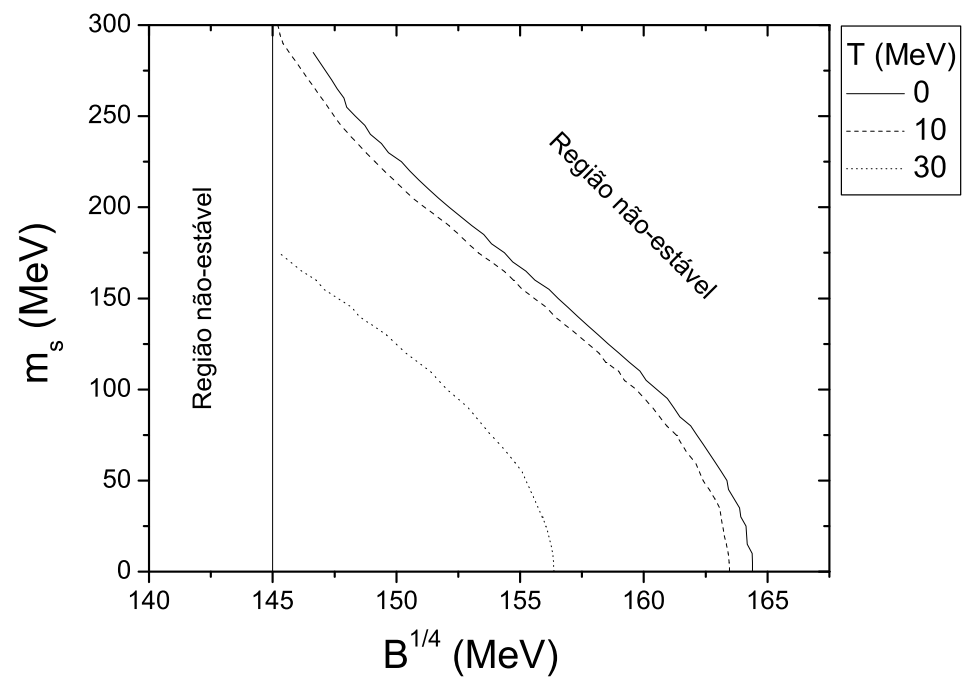

Figura 2.1: Janela de estabilidade para a SQM sem emparelhamento à temperatura finita e $\alpha_{c}=0$. As curvas foram calculadas para $E / A=939 \mathrm{MeV}$ fixo e diferentes temperaturas, conforme indicado. A linha vertical representa o mínimo valor de $B$ para estabilidade da SQM. A região favorável é aquela delimitada pelas curvas apresentadas para cada temperatura e à direita da linha vertical.

\subsection{Strangelets}

Para descrever strangelets, bem aquém do limite termodinâmico, é necessária a introdução de contribuições de superfície e curvatura (que não deve ser desprezada para a matéria de quarks) para compor os potenciais termodinâmicos da matéria em bulk:

$$
\Omega_{i}=\mp T \int_{0}^{\infty} d k \frac{d N_{i}}{d k} \ln \left[1 \pm \exp \left(-\frac{\epsilon_{i}(k)-\mu_{i}}{T}\right)\right]
$$

onde $d N_{i} / d k$ é a densidade de estados para uma partícula do tipo $i$.

Na multiple reflection expansion [83, 84], uma expansão perturbativa adequada ao tratamento de problemas de contorno que quando feita sobre uma esfera, torna-se simples e algébrica (chamada assim porque pode ser interpretada como um movimento descrito pelo propagador livre de um ponto $\vec{x}$ a outro $\overrightarrow{a_{1}}$, sendo refletido, depois movendo-se a $\overrightarrow{a_{2}}$ e assim por diante), a densidade de estados dos quarks dentro da cavidade é dada por

$$
\frac{d N_{i}}{d k}=g_{i}\left\{\frac{1}{2 \pi^{2}} k^{2} V+f_{S}^{(i)}\left(\frac{m_{i}}{k}\right) k S+f_{C}^{(i)}\left(\frac{m_{i}}{k}\right) C\right\}
$$



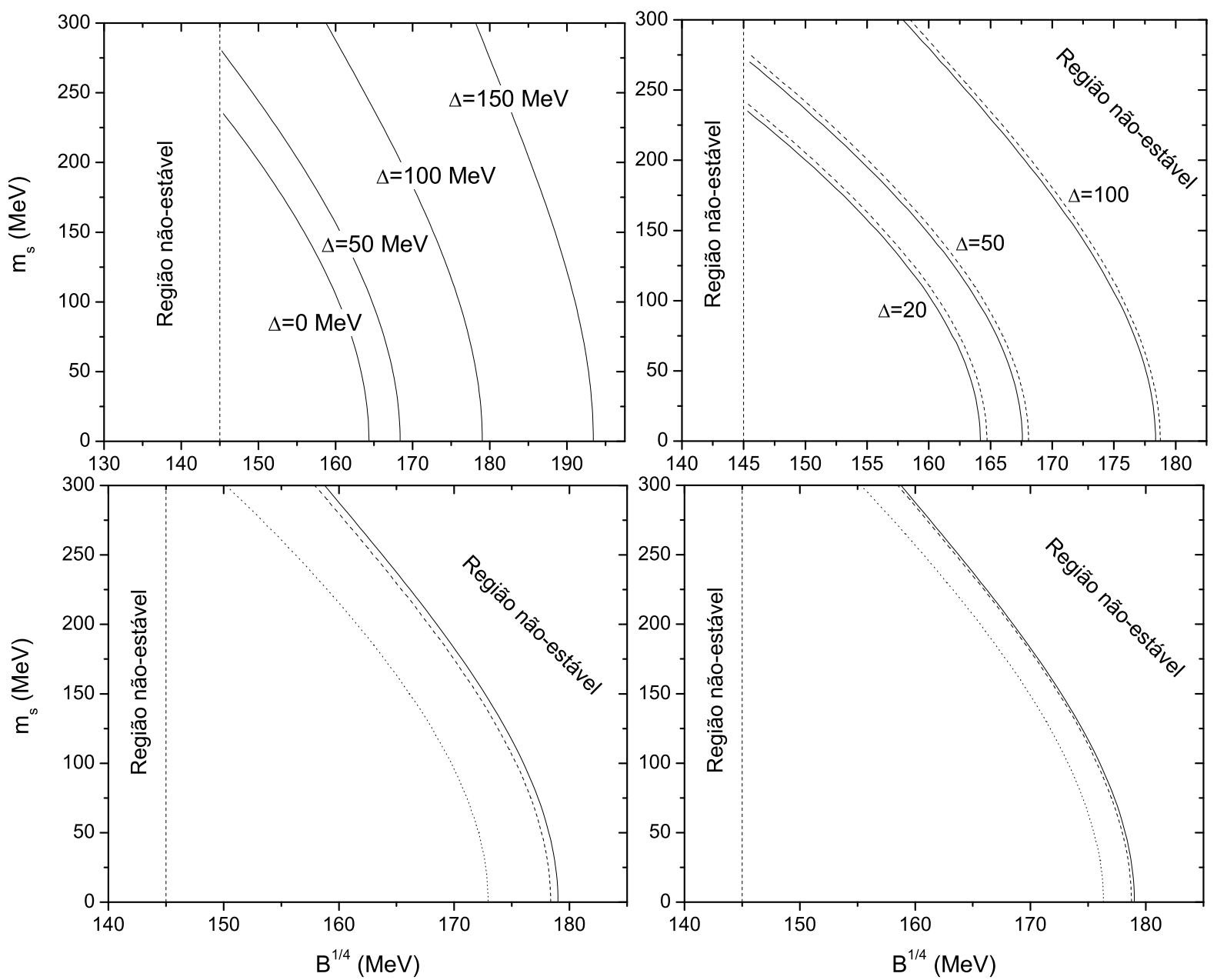

Figura 2.2: Acima, à esquerda, janela de estabilidade para a $\mathrm{SQM}$ a $\mathrm{T}=0$ (seguindo trabalho apresentado na referência [21]). Acima, à direita, janela de estabilidade para a matéria CFL para $\mathrm{T}=10 \mathrm{MeV}$ e valores de $\Delta$ conforme indicados. As linhas cheias e pontilhadas representam cálculos feitos com $\Delta=\Delta_{0}$ e $\Delta=\Delta(T)$, respectivamente (ver texto para maiores detalhes). Abaixo, janelas de estabilidade em temperatura finita e $\Delta=$ 100. As linhas cheias, tracejadas e pontilhadas são para $T=0, T=10 \mathrm{MeV}$ e $T=30 \mathrm{MeV}$, respectivamente. À esquerda, curvas obtidas considerando-se $\Delta$ fixo, enquanto que à direita, $\Delta=\Delta(T)$. Todas as curvas apresentadas foram calculadas para $E / A=939 \mathrm{MeV}$ fixo. A linha vertical é o mínimo valor de $B$ requerido para estabilidade. A hipótese de Witten é satisfeita se os valores de $m_{s}$ e $B^{1 / 4}$ estiverem dentro da região delimitada pelas curvas de $E / A=939 \mathrm{MeV}$ e $B^{1 / 4}=145 \mathrm{MeV}$. Como esperado, a $T \neq 0$, estas regiões são reduzidas. 
onde $V, S$ e $C$ são o volume, a superfície e a curvatura da strangelet e $m_{i}$, a massa do quark $i$, onde $i$ denota o sabor do quark.

O termo de superfície para quarks é dado por [85]

$$
f_{S}^{(i)}\left(\frac{m_{i}}{k}\right)=-\frac{1}{8 \pi}\left[1-\frac{2}{\pi} \arctan \left(\frac{k}{m_{i}}\right)\right] .
$$

Para a contribuição de curvatura, o seguinte ansatz [78] para quarks massivos é adotado

$$
f_{C}^{(i)}\left(\frac{m_{i}}{k}\right)=\frac{1}{12 \pi^{2}}\left\{1-\frac{3 k}{2 m_{i}}\left[\frac{2}{\pi}-\arctan \left(\frac{k}{m_{i}}\right)\right]\right\}
$$

enquanto que para os gluons [86], $f_{C}^{(g)}=-1 / 6 \pi^{2}$.

A energia é obtida como

$$
E=\sum_{i}\left(\Omega_{i}+N_{i} \mu_{i}\right)+B V+T S
$$

Para o caso CFL, o termo $-3 \Delta^{2} \mu^{2} / \pi^{2} V$ deve ser adicionado à expressão do potencial termodinâmico $\Omega$ em procedimento similar àquele empreendido para a matéria em bulk. A condição para equilíbrio mecânico para uma strangelet em vácuo é dada por $B=-\sum_{i} \partial \Omega_{i} / \partial V$. Para strangelets sem emparelhamento a relação para os potenciais termodinâmicos encontrada através da minimização da energia livre com respeito ao número de quarks de cada espécie e sujeito ao vínculo $A=1 / 3 \sum_{i} N_{i}$ é de $\mu_{u}=\mu_{d}=\mu_{s}$ [79]. Para strangelets CFL, esta relação deve ser substituida por $\mu_{u}=\mu_{d}$ e $\mu_{s}=\sqrt{\mu_{u}^{2}+m_{s}^{2}}$, que é um segundo vínculo imposto para que haja emparelhamento, proveniente da condição de mesmo momento de Fermi para os quarks (equação 1.4). Os valores para os potenciais químicos foram obtidos numericamente a partir de um dado conjunto de $B, \Delta$ e $m_{s}$.

Os resultados numéricos obtidos por nós para strangelets esféricas são mostrados nas figuras 2.3, 2.4 e 2.7 para a energia total dessas partículas como função de diferentes parâmetros que as caracterizam. Para o caso sem emparelhamento, restringimos o estudo para strangelets pequenas o sufiente $\left(A \ll 10^{7}\right)$ para que não haja elétrons internos ao sistema (nestes casos o raio da strangelet é menor que o comprimento de onda Compton do elétron). 


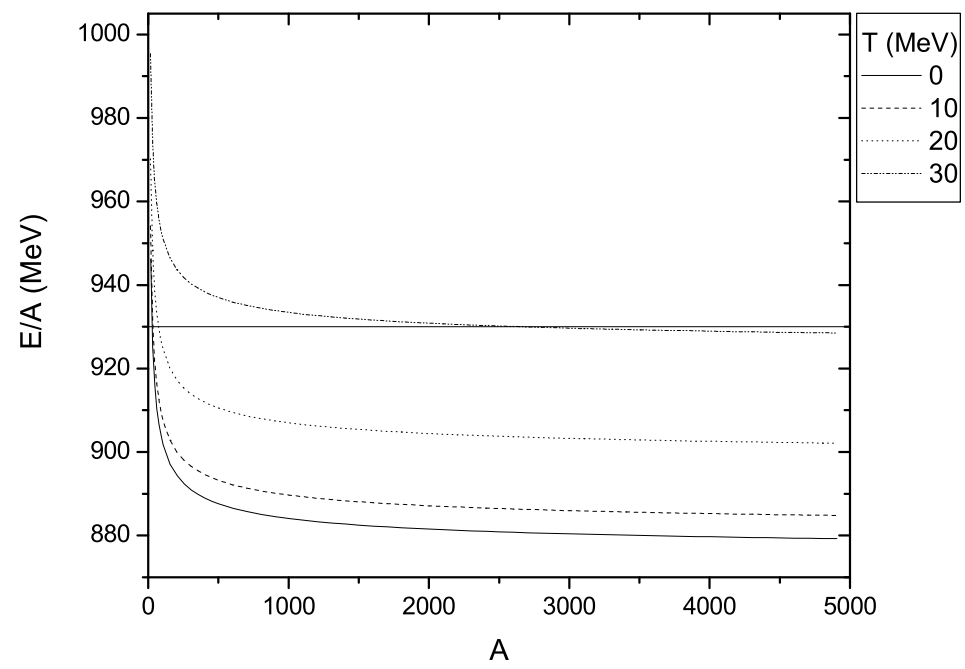

Figura 2.3: Energia por unidade de número bariônico para strangelets sem emparelhamento de quarks com $m_{s}=150 \mathrm{MeV}$ como função de $A$ para $T$ fixo, conforme indicado, e seguindo a referência [79]. A linha horizontal em $E / A \approx 930 \mathrm{MeV}$ indica o limite em energia acima do qual strangelets decaem para matéria nuclear ordinária.

Assim como para a matéria em bulk, há uma competição no caso $\Delta=\Delta(T)$ entre a diminuição efetiva do gap de emparelhamento e o aumento do potencial químico na matéria CFL e o termo extra na entropia volumétrica quando comparado ao caso de $\Delta$ constante. No entanto, para pedaços finitos de SQM, os termos adicionais de superfície e curvatura que contribuem ao potencial termodinâmico com sinal oposto ao termo volumétrico são afetados apenas pela mudança em $\mu$ (maior quando $\Delta=\Delta(T)$ ) e no raio da strangelet (que é menor mas não afetado de maneira significativa, sendo a diferença menor que $1 \%$ ). O resultado final é que a estabilidade para um dado conjunto de $m_{s}, B, \Delta_{0}$, A, e temperatura é agora desfavorecido no cenário de $\Delta$ dependente da temperatura, ao contrário da matéria em bulk, na qual verificamos um pequeno aumento da região de estabilidade.

O comportamento da energia total por unidade de número bariônico é de decrescer com o aumento do gap de emparelhamento e do número bariônico da strangelet, e aumentar com o acréscimo nos valores de $B, m_{s}$ e $T$. Isto pode ser compreendido através da comparação com o comportamento das janelas de estabilidade da matéria estranha mostrada nas figuras 2.1 e 2.2.

Nossos cálculos mostraram que o coeficiente $R_{0}$, definido através do raio da strangelet como $R=R_{0} A^{1 / 3}$, decresce com o aumento de $A$ e $B$ mas cresce com $m_{s}$ e $\Delta$ (mantendo-se os outros parâmetros fixos para cada comparação). Este também é maior quando há um aumento 

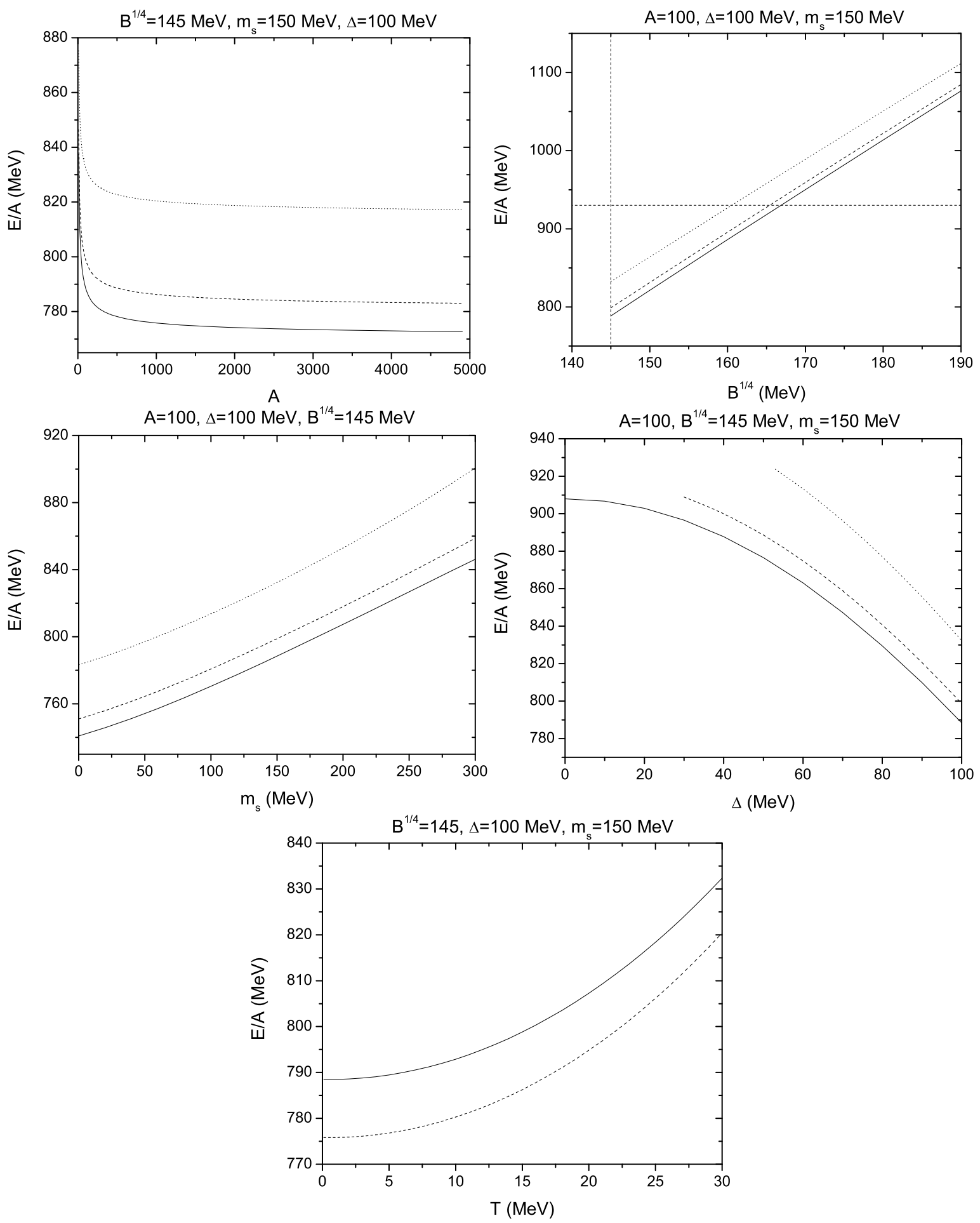

Figura 2.4: Energia por unidade de número bariônico para strangelets CFL como função do número bariônico, constante de sacola, massa do quark $s$, gap de emparelhamento e temperatura, da esquerda para a direita, de cima para baixo, respectivamente. Os valores das constantes mantidas fixas encontram-se indicados para cada gráfico. Os primeiros quatro gráficos foram feitos para $T=0$ (linha cheia), $T=15 \mathrm{MeV}$ (linha tracejada) e $T=30 \mathrm{MeV}$ (linha pontilhada). As curvas para temperatura finita partem de valores diferentes de $\Delta$ no gráfico de $E / A \times \Delta$ pois o sistema não é estável acima da temperatura crítica para um dado gap. O gráfico que exprime a dependência em $T$ foi feito para $A=100$ (linha cheia) e $A=1000$ (linha tracejada). 

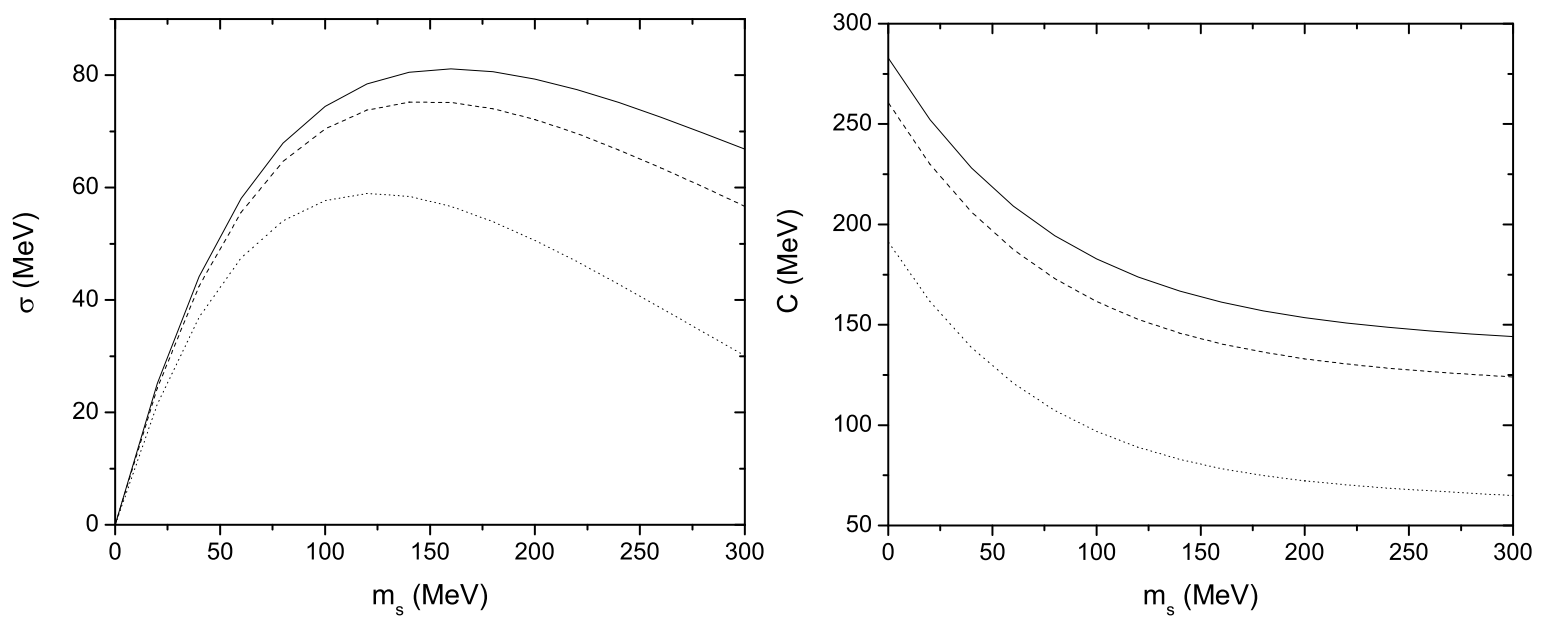

Figura 2.5: Energias de superfície (à esquerda) e curvatura (à direita) para strangelets CFL como função de $m_{s}$. Os valores das constantes que estão fixas são $T=0$ (linha cheia), $T=15 \mathrm{MeV}$ (linha tracejada), e $T=30 \mathrm{MeV}$ (linha pontilhada), $A=100, B^{1 / 4}=145 \mathrm{MeV}$ e $\Delta=100 \mathrm{MeV}$.
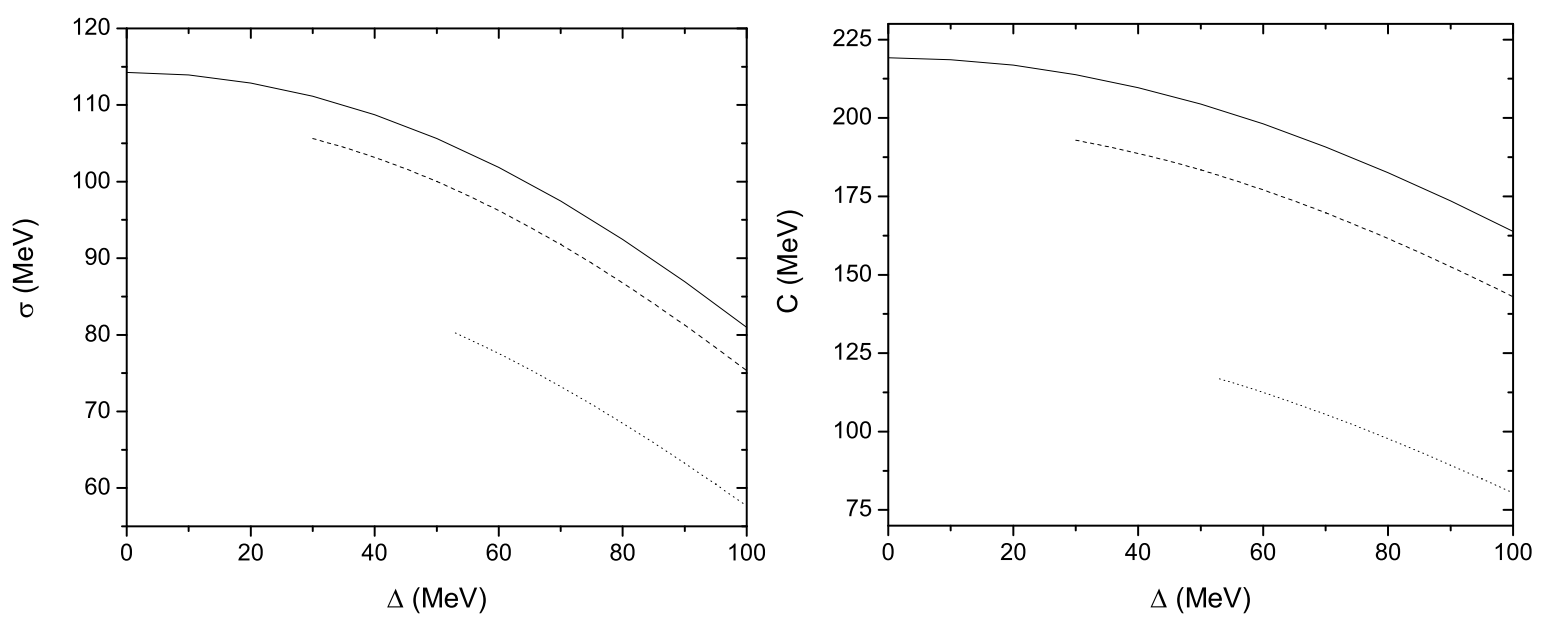

Figura 2.6: Energias de superfície (à esquerda) e curvatura (à direita) para strangelets CFL como função de $\Delta$. Os valores das constantes que estão fixas são $T=0$ (linha cheia), $T=15 \mathrm{MeV}$ (linha tracejada), e $T=30 \mathrm{MeV}$ (linha pontilhada), $A=100, B^{1 / 4}=145 \mathrm{MeV}$ e $m_{s}=150 \mathrm{MeV}$. A temperatura crítica para $\Delta \lesssim 30 \mathrm{MeV}$ está abaixo de cinqüenta $\mathrm{MeV}$ e para $\Delta \lesssim 50 \mathrm{MeV}$ é menor que trinta $\mathrm{MeV}$ e esse é o motivo das curvas para temperatura finita começarem em valores diferentes de $\Delta$. 

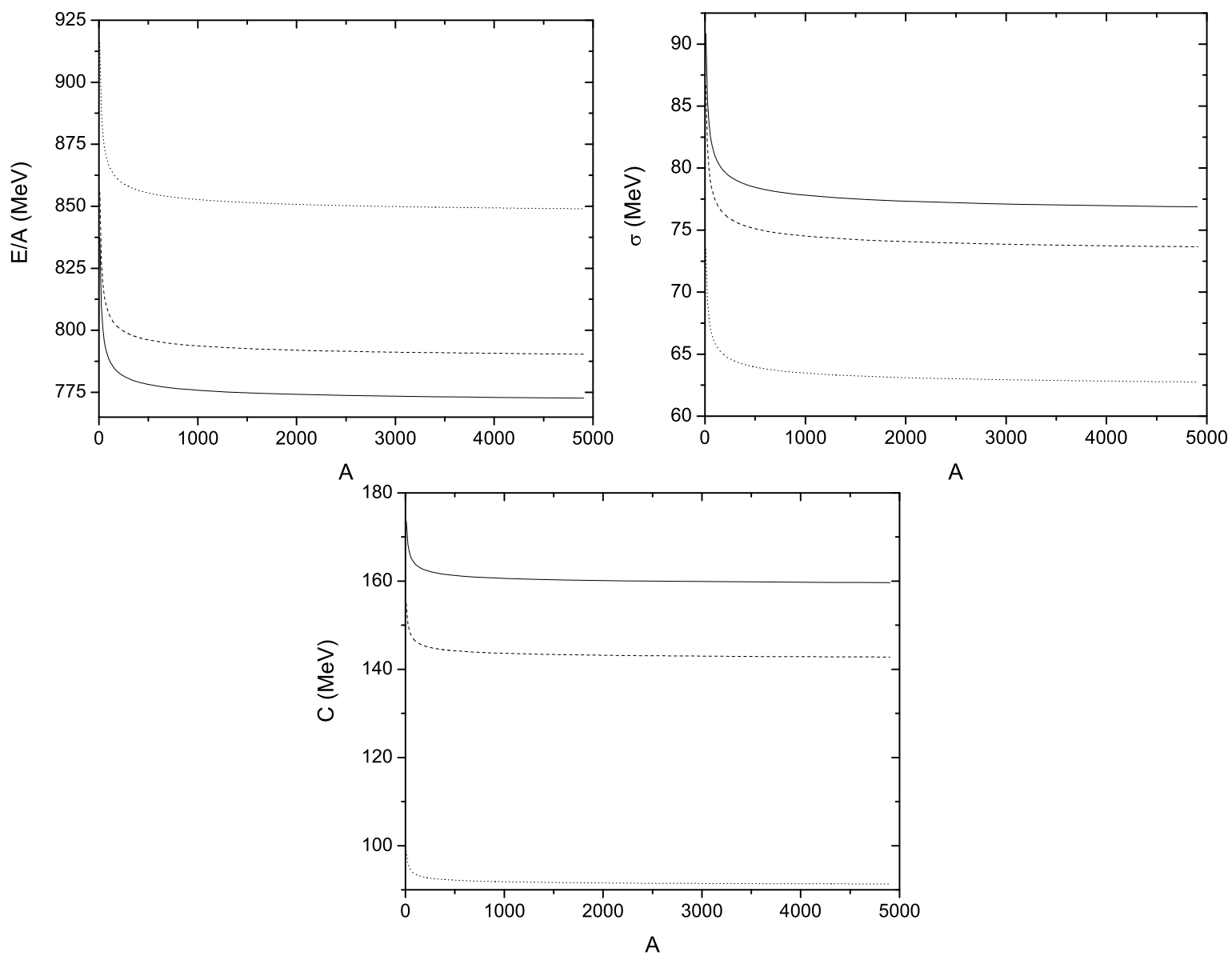

Figura 2.7: Energias total por unidade de número bariônico, de superfície e de curvatura, da esquerda para a direita, de cima para baixo, respectivamente, para strangelets CFL como função de $A$ calculadas para $\Delta=\Delta(T)$. Os valores das constantes fixas são $T=0$ (linha cheia), $T=15 \mathrm{MeV}$ (linha tracejada) e $T=30 \mathrm{MeV}$ (linha pontilhada), $m_{s}=150 \mathrm{MeV}, B^{1 / 4}=145 \mathrm{MeV}$ e $\Delta_{0}=100 \mathrm{MeV}$. 
na temperatura do sistema, já que a energia térmica dos quarks e gluons também aumenta. Estes comportamentos são facilmente compreendidos: aumentando o conteúdo bariônico da strangelet, seus parâmetros devem se aproximar daqueles encontrados para a matéria em bulk, resultando em um decréscimo em $R / A^{1 / 3}$. Também, ao aumentar o valor da constante de sacola, a pressão do vácuo sobre o conteúdo da strangelet é maior, explicando a dependência do raio com este parâmetro. Com o aumento da massa do quark strange, o conteúdo de quarks $s$ diminui e, então, mantendo-se $A$ fixo, o raio aumenta para manter o vínculo $A=\sum_{i} N_{i}$, sendo que o mesmo pode ser dito do aumento no gap de emparelhamento.

Nas figuras 2.5 e 2.6, a dependência das energias de superfície e curvatura, definidas como o coeficiente que aparece multiplicando $A^{2 / 3}$ e $A^{1 / 3}$ na expressão da energia total (equação 2.10), respectivamente, com $m_{s}$ e $\Delta$ também é evidenciada para strangelets no estado CFL.

As contribuições de superfície e curvatura decrescem em temperaturas mais altas, um comportamento também visto na matéria nuclear ordinária (veja, por exemplo, [87] e referências aí citadas). A energia de superfície em função da massa do quark strange apresenta um máximo em $m_{s} \approx 150 \mathrm{MeV}$ e vai a zero para quarks sem massa, o que era esperado já que apenas os componentes massivos contribuem a este parâmetro. Adicionalmente, mostra um decréscimo para altos valores de $m_{s}$ devido à supressão de quarks strange quando estes possuem uma massa muito elevada, já que o ganho de energia pela introdução do mar de Fermi associado a esta partícula irá diminuir se o nível mais baixo de energia estiver próximo do potencial químico da matéria contendo apenas os quarks $u$ e $d$ e esvanecer completamente se estiver acima deste.

Um simples ajuste numérico para as energias de superfície e curvatura de strangelets à temperatura finita também foi obtido (até segunda ordem na temperatura $T$ ) para $\Delta \equiv \Delta_{0}=$ $100 \mathrm{MeV}$ (ou seja, para um gap de emparelhamento independente da temperatura, no caso $\mathrm{CFL}), B^{1 / 4}=145 \mathrm{MeV}$ e $m_{s}=150 \mathrm{MeV}$, e é dado por

$$
\begin{aligned}
\sigma_{N S Q M}(T, A) & =\left(82,07-0,01 T-0,02 T^{2}\right) \times\left(0,95+0,18 e^{-\frac{A+9,7}{38,2}}\right) \\
\sigma_{C F L}(T, A) & =\left(81,09+0,01 T-0,03 T^{2}\right) \times\left(0,96+0,17 e^{-\frac{A}{22,5}}+0,05 e^{-\frac{A}{384,2}}\right)
\end{aligned}
$$



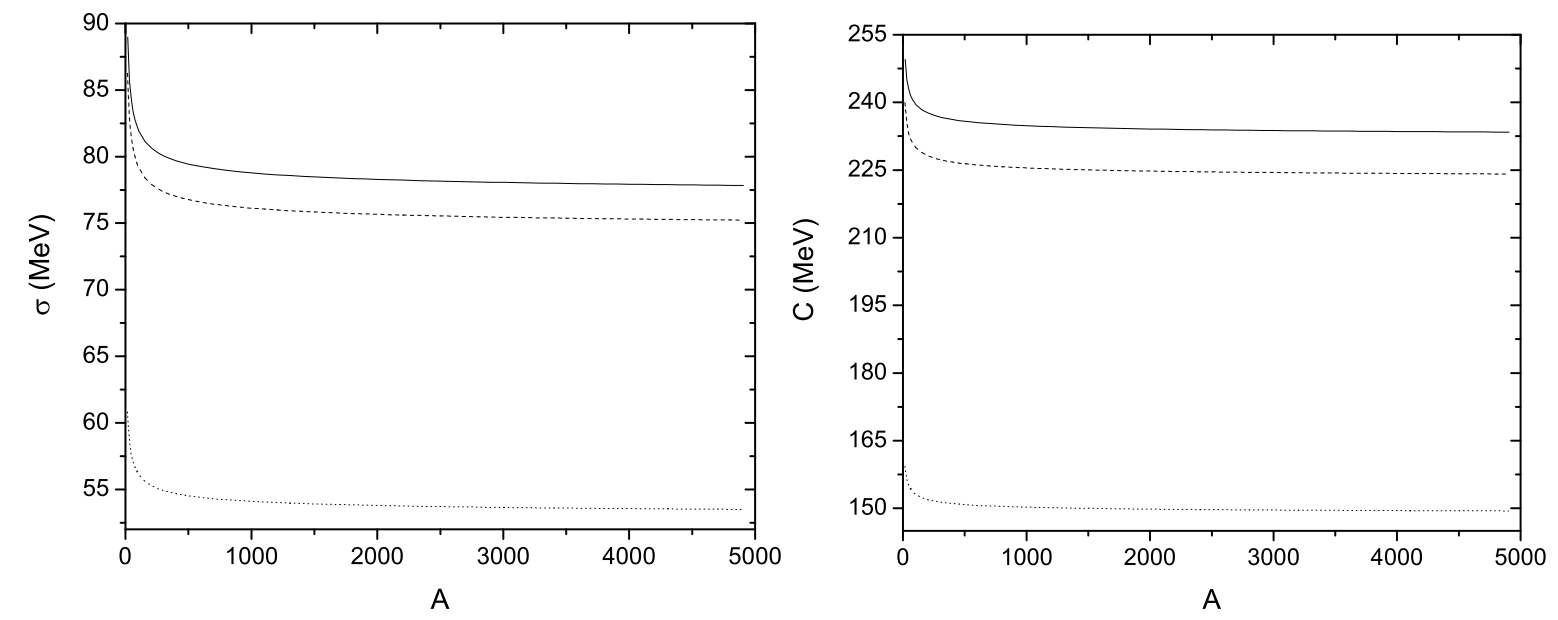

Figura 2.8: Energias de superfície (à esquerda) e curvatura (à direita) como função de $A$ para $T$ fixo, sendo a linha cheia para $T=0$, a tracejada para $T=15 \mathrm{MeV}$ e a pontilhada, $T=30 \mathrm{MeV}$, para strangelets sem emparelhamento, com $m_{s}=150 \mathrm{MeV}$ e $B^{1 / 4}=145 \mathrm{MeV}$.

$$
\begin{array}{r}
C_{N S Q M}(T, A)=\left(239,78-0,01 T-0,1 T^{2}\right) \times\left(0,98+0,09 e^{-\frac{A+10,3}{39,4}}\right) \\
C_{C F L}(T, A)=\left(163,85+0,003 T-0,09 T^{2}\right) \times\left(0,98+0,08 e^{-\frac{A}{23,2}}+0,03 e^{-\frac{A}{393,9}}\right)
\end{array}
$$

sendo os valores obtidos em $\mathrm{MeV}$ com $\mathrm{T}$ dado em $\mathrm{MeV}$.

Como esperado, o comportamento dos parâmetros que caracterizam strangelets é qualitativamente o mesmo haja ou não emparelhamento, ou seja, o sistema à temperatura finita é menos estável do que à temperatura nula mas as contribuições de superfície e curvatura diminuem com $T$, algo bem estabelecido para sistemas nucleares. Um ponto interessante é que para $\Delta=100$ $\mathrm{MeV}$, o potencial químico para o quark strange encontra-se muito próximo ao potencial químico dos componentes de strangelets estáveis sem emparelhamento à mesma temperatura e mesmo valores de $B$ e $m_{s}$, mas $\mu_{u}$ e $\mu_{d}$ é bem menor. Como conseqüência, a energia de superfície (determinada apenas pelo quark $s$ massivo) é quase a mesma para os dois cenários, mas a energia de curvatura é muito menor para strangelets CFL. Isto indica que para valores do gap de emparelhamento menores que $100 \mathrm{MeV}$, a energia de superfície é maior no estado CFL do que no caso sem emparelhamento. No entanto, a energia de curvatura é sempre menor para strangelets CFL, independentemente do valor de $\Delta$. 


\subsubsection{A carga elétrica}

Até aqui temos ignorado o possível efeito de blindagem da carga elétrica que pode afetar os cálculos da carga efetiva destes sistemas. É conhecido que a carga elétrica efetiva em condutores pode ser modificada a partir de uma certa distância devido à redistribuição das partículas carregadas no meio. O comprimento de Debye determina a escala com a qual os portadores de carga que se movem em plasmas e outros condutores podem blindar campos elétricos presentes num meio.

O efeito de blindagem do campo elétrico em strangelets sem emparelhamento é de grande importância para determinar-se a carga total dessas partículas [88]. Nesse caso, o raio de blindagem de Debye, $\lambda_{D}$, é dado, utilizando-se unidades gaussianas, por

$$
\lambda_{D}^{-2}=q_{D}^{2}=4 \pi \sum_{i} Q_{i}^{2}\left(\frac{\partial n_{i}}{\partial \mu_{i}}\right)_{n_{j}, j \neq i}
$$

sendo $Q_{i}$ a carga de cada quark e $n_{i}$, sua densidade numérica.

Para que se possa determinar o potencial eletrostático da distribuição da densidade de carga, $\rho$, como função da posição, resolve-se a equação de Poisson

$$
\nabla^{2} V(r)=-4 \pi \rho(r)
$$

com $\rho(r)$ a densidade de carga e condições de contorno que o potencial eletrostático a uma distância $r$ do centro da strangelet, $V(r)$, seja finito na origem e $V(R)=Z e / R$, onde $R$ é o raio da strangelet e $Z$ sua carga elétrica. Utilizando a aproximação de Thomas-Fermi, $\mu_{i}(r)+Q_{i} V(r)=\mu$, onde $\mu_{i}(r)$ é o potencial químico de cada sabor (que varia internamente à strangelet) e $\mu$ é o potencial químico comum, e que os potenciais eletrostáticos são pequenos quando comparados aos potenciais químicos ${ }^{\ddagger}$, obtém-se que a carga total da strangelet sem emparelhamento pode ser escrita como

$$
Z=\frac{4 \pi \rho_{0} R}{q_{D}^{2} e}\left[1-\frac{\tanh \left(q_{D} R\right)}{q_{D} R}\right]
$$

\footnotetext{
${ }^{\ddagger}$ Referir a [88] para maiores detalhes.
} 
sendo esta carga obtida da solução regular da equação 2.16 e $\rho_{0}$ a densidade de carga quando os potenciais químicos dos três sabores de quarks são iguais.

Até aqui o problema foi tratado na aproximação clássica. Em teoria de campos, na expressão para a densidade de energia, há um termo proporcional a $A_{0}^{2} / \lambda_{D}^{2}$, onde $A_{0}$ é o campo de gauge para o boson de gauge sem massa. Desta forma, a expressão geral para o raio de blindagem de Debye pode ser escrito como

$$
\lambda_{D}^{-2} \propto \frac{\partial^{2} \text { Densidade de energia }}{\partial \mu_{e}^{2}},
$$

onde $\mu_{e}$ é o potencial químico para a carga elétrica. Isso significa que $\lambda_{D}$ relaciona-se à resposta de um meio a mudanças em $\mu_{e}$.

Para a matéria estranha sem emparelhamento de quarks, a expressão 2.15 corresponde a expressão mais geral 2.18. Para a matéria CFL, o boson de gauge sem massa é o fóton rotacionado ou $\tilde{Q}$, e a carga $\tilde{Q}$ de todos os pares de Cooper que se formam no condensado é zero. Como todas as quasi-partículas estão emparelhadas, devido a que a simetria Ũ(1) em não é quebrada no estado fundamental, a fase CFL não é um supercondutor eletromagnético, mas um isolante Q [20].

Na matéria CFL, o potencial químico de carga elétrica relevante é $\mu_{\tilde{Q}}$ e a raiz quadrática média de 2.18 é zero [89]. Então o campo elétrico não é blindado e a carga elétrica de uma strangelet no estado CFL será determinada apenas pelos efeitos de existência de uma extensão finita para essa matéria.

Os comportamentos para a carga elétrica de strangelets com emparelhamento (não blindada) e sem emparelhamento (blindada se $R>\lambda_{D}$ ) para $T, B, m_{s}$ e $\Delta=\Delta_{0}$ fixos como função do número bariônico são mostrados na figura 2.9.

Strangelets sem emparelhamento de quarks apresentam pouca variação na carga atômica $Z$ com a temperatura. Isso ocorre porque as mudanças no raio da partícula e no raio de blindagem de Debye são pequenos (ambos aumentam em até 5\%) e como a carga elétrica é blindada e dada pela equação 2.15, o aumento para temperaturas elevadas quando comparado ao caso de temperatura nula é menor que $5 \%$. 

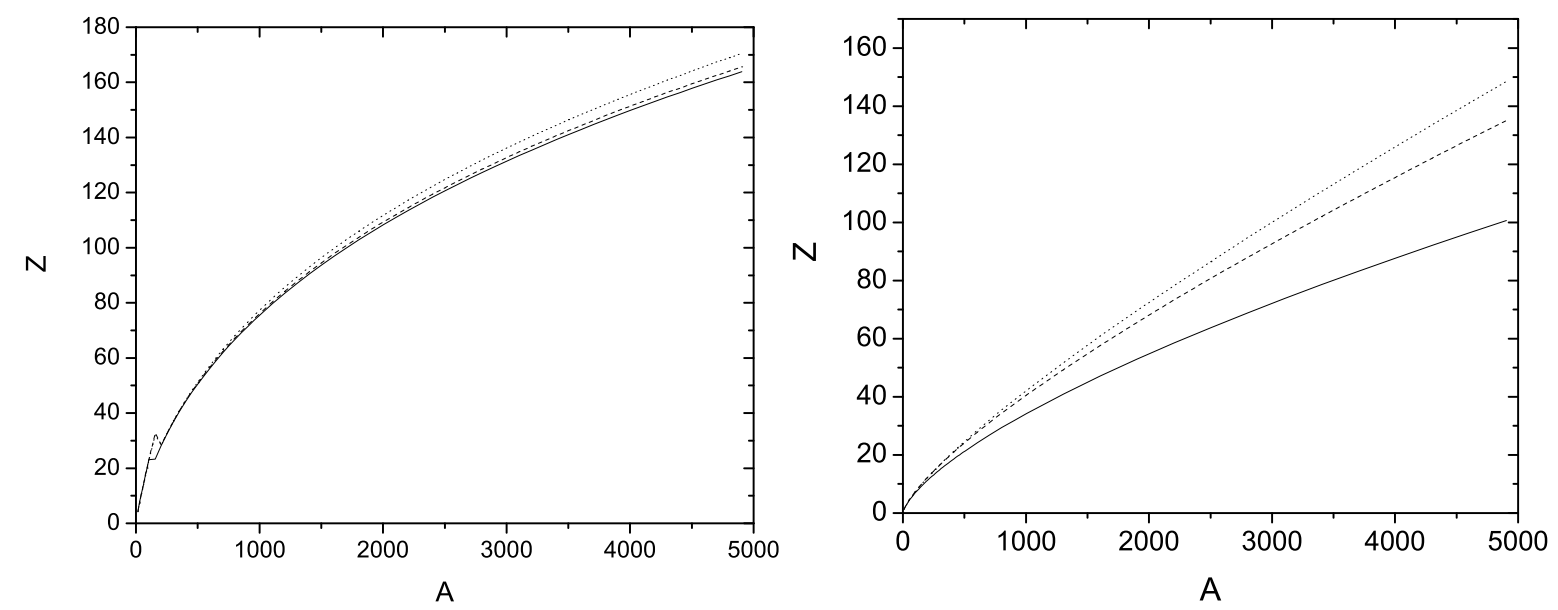

Figura 2.9: Carga elétrica como função do número bariônico para strangelets sem emparelhamento (à esquerda) e CFL (à direita) para $T=0$ (linha cheia), $T=10$ (linha tracejada) e $T=30$ (linha pontilhada), $B^{1 / 4}=145$ $\mathrm{MeV}, m_{s}=150 \mathrm{MeV}$ e $\Delta=\Delta_{0}=100$.

A carga elétrica aumenta com o aumento na temperatura para strangelets CFL de grande número bariônico devido a dependência da densidade numérica dos diferentes sabores de quarks dentro da strangelet com $T$. Para os quarks leves, a temperatura favorece ligeiramente o aumento na sua densidade numérica através do termo $\mu T^{2} V$. Mas para o quark strange massivo, o efeito é oposto, já que $N_{s}=\int_{0}^{\infty} d N s / d k\left(1+\exp \left(\left(\sqrt{k^{2}+m_{s}^{2}}-\mu_{s}\right) / T\right)\right) d k$. Então, $Z / A^{2 / 3}$ desvia do valor que tende a uma constante, esperado da supressão do quark $s$ perto da superfície quando $T=0$ [90], devido a uma maior importância do desbalanço volumétrico na densidade numérica dos quarks de diferentes sabores quando a temperatura é elevada.

Em resumo, vemos que a matéria estranha no estado CFL é mais estável que SQM sem emparelhamento de quarks. Mesmo quando se considera o estado CFL, se a temperatura é próxima à temperatura crítica para supercondutividade, ainda há possibilidade para a (meta) estabilidade, dependendo dos valores assumidos pelos demais parâmetros que caracterizam a matéria. Isto sugere que o processo de transição de uma estrela de nêutrons para estrela estranha poderia proceder logo após a explosão de supernova e o sistema poderia, inclusive, não passar pelo estágio de estrela de nêutrons, procedendo diretamente à conversão de matéria nuclear ordinária para o estado CFL se condições propícias forem originadas no interior desses objetos compactos. Como resultado geral, é possível observar que a temperatura acima de 
zero tem sempre como conseqüência desestabilizar o sistema, mesmo quando consideramos a dependência de $\Delta$ com $T$ o que leva a SQM em bulk a ser ligeiramente favorecida quando comparada a sua "versão de $\Delta$ constante", mas ainda assim, menos estável que a $T=0$.

Também é possível notar um fato bastante distintivo entre strangelets com e sem emparelhamento de quarks relacionado à existência de um número bariônico crítico para estabilidade, $A_{\text {crit }}$. Esta quantidade representa o mínimo $A$ para o qual strangelets são estáveis contra o decaimento através da emissão de nêutrons. Os efeitos de superfície e curvatura tendem a desestabilizar a matéria estranha para baixo conteúdo bariônico. Como resultado, a energia necessária para criar pequenos pedaços de SQM aumenta conforme o número bariônico decresce até que atinja um valor acima do limiar para decaimento por emissão de nêutrons, ou seja, até que sua energia por unidade de número bariônico esteja acima de $~ 930 \mathrm{MeV}$ (ver figura 2.3). Como mostrado em [79] e [45], o número bariônico crítico para strangelets sem emparelhamento de quarks existe mesmo a temperatura zero. É sabido que quanto menor o valor da constante de sacola (sempre respeitando o limite $B^{1 / 4} \geq 145 \mathrm{MeV}$ ) e maior o do gap de emparelhamento, mais estável é a matéria estranha em bulk $[15,21]$. No caso de strangelets CFL com altos valores de $\Delta$ e relativamente baixos valores de $B$, quando a análise é feita nas bases do modelo de sacola do MIT, a existência de $A_{\text {crit }}$ não parece tão óbvia. Deve ser notado, entretanto, que o modelo de gota líquida não porporciona uma boa descrição para baixo número bariônico, mostrando-se menos confiável que análises feitas com o modelo de camadas para strangelets [16].

Outro ponto importante é que para altos valores de $A$, strangelets CFL parecem ser absolutamente estáveis mesmo a temperaturas da ordem de $30 \mathrm{MeV}$ quando $\Delta=100 \mathrm{MeV}$. No entanto, espera-se que valores do gap de emparelhamento muito maiores que poucas centenas de $\mathrm{MeV}$ não descrevam esses sistemas. Assim, a temperatura crítica para que haja emparelhamento de quarks dentro das strangelets não deve ser maior que 50-80 MeV. Para temperaturas acima desse valor, os quarks dentro de uma strangelet não estariam mais emparelhados e o ganho em energia para este estado que há em comparação com strangelets em um estado não supercondutor desapareceria. Como strangelets sem emparelhamento de quarks não são estáveis a temperaturas tão altas quanto às máximas temperaturas críticas esperadas, a estabilidade da matéria estranha se desfaria acima de $T_{\text {crit }}$ se o gap de emparelhamento é bastante elevado.

Também verificamos que strangelets são mais favorecidas no estado CFL, como esperado. 
Em particular, a energia de curvatura para strangelets CFL é menor que para strangelets sem emparelhamento, o que pode influenciar o processo de fragmentação da matéria estranha em bulk, um ponto importante quando se considera a possível presença desses exóticos entre a população de raios cósmicos e sua produção em colisões de íons pesados (apesar de as altas temperaturas atingidas por estes últimos experimentos desfavorecerem a produção de strangelets estáveis nesse meio, conforme já suspeitado em [90] e detalhado neste estudo) ${ }^{\S}$.

${ }^{\S}$ Estes resultados foram aceitos para publicação na Physical Review C 


\section{Capítulo 3}

\section{A passagem de strangelets pelo meio interestelar}

Já mencionamos anteriormente (seção 1.3) que a hipótese da matéria estranha leva naturalmente à consideração de eventos que poderiam ejetar strangelets na Galáxia, para assim "contaminar", por sua vez, o fluxo de raios cósmicos no meio interestelar com uma componente exótica.

Apesar da baixa densidade média de matéria no meio interestelar, os tempos de confinamento de partículas carregadas nos campos magnéticos galácticos é bastante elevado, de modo que as colisões entre a partícula de interesse e o meio podem se tornar um fator relevante. Particularmente, a passagem por regiões nas quais a densidade do meio interestelar é substancialmente maior, como as regiões HII (nuvens de hidrogênio ionizado) e remanescentes de supernovas, deve influir na determinação do fluxo.

Neste capítulo discutiremos o grau de ionização de strangelets e como o espectro de fragmentação inicial proveniente das fontes poderia ser reprocessado através de colisões com a matéria existente no meio interestelar.

\subsection{Estados de ionização de strangelets}

Como já discutido nos capítulos 1 e 2, a matéria estranha sem emparelhamento (também chamada de "normal" neste trabalho) em bulk contém os quarks $u, d, s$ e elétrons em equilíbrio 
$\beta$. Por outro lado, a SQM no estado CFL é automaticamente neutra em bulk e estruturas finitas apresentam uma pequena carga positiva [90]. Desta forma, é natural que strangelets CFL sejam circundadas por uma nuvem eletrônica de maneira a neutralizar sua carga total, formando um átomo exótico. O mesmo ocorrerá com a matéria estranha normal se o raio da strangelet for menor que o comprimento de onda Compton do elétron, uma condição satisfeita desde que $A \ll 10^{7}$.

No que se segue, e durante toda a análise presente nesta Tese, e a menos que se especifique o contrário, considerar-se-á que a massa de repouso da strangelet é de $\epsilon_{0} A \sim(930 \times A)$ $\mathrm{MeV}$, com $\epsilon_{0}$ o valor assintótico da energia por número bariônico da matéria estranha. Não consideraremos o fato de que a energia por número bariônico decresce com $A$ (conforme pode ser visto na seção 2), dado que as incertezas encontradas em outros parâmetros utilizados para sua descrição são possivelmente maiores que o erro associado a essa aproximação . Também, a massa do quark $s$ será tomada em $m_{s}=150 \mathrm{MeV}$ e o gap de emparelhamento da matéria estranha CFL, $\Delta=100 \mathrm{MeV}$ neste estudo. Com esses valores, o número atômico das strangelets é dado por $Z=0.125 A$ para $A \ll 150$ e $Z=8 A^{1 / 3}$ para $A \gg 150$ [88] no modelo de sacola do MIT para strangelets normais e $Z=0.3 A^{2 / 3}$ para o modelo CFL [90].

Strangelets provenientes de quaisquer que sejam os eventos de injeção viajariam no meio interestelar, ou ISM (da sigla em inglês, interstellar medium), e se tornariam ionizadas por colisões e interações com fótons. Uma simples análise para avaliar-se o grau de ionização de strangelets semi-relativísticas cercadas por uma nuvem eletrônica devido a estas interações foi realizada na aproximação do modelo do átomo de Bohr. Strangelets encontram-se parcialmente neutralizadas por elétrons provenientes da excitação do vácuo se $Z \gg 100$ [44], mas para os casos de interesse desta simples análise o número bariônico é tal que não precisaremos levar em conta este efeito.

Consideramos uma colisão de dois corpos (elétron incidente - elétron na nuvem eletrônica) ao invés de um problema de muitos corpos, já que isto envolveria muitas variáveis e consideraçoẽs tais que tornariam esta análise extremamente complexa. A ionização é considerada resultante prioritariamente de interações com elétrons no ISM com distribuição Maxwelliana de velocidades em uma temperatura em torno de $100 \mathrm{~K}$, uma condição padrão para elétrons no ISM.

Os resultados são mostrados na figura 3.1 para strangelets com energia total de $1 \mathrm{GeV} / \mathrm{A}$. 


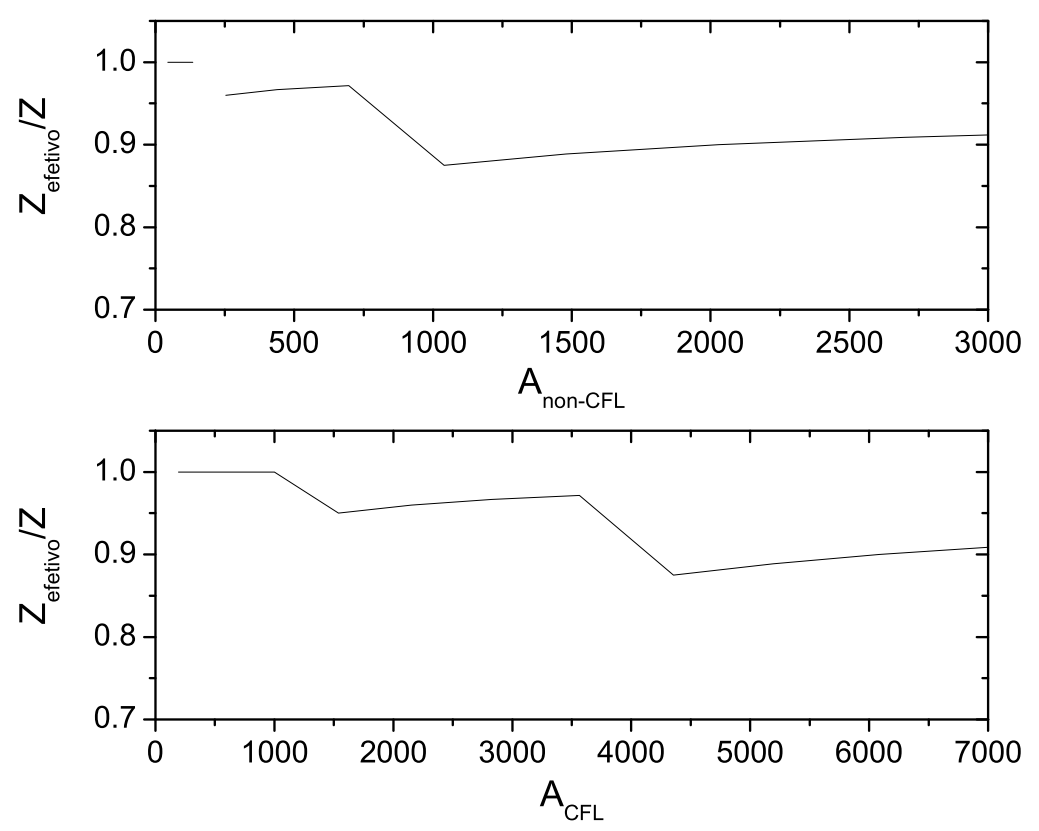

Figura 3.1: Carga efetiva $Z_{\text {eff }}$ versus número bariônico $A$ para strangelets normais (painel superior) e CFL (painel inferior) de energia $1 \mathrm{GeV} / \mathrm{A}$ após interação com elétrons no meio interestelar.

Considerando a densidade média no meio interestelar de 1 partícula $/ \mathrm{cm}^{3}$, o livre caminho médio para uma colisão eletrônica que pode ou não resultar em ionização é da ordem de $10^{15} \mathrm{~cm}$, ou $10^{-3} \mathrm{pc}$, bastante pequeno para os padrões da Astronomia.

O grau de ionização tornou-se estável com uma distância percorrida da ordem de alguns parsecs para strangelets com energia de $1 \mathrm{GeV} / \mathrm{A}$. Para strangelets ultra-relativísticas (o tipo de candidatos que seriam responsáveis pelos eventos Centauros [71], com energia de $E / A \sim \mathrm{TeV}$ ) os cálculos indicam ionização total. Para o fluxo de radiação no ISM, a influência do campo de radiação na ionização de strangelets será negligenciável a menos que sua trajetória passe por uma região que contenha fótons muito energéticos (ou seja, nas vizinhanças de estrelas WolfRayet, O ou B e/ou regiões de formação estelar), mas devido aos resultados obtidos, ignoramos esta fonte adicional de ionização.

O átomo de Bohr é uma aproximação rudimentar para a distribuição eletrônica em torno da strangelet, pois não leva em conta correções quânticas tão importantes quanto o acoplamento spin-órbita e efeitos não-locais, nem correções relativísticas para corpos com muitos elétrons $(Z \geq 40)$. No entanto, não há expressões gerais para que essas correções sejam aplicadas para átomos de muitos elétrons. A existência de modelos (por exemplo, cálculos de Hartree-Fock) 
são restritos a átomos com poucos elétrons, o mesmo para correções experimentais. Desta forma, os cálculos apresentados devem ser vistos como estimativas para compreender-se a influência mais significativa decorrente de cada processo, e não como prevendo valores exatos. No entanto, essa análise (e as que se seguem) mostra-se válida especialmente pela possibilidade de considerar-se apenas um processo por vez e verificar sua relevância em um quadro mais geral.

Entretanto, para partículas de baixa energia, a captura eletrônica pode ser tão importante quanto o processo de ionização até então discutido. Uma seção de choque aproximada para a captura de elétrons de velocidade $v$ por uma partícula carregada de número atômico $Z$ pode ser dada por [91] [92]

$$
\sigma_{c}=Z^{2} 2^{2 / 3} \alpha^{4} \frac{h^{2} \nu^{2}}{m_{e}^{2} v^{2} c^{2}}\left(\frac{m_{e} c^{2}}{h \nu}\right)^{7 / 2} \times 6.65 \times 10^{-25} \mathrm{~cm}^{2}
$$

onde $h \nu \approx E_{e}$ para $E_{e}>>I, I$ e $E_{e}$ sendo as energias do elétron enquanto ligado ao núcleo e livre no ISM, respectivamente, e $m_{e} c^{2}$, a massa de repouso do elétron. Esta forma da seção de choque para recombinação radiativa é obtida relacionando-se a captura de um elétron por um núcleo totalmente ionizado de carga $Z e$ com a captura no estado correspondente do átomo de hidrogênio. A seção de choque de captura pelo átomo de hidrogênio, por sua vez, é proporcional à energia do gama emitido neste processo e também à seção de choque para a absorção de um quantum de freqüência $\nu$ por um íon de $H^{-}$(resultando na emissão de um elétron de velocidade $v$ ), e inversamente proporcional ao momento do elétron absorvido. No caso de um núcleo parcialmente ionizado, a seção de choque ainda é parcialmente dada pela equação (3.1), mas um cálculo especial deve ser feito para obter-se a seção de choque de captura em um orbital com número quântico $n_{0}$, geralmente dado em tabelas para núcleos ordinários.

O átomo ou íon formado pela captura eletrônica pode perder este elétron em novas interações. Para materiais leves, a seção de choque para perda eletrônica pode ser aproximadamente expressa, para $v>v_{0}[93]$, por

$$
\sigma_{l}=8 \pi a_{0}^{2} Z^{-2}\left(\frac{v_{0}}{v}\right)^{2}
$$


onde $a_{0}=\hbar^{2} / m e^{2}=0,53 \times 10^{-8} \mathrm{~cm}$ é o raio de Bohr e $v_{0}=e^{2} / \hbar$, enquanto que para materiais de $Z$ intermediários,

$$
\sigma_{l}=\pi a_{0}^{2} Z^{-1}\left(\frac{v_{0}}{v}\right)
$$

devido ao efeito de blindagem.

Assim, uma comparação das equações 3.1, 3.2 e 3.3 mostra que a captura eletrônica seria importante apenas para strangelets de alto $Z$, precisamente onde esta análise simplificada não é mais válida devido aos efeitos de excitação do vácuo. Para as análises de população de strangelets que podem vir a ser aprisionadas no campo magnético terrestre, acreditamos que o número bariônico das strangelets envolvidas seja tal que esses efeitos serão de mínima relevância.

Em suma, estes resultados indicam que podemos adotar ionização total como uma boa aproximação para a fluxo de strangelets provenientes do ISM e que poderiam formar um cinturão de radiação na magnetosfera, proposta que será analisada mais adiante.

\subsection{Interações hadrônicas}

Strangelets provenientes de quaisquer que sejam os eventos responsáveis pela sua ejeção no meio interestelar, estarão sujeitas a interações com a matéria da qual este meio é composto, causando um certo grau de reprocessamento do espectro de injeção nas fontes.

Para a análise de interações nucleares, diferentes modelos são utilizados, cada qual construído com características que visam explicar comportamentos específicos verificados experimentalmente. Enquanto os processos constituem um conceito geral, os modelos que os descrevem podem apresentar restrições quanto ao intervalo de energia, composição do alvo e projétil, entre outros, para sua aplicabilidade. Assim, existem diversos modelos contruídos para explicar o mesmo processo, com diferentes graus de sucesso. Estes podem ser classificados em: baseados amplamente em medidas experimentais, com a geração de extensas e detalhadas tabelas; predominantemente baseados em parametrizações ou extrapolações de dados experimentais, 
sendo necessárias algumas considerações teóricas sobre as quais se baseiam; e modelos predominantemente teóricos.

Quando dados experimentais encontram-se disponíveis em quantidades apropriadas, os modelos que neles se baseiam neles provêm a melhor descrição possível. Entre eles, encontram-se, por exemplo, os que descrevem o transporte de nêutrons, evaporação de fótons, absorção em repouso, cálculos da seção de choque de reação, produção de isótopos e decaimento radiativo. As limitações estão presentes para as análises de altas energias, para partículas de baixa meia-vida e para bárions estranhos.

Modelos baseados em parametrizações e extrapolações de dados experimentais são amplamente utilizados e incluem fissão induzida, captura e espalhamento elástico e inelástico.

Os modelos teóricos propõem diferentes abordagens para explicar o comportamento das interações hadrônicas em diferentes regiões em energia e de acordo com o grau de detalhe desejável. Estes incluem: modelos de corda (parton string model, quark gluon string); Fermi break-up, capaz de prever estados finais de núcleos excitados de número bariônico $A<17$; multifragmentação estatística (descrito com maiores detalhes no apêndice A), usado para prever o estado final de um núcleo com alta energia de excitação $\left(E_{\text {exc }} / A>3 \mathrm{MeV}\right)$; evaporação de partículas, que compara a energia de excitação adquirida pelo núcleo na colisão com a energia de separação de nucleons e elementos leves, considerando a probabilidade de emissão dessas partículas através do princípio de balanço detalhado; evaporação de fótons; entre outros. Estes modelos dependem de algum grau de redução de dados de reações nucleares mas somente de maneira a proporcionar parâmetros não previstos na teoria.

Modelos que pretendem ser mais completos envolvem diferentes canais de excitação nuclear e decaimento. Como exemplo, o modelo de cascata intranuclear Bertini Intranuclear Cascade Model trata as interações nucleares em termos de colisões partícula-partícula, suposição razoável quando o comprimento de onda de DeBroglie da partícula incidente é comparável (ou menor) que a distância média entre os nucleons que compõem o alvo. Sua utilização encontra-se restrita ao intevalo de energias $[200 \mathrm{MeV}, \sim 10 \mathrm{GeV}]$ e se considera que os nucleons apresentam uma distribuição de gás de Fermi sendo incorporado o princípio de exclusão de Pauli. Em seguida, um modelo de pré-equilíbrio é utilizado para determinar a evaporação a partir de dados experimentais e alcançar o estado de equilíbrio. Para os casos de alta energia de excitação, é 
verificada a possibilidade de break-up nuclear e evaporação na configuração de equilíbrio de energia.

Os processos de interação hadrônica que serão estudados para as colisões strangelet-núcleo no ISM são: fusão, diminuição do número bariônico por abrasão e fissão. Também serão considerados processos de perda de energia (desexcitação), resultado do ganho de energia pela strangelet na colisão, conforme descritos a seguir.

\subsubsection{Abrasão}

O modelo de abrasão proposto por Wilson et al [94] é um modelo simples construído para descrever qualitativamente o processo chamado mais genericamente de espalação. Ele se baseia em argumentos geométricos ao invés de considerar a interação nucleon-nucleon em maiores detalhes. Assim sendo, o custo computacional deste modelo é bastante reduzido quando comparado àquele necessário para a implementação de modelos como os de cascata, mas a acurácia é, claramente, também reduzida. Apesar das evidentes perdas de detalhes, este modelo é ainda utilizado, em especial para o estudo de sistemas nos quais os dados experimentais são reduzidos ou onde outros modelos falham *.

O processo de abrasão é o de interação inicial, rápido, no qual a região do alvo na trajetória do projétil é varrida por este, o que pode levar à remoção de matéria do alvo (ou projétil) na colisão [94] (ver figura 3.2). Considera-se também que os nucleons "espectadores" da colisão (ou seja, os nucleons que não se encontram na zona de interação) sofrem pouca alteração de momento.

Este é um modelo simplificado e macroscópico que visa explicar a perda de massa das partículas envolvidas em interações nucleares baseando-se amplamente em argumentos geométricos. Assim, a utilização deste método para o presente estudo torna-se uma escolha bastante natural, já que strangelets ainda não foram detectadas (ao menos de maneira indubitável...), não havendo, portanto, dados experimentais para o aprimoramento dos modelos.

A distância de maior aproximação, $r_{m i n}$, entre as duas partículas interagentes é dada pela

*Um exemplo, pode ser encontrado na construção do sofisticado software Geant4, desenvolvido para simular a passagem de partículas pela matéria, já que este possibilita a implementação do modelo de abrasion-ablation para compor a simulação. 


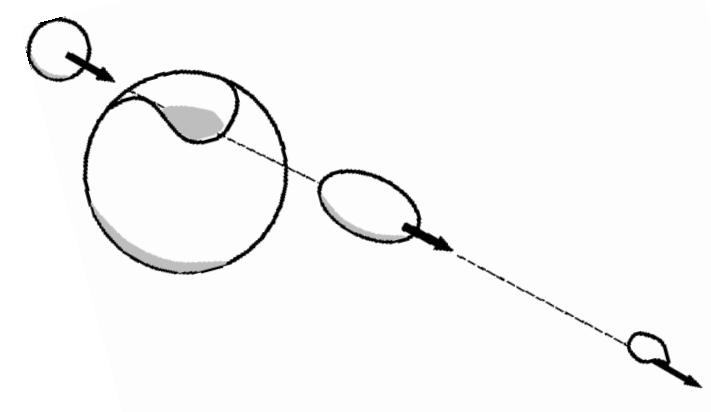

Figura 3.2: Representação pictórica do processo de abrasão. Este processo pode levar r̀emoção de matéria do alvo (projétil) na região de interação deste com o projétil (alvo).

equação de conservação de energia:

$$
b^{2}=r_{\min }\left(r_{\min }-\frac{Z_{p} Z_{T} e^{2}}{E_{t o t}}\right)
$$

onde $b$ é o parâmetro de impacto, $E_{t o t}$ a energia total no referencial do centro de massa e $Z_{p}$ e $Z_{T}$ são os números atômicos do projétil e alvo, respectivamente.

A quantidade de matéria do projétil que sofre abrasão é dada por

$$
\Delta_{a b r}=F A_{p}\left[1-\exp \left(-C_{T} / \lambda\right)\right]
$$

onde $F$ é a fração do projétil na zona de interação, $\lambda$ é o livre caminho médio, $A_{p}$ é a massa bariônica do projétil e $C_{T}$ é a máxima corda (segmento que conecta dois pontos distintos sobre uma circunferência) na interface do projétil e alvo. Se $R_{T}>R_{P}$, onde $R_{T}$ é o raio do alvo e $R_{P}$, do projétil e $r$ a distância de maior aproximação, 


$$
\begin{aligned}
& F=0.75(1-\nu)^{1 / 2}\left(\frac{1-\beta}{\nu}\right)^{2} \\
& -0.125\left[3(1-\nu)^{1 / 2}-1\right]\left(\frac{1-\beta}{\nu}\right)^{3}, \quad \text { Se } R_{T}-R_{P} \leq r \leq R_{T}+R_{P}, \\
& F=1, \quad \text { Se } r<R_{T}-R_{P},
\end{aligned}
$$

são os fatores para colisões centrais e periféricas (ver figura 3.3), respectivamente, e se $R_{P}>$ $R_{T}$

$$
\begin{aligned}
& F=0.75(1-\nu)^{1 / 2}\left(\frac{1-\beta}{\nu}\right)^{2}-0.125\left(\frac{1-\beta}{\nu}\right)^{3} \times \\
& \left\{\frac{3(1-\nu)^{1 / 2}}{\mu}-\frac{\left[1-\left(1-\mu^{2}\right)^{3 / 2}\right]\left[1-(1-\mu)^{2}\right]^{1 / 2}}{\mu^{3}}\right\}, \quad \text { Se } R_{P}-R_{T} \leq r \leq R_{P}+R_{T} \\
& F=\left[1-\left(1-\mu^{2}\right)^{3 / 2}\right]\left[1-\left(\frac{\beta}{\nu}\right)^{2}\right]^{1 / 2}, \\
& \text { Se } r<R_{P}-R_{T} \text {, }
\end{aligned}
$$

onde

$$
\begin{aligned}
& \nu=R_{P} /\left(R_{P}+R_{T}\right), \\
& \beta=r /\left(R_{P}+R_{T}\right), \\
& \mu=1 / \nu-1=R_{T} / R_{P} .
\end{aligned}
$$

A corda pode ser expressa, se $R_{P}>R_{T}$, como

$$
\begin{array}{ll}
C_{T}=2 \sqrt{R_{P}^{2}-x^{2}}, \quad & \text { Se } r>R_{P}, \\
C_{T}=2 R_{T}, & \text { Se } r \leq R_{P},
\end{array}
$$

onde $x=\left(r^{2}+R_{P}^{2}-R_{T}^{2}\right) / 2 r$, ou, se $R_{T}>R_{P}$, 


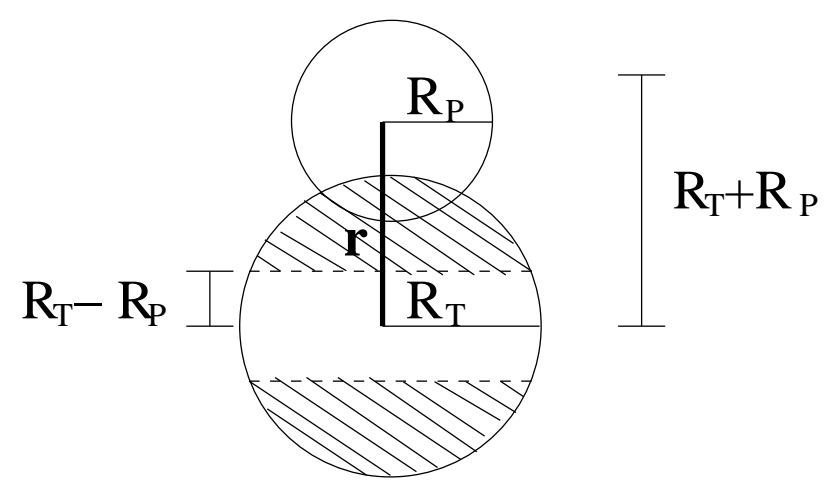

Colisão periferica

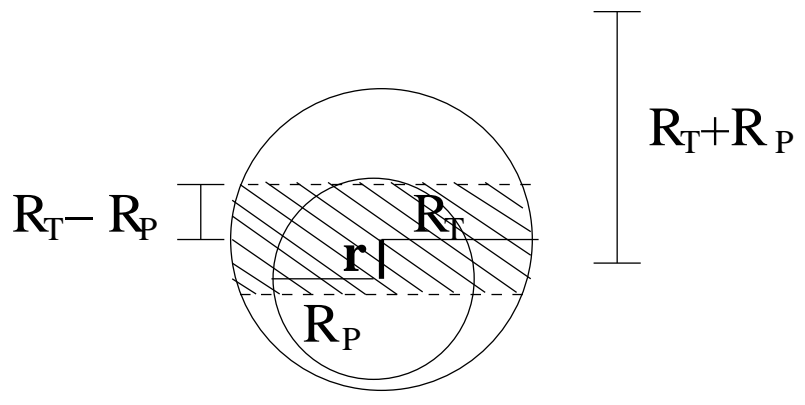

\section{Colisão central}

Figura 3.3: Representação esquemática para as condições em que ocorrem colisões periféricas (acima) e centrais (abaixo). Em cada figura, os limites para a distância de maior aproximação, $r$, entre as duas partículas de raios $R_{T}$ e $R_{P}$ para classificação da colisão são indicados pelas áreas hachuradas para o caso $R_{T}>R_{P}$.

$$
\begin{array}{ll}
C_{T}=2 \sqrt{R_{T}^{2}-x^{2}}, & \text { Se } r>R_{T}, \\
C_{T}=2 \sqrt{R_{T}^{2}-r^{2}}, & \text { Se } r \leq R_{T},
\end{array}
$$

onde $x=\left(r^{2}+R_{T}^{2}-R_{P}^{2}\right) / 2 r$.

Para estudarmos a interação de strangelets com a matéria nuclear ordinária, consideraremos que "pseudo-bárions" são formados temporariamente no interior da strangelet, em procedimento similar ao utilizado na literatura para o estudo da diferença na energia de ligação entre os núcleos de ${ }^{3} \mathrm{He}$ e ${ }^{3} \mathrm{H}$ (veja, por exemplo [95]). Neste estudo com o hélio e o trítio considera-se a formação de clusters de seis quarks devido à proximidade de dois nucleons. O procedimento consiste em considerar que os quarks manterão suas identidades desde que a distância entre eles seja maior que uma dada escala de comprimento, $r_{0}$. Quando há sobreposição dos quarks 


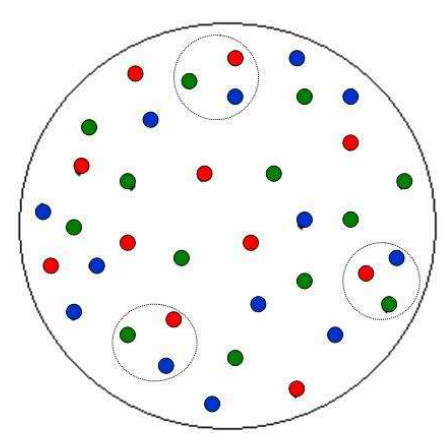

Figura 3.4: Representação pictórica da formação de clusters considerados na interação de strangelets com núcleos ordinários. Três quarks podem permanecer temporariamente ligados quando a distância entre eles é menor que um dado $r_{0}$.

$\left(r<r_{0}\right)$, estes são tratados como confinados a uma mesma região esférica. Adotamos, portanto, a mesma abordagem sendo que os clusters são pensados de modo pictórico como ilustrado pela figura 3.4. Não consideramos a possibilidade de formação de clusters com número de quarks diferente de três por estarmos interessados somente em analisar a mudança no número bariônico dessas partículas (o que não aconteceria para a abrasão de mésons ou com a ejeção de um único quark, já que o "esticamento" do campo de cor daria origem a pares quark-antiquark sendo que um quark continuaria ligado à strangelet). Também não são levados em conta clusters com número maior de quarks (por exemplo, um pentaquark) pois estes teriam probabilidade de formação bastante reduzida, tornando-se irrelevante nesta análise.

Consideramos que em um dado instante, uma dada fração dos quarks que compõem a strangelet estejam agrupados em três quarks temporariamente ligados. O livre caminho médio é tomado com base nos valores obtidos experimentalmente para a seção de choque nucleon-nucleon † [96] e o modelo de abrasão é utilizado para estimar-se a mudança em número bariônico para

\footnotetext{
${ }^{\dagger}$ No modelo de quarks aditivos, a seção de choque para uma dada partícula seria proporcional ao número de quarks de valência que a compõe. Sabe-se que diferentes composições de bárions afetam o valor da seção de choque, sendo esta, então, uma primeira aproximação, que deve fornecer a ordem de grandeza correta para o livre caminho médio.
} 
cada processo de colisão.

\subsubsection{Fusão}

$\mathrm{O}$ processo de fusão é representado genericamente por $A+B \rightarrow C$, onde $A$ e $C$ são strangelets e $B$ o núcleo incidente.

Para que uma reação de fusão nuclear ocorra, os núcleos interagentes precisam superar a barreira Coulombiana repulsiva entre eles, $V=1,44 Z_{1} Z_{2} / R \mathrm{MeV}$, onde $Z_{1}$ e $Z_{2}$ são os números atômicos das partículas e $R$, a distância (em fm) entre elas. No exemplo mais relevante, a fusão nuclear nas estrelas, a matéria no interior estelar pode ser aproximada como tendo uma distribuição de velocidades de Maxwell-Boltzmann caracterizada por uma dada temperatura $T$. Para temperaturas menores que aproximadamente $10^{7} \mathrm{~K}$, a energia média das partículas interagentes é ordens de grandeza menor do que a barreira Coulombiana que as separa. No entanto, as partículas que têm possibilidade de penetrar a barreira são aquelas com energias próximas à máxima energia na distribuição de Maxwell-Boltzmann, sendo o tunelamento quântico, portanto, o mecanismo pelo qual estas reações no interior das estrelas jovens tornam-se possíveis. No nosso caso, estudaremos a reação de fusão de dois corpos, strangelet + núcleo, adaptando os conceitos gerais quando necessário.

Para energias em centro de massa menor do que a barreira coulombiana do sistema, costuma ser utilizada a seguinte parametrização para a seção de choque de fusão:

$$
\sigma=\sigma_{\text {geom }} \times \tau \times \mathcal{R}
$$

onde $\sigma_{\text {geom }}$ é a seção de choque geométrica, $\tau$ é a transparência da barreira e $\mathcal{R}$, a probabilidade de que nucleons que entram em contato se fundam. A primeira quantidade é da ordem do quadrado do comprimento de onde de De Broglie do sistema:

$$
\sigma_{\text {geom }} \sim \lambda_{\text {DeBroglie }}^{2}=\left(\frac{\hbar}{m_{r} v}\right)^{2} \propto \frac{1}{E}
$$

onde $m_{r}=m_{1} m_{2} /\left(m_{1}+m_{2}\right)$ é a massa reduzida do sistema de partículas de massas $m_{1}$ e $m_{2}$. 
A transparência da barreira é bem aproximada pelo conhecido fator de Gamow,

$$
\tau=\tau_{G}=\exp \left(-\sqrt{E_{G} / E}\right)
$$

onde $E_{G}=\left(\pi \alpha_{f} Z_{1} Z_{2}\right)^{2} 2 m_{r} c^{2}$ é a energia de Gamow. No entanto, a equação 3.19 só é válida enquanto $E<<E_{G}$. Para a maioria das reações, a variação de $\mathcal{R}(E)$ é pequena comparada à forte variação devido ao fator de Gamow.

Assim, a seção de choque em geral é escrita como

$$
\sigma(E)=\frac{S(E)}{E} \exp \left(-\sqrt{E_{G} / E}\right)
$$

onde a função $S(E)$ é chamada de fator astrofísico $S$, que para muitas reações é uma função que depende fracamente da energia.

No entanto, para energias acima da barreira Coulombiana, faz-se necessária a estimativa da quantidade de energia perdida por interações entre alvo e projétil durante o período de contato. Seguindo a proposta formulada em [97], consideramos que quando a quantidade de energia depositada pelo projétil na strangelet (no referencial desta última) é da ordem da energia de ligação deste projétil na matéria estranha, então ocorre fusão. Consideramos, também, que somente ocorre fusão em colisões centrais, de acordo com os parâmetros geométricos definidos para o processo de abrasão. Assim, para a menor corda percorrida pelo núcleo interagente na strangelet numa colisão central (igual a $2 \sqrt{2 R_{s t r} r_{p}-r_{p}^{2}}$, onde $R_{s t r}$ é o raio da strangelet e $r_{p}$, o do núcleo de número bariônico $A_{p}$ ) será considerada que a máxima quantidade de energia depositada equivale à energia de ligação da strangelet que sofreu fusão $\left(E_{l i g} \simeq M_{n}-M\left(A+A_{p}\right) /\left(A+A_{p}\right)\right.$, onde $M_{n}$ é a massa do nucleon e $M(A)$ a massa da strangelet de número bariônico $A$ ). A partir do comprimento desta corda será feito um escalonamento para distâncias percorridas maiores (com limite máximo no diâmetro da strangelet). Então, para um núcleo com energia igual ou menor do que a energia de ligação já escalonada, haverá fusão. Esta construção permite associar cada corda geométrica de interação com uma função degrau em energia para fusão e resulta consistente com a abordagem geométrica adotada em geral. 


\subsubsection{Fissão}

A fissão de strangelets pode resultar de processos que transferem suficiente energia de excitação na colisão. Assim como em estudos anteriores [98], consideraremos, em analogia aos núcleos ordinários, o modelo de gota líquida. Se energia é adicionada ao sistema, oscilações ocorrem internamente à gota, o que tende a distorcer o formato nuclear. A força associada à tensão de superfície tende a fazer com que a gota volte ao seu formato original, enquanto que a energia de excitação tende a distorcê-la ainda mais. A energia de Coulomb pode atuar no sentido de fazer com que a distorção sofrida culmine na separação do núcleo em duas gotas que se tornam esféricas.

Quando a distância entre os fragmentos 1 e 2 resultantes da possível fissão da gota nuclear é $r=0$, o que representa o estado inicial de gota esférica, $E_{0}$ é a diferença em energia de repouso (quantidade de energia disponível para a fissão) dada por

$$
E_{0}=M(A, Z)-M\left(A_{1}, Z_{1}\right)-M\left(A_{2}, Z_{2}\right)
$$

onde $(A, Z)$ representa o núcleo que pode sofrer fissão.

A menor energia que é necessária introduzir ao sistema para que haja fissão (energia de ativação) é aquela que leva ao processo de fragmentação do sistema em dois fragmentos de massas iguais.

Em sistemas nucleares, quando há fissão espontânea, a energia de interação eletrostática resultante da repulsão mútua dos dois fragmentos pode auxiliar no processo de fissão, diminuindo a energia necessária introduzir ao sistema para que a fragmentação ocorra. Em nossos cálculos iremos ignorar esta possível contribuição já que esta energia é desprezível quando comparada às massas das strangelets.

\subsubsection{Excitação}

Após a colisão entre duas partículas, há a possibilidade de que, além dos processos descritos anteriormente, haja excitação de graus de liberdade internos das mesmas devido à transferência de energia entre o projétil e o alvo. 
Ainda com base em argumentos geométricos, a energia de excitação devido à transferência de energia cinética através da superfícies dos núcleos interagentes pode ser aproximada pela energia média transferida a um nucleon por unidade de caminho interseccionado (da ordem de $13 \mathrm{MeV} / \mathrm{fm}^{\ddagger}$ ) e pela mais longa corda na superfície do projétil, $C_{l}$ [94]:

$$
\begin{array}{ll}
E_{x}=13\left[1+\left(C_{T}-1,5\right) / 3\right] C_{l}, & \text { Se } C_{T}>1,5 \mathrm{fm}, \\
E_{x}=13 C_{l}, & \text { Se } C_{T} \leq 1,5 \mathrm{fm},
\end{array}
$$

onde $C_{T}$ é dado pelas equações 3.13 a 3.16 e $E_{x}$ é obtido em MeV. Em metade das colisões considera-se a energia de excitação dada por $E_{x}$ e para os eventos restantes, considera-se a energia do projétil não modificada.

A corda $C_{l}$, a máxima distância percorrida por qualquer constituinte do alvo pelo interior do projétil, é escrita como

$$
\begin{array}{ll}
C_{l}=2 \sqrt{R_{P}^{2}+2 r R_{T}-r^{2}-R_{T}^{2}}, & \text { Se } r>R_{T}, \\
C_{l}=2 R_{P}, & \text { Se } r \leq R_{T},
\end{array}
$$

sendo obtida em fm.

No caso em que ocorra o processo de abrasão, além da energia transferida na colisão, devese considerar a energia de excitação resultante da distorção sofrida pelo núcleo. Esta é devido à mudança no formato essencialmente esférico da partícula ocasionado pela abrasão de nucleons e pode ser escrita como

$$
E_{S}=0,95 \Delta S
$$

se a colisão for periférica e não há distorção significativa do núcleo, e

\footnotetext{
${ }_{\ddagger}^{\ddagger}$ Como strangelets são compostas de quarks, é razoável considerar que a interação dessas partículas com matéria nuclear ordinária possua o mesmo comportamento que aquele visto entre dois núcleos. Assim, o valor de $C_{l}$ deve ser da mesma ordem de grandeza daquele visto entre nucleons.
} 


$$
E_{S}=0,95(1+5 F) \Delta S
$$

se a distância de maior aproximação é tal que $r<<R_{P}+R_{T}$. O fator $F$ é dado pelas equações 3.6 a 3.9 e $E_{S}$ será dado em $\mathrm{MeV}$ desde que $\Delta S$ esteja em $\mathrm{fm}^{2}$.

O fator de "excesso de superfície", $\Delta S$, é dado por

$$
\Delta S=4 \pi R_{P}^{2}\left[1+P-(1-F)^{2 / 3}\right]
$$

onde $P$, se $R_{T}>R_{P}$, é dado por

$$
\begin{aligned}
& P=0,125(\mu \nu)^{1 / 2}\left(\frac{1}{\mu}-2\right)\left(\frac{1-\beta}{\nu}\right)^{2} \\
& -0,125\left[0,5(\mu \nu)^{1 / 2}\left(\frac{1}{\mu}-2\right)+1\right]\left(\frac{1-\beta}{\nu}\right)^{3}, \\
& P=-1,
\end{aligned}
$$

e se $R_{P}>R_{T}$

$$
\begin{array}{rlrl}
P= & 0,125(\mu \nu)^{1 / 2}\left(\frac{1}{\mu}-2\right)\left(\frac{1-\beta}{\nu}\right)^{2} & \\
& -0,125\left(\frac{1-\beta}{\nu}\right)^{3}\left\{0,5\left(\frac{\nu}{\mu}\right)^{1 / 2}\right)\left(\frac{1}{\mu}-2\right) & & \text { Se } R_{P}-R_{T} \leq r \leq R_{P}+R_{T} \\
& \left.-\frac{\left[(1 / \nu)\left(1-\mu^{2}\right)^{1 / 2}-1\right][(2-\mu) \mu]^{1 / 2}}{\mu^{3}}\right\}, & \\
P= & {\left[\frac{1}{\nu}\left(1-\mu^{2}\right)^{1 / 2}-1\right]\left[1-\frac{\beta^{2}}{\nu}\right]^{1 / 2},} & \text { Se } r<R_{P}-R_{T}
\end{array}
$$

sendo $\mu, \nu$ e $\beta$ dados por 3.10 a 3.12 .

A hipótese da matéria estranha sugere que a fusão de um próton com a matéria de quarks leva às seguintes reações seqüenciais: $p \longrightarrow 2 u+d, u+d \longrightarrow s+u$, resultando em liberação adicional de energia para cada nucleon absorvido. No processo de fusão, a energia de excitação pode ser calculada, então, pelo "excesso de massa", $E_{x}$, e escrita como 


$$
E_{x}=M_{N}\left(A_{N}\right)+M_{s t r}\left(A_{s t r}\right)-M_{s t r}\left(A_{s t r}+A_{N}\right),
$$

sendo $A_{s t r}$ e $A_{N}$ os números bariônicos da strangelet e do núcleo com o qual esta interage e $M_{N}(A)$ e $M_{s t r}(A)$, as massas para a matéria nuclear ordinária e matéria estranha para um dado $A$, respectivamente.

\subsubsection{Desexcitação}

A strangelet que absorveu energia durante a colisão, emitirá essa energia por algum processo de desexcitação para voltar ao seu estado fundamental.

Na fusão de uma strangelet e um núcleo, há primeiro a formação de um estado intermediário que, em geral, está em um estado excitado. Também no caso de abrasão, a strangelet pode ficar em um alto estado de deformação, com grande energia de excitação.

A strangelet original pode sofrer desexcitação através da evaporação de nucleons. Para a emissão de nêutrons, seguiremos o procedimento detalhado por Berger e Jaffe [85].

Uma strangelet que emite um nêutron através da interação forte dá origem a uma strangelet com parâmetros que mudaram em $\Delta A=-1, \Delta Y=-1$ e $\Delta Z=0$. Este decaimento induzido pela interação forte é possível quando

$$
\frac{\partial E}{\partial A}+\frac{\partial E}{\partial Y}>M_{n}
$$

onde $M_{n}$ é a massa do nêutron e $Y$ é a hipercarga (operador que é combinação da carga, isospin e número bariônico, pode ser utilizado para se referir a conservação da estranheza).

Esta forma de emissão de nêutrons deve proceder em escalas de tempo típicas das interações fortes. É possível também a emissão de prótons com origem no mesmo processo, sendo então similar à do nêutron, exceto pela barreira Coulombiana. Por esta razão, a emissão de prótons é desprezível em relação a de nêutrons.

A emissão de nêutrons através da ação da força fraca cria uma strangelet com parâmetros que mudam em $\Delta A=-1$ e $\Delta Y=\Delta Z=0$, ou seja, acontece quando 


$$
\frac{\partial E}{\partial A}>M_{n}
$$

Este decaimento é mais lento que aquele determinado pela interação forte já que envolve o processo de mudança de sabor pela interação fraca.

O funcional de energia para a matéria estranha com correções de superfície, de efeitos de Coulomb e simetria ao limite em bulk pode ser expandido em potências de $\left(Y-Y_{\min }\right)$ e $(Z-$ $Z_{\text {min }}$ ), com $Y_{\min }$ e $Z_{\text {min }}$ os valores de hipercarga e número atômico para strangelets no mínimo de energia, respectivamente. Considerando que as strangelets deste estudo estão numa região próxima à estabilidade, então o termo $\left(Y-Y_{\min }\right)$ na fórmula de massa é desprezível e será apenas relevante a emissão de nêutrons por interações fracas (ver [85] para mais detalhes).

A quantidade de energia perdida pela emissão de píons pode ser calculada com o modelo de tubos de fluxo cromoelétrico (chromoelectric flux tube model) [99]

$$
\frac{d E}{d t}=-1,12 \times 10^{20} A^{2 / 3} T^{2} \exp (-381,1 / T) \mathrm{MeV} \mathrm{s}^{-1} .
$$

É possível verificar que a perda de energia só é considerável se a temperatura atingida pela matéria for bastante elevada (pelo menos da ordem de dezenas de $\mathrm{MeV}$ ).

A matéria estranha a uma dada temperatura $T$ é preenchida por radiação, em equilíbrio termodinâmico com os quarks. Se denotarmos por $\omega_{p}$ a freqüência de plasma no meio de quarks, o fluxo total de energia emitido na direção normal à superfície da matéria estranha apresenta um corte em $\omega=\omega_{p}$. Isto torna a matéria estranha um emissor pobre de fótons termalizados a energias abaixo de aproximadamente $20 \mathrm{MeV}$.

Ao considerar-se o processo de emissão por bremsstrahlung $\left(q_{1}+q_{2} \rightarrow q_{1}^{\prime}+q_{2}^{\prime}+\gamma\right)$, no qual um fóton com freqüência muito menor que a energia do quark é emitido, a emissão de superfície para a matéria estranha resulta cerca de quatro ordens de magnitude menor do que a emissão de equilíbrio de um corpo negro a uma dada temperatura $T$ [100]. Assim, a equação a ser resolvida é

$$
C_{v} \frac{d T}{d t}=-\zeta 4 \pi R^{2} \sigma T^{4}
$$


onde $\zeta \sim 10^{-4}, C_{v}$ é o calor específico da matéria estranha e $\sigma$ a constante de Stefan-Boltzmann.

O esfriamento pela emissão volumar de neutrinos é outro mecanismo para a perda de energia que deve ser estudado. A luminosidade devido a este processo é dada por

$$
L_{\nu}=\frac{4}{3} \pi R^{3} \epsilon_{\nu}
$$

onde $\epsilon_{\nu}$ é a emissividade de neutrinos.

Para a matéria sem emparelhamento [101, 102], temos o calor específico para quarks e a emissividade para os processos URCA modificado (QMU), bremsstrahlung (QB) e decaimento $\beta$ de quarks dados por

$$
\begin{aligned}
C_{q} & \simeq 10^{21}\left(\frac{\rho_{b}}{\rho_{0}}\right)^{2 / 3} T_{9} \mathrm{erg} \mathrm{cm}^{-3} \mathrm{~K}^{-1}, \\
\epsilon_{\nu}^{Q M U} & \sim \epsilon_{\nu}^{Q B} \sim 10^{20} T_{9}^{8} \mathrm{ergs} \mathrm{cm}^{-3} \mathrm{~s}^{-1}, \\
\epsilon_{\nu}^{\beta} & =8.0 \times 10^{24} T_{9}^{6} \mathrm{erg} \mathrm{cm}^{-3} \mathrm{~s}^{-1}
\end{aligned}
$$

onde $\rho_{b}$ e $\rho_{0}$ são as densidades bariônica e de saturação nuclear, respectivamente, e $T_{9}$ é a temperatura em unidades de $10^{9} \mathrm{~K}$. Para a matéria CFL, no qual os processos URCA, URCA modificado e bremsstrahlung são suprimidos pelo emparelhamento, o processo dominante é o que envolve os bósons de Goldstone [103], e assim temos

$$
\begin{aligned}
C_{C F L} & =3.2 C_{q} \frac{T_{c}}{T}\left[2.5-1.7 \frac{T}{T_{c}}+3.6 \frac{T^{2}}{T_{c}}\right] \exp \left(-\frac{\Delta}{T}\right), \\
\epsilon_{\nu}^{C F L} & =1.0 \times 10^{-11} \mu_{100}^{-6} T_{9}^{15} \operatorname{erg~cm}^{-3} \mathrm{~s}^{-1}, \quad \mathrm{~T}<<\Delta,
\end{aligned}
$$

onde $T_{c}$ é a temperatura crítica para o estado CFL (acima da qual não há estado supercondutor) e $\mu_{100}$ é o potencial químico em unidades de $100 \mathrm{MeV}$. 


\subsection{Cálculos numéricos}

A densidade média de matéria no meio interestelar é bastante baixa, $n_{I S M} \sim 1$ partícula/ $/ \mathrm{cm}^{3}$. Assim, a média de interações ao longo do caminho de uma strangelet no ISM é reduzida. No entanto, a Galáxia não tem uma distribuição homogênea de matéria, de modo que o livre caminho médio para estas partículas deve variar localmente no meio interestelar.

Um exemplo direto de aumento da densidade de matéria pode ser encontrado no cinturão de Gould, uma nuvem molecular gigante cujo centro encontra-se a $104 \pm 4$ pc do Sol, com dimensões de 60 pc para sua altura e semi-eixos $a=354 \pm 5$ pc e $b=232 \pm 5$ pc. Sua densidade é da ordem de $10^{3}$ partículas $/ \mathrm{cm}^{3}$ e é formada majoritariamente por moléculas de $H_{2}$. Esta é uma das regiões extensas que poderia causar alterações no número bariônico de strangelets que penetrassem seu interior.

Para proceder à análise dos possíveis processos para interação hadrônica entre uma strangelet e prótons e seus canais de desexcitação foi criado um programa em linguagem C específico. A estrutura deste programa é detalhada a seguir. Um diagrama esquemático pode ser visto na figura 3.5. Assim, a partir de uma strangelet de dado número bariônico $A$ e energia cinética $E$, os seguintes passos são seguidos:

i Escolha randômica do parâmetro de impacto $b \leq R_{p}+R_{s t r}$, onde $R_{p}$ e $R_{s t r}$ são os raios do próton e strangelet, respectivamente;

ii Cálculo da distância de maior aproximação de acordo com a equação 3.4;

iii Sorteio da energia de excitação adquirida pela strangelet por transferência de energia na colisão. Em metade dos eventos, a energia de excitação é nula e em metade, dada pela equação 3.22;

iv Cálculo da mínima energia de ativação para fissão, conforme 3.21

\section{v Interação hadrônica:}

Se a distância de maior aproximação é maior que a soma dos raios das duas partículas, tem-se espalhamento Coulombiano. 
Do contrário, para energias abaixo da barreira Coulombiana, há o sorteio da probabilidade de fusão de acordo com 3.20 para verificar se este processo é favorecido. Para energias acima da barreira, verifica-se o critério de deposição de energia. Se os critérios forem preenchidos, ocorre a fusão e é computada a energia de excitação de acordo com 3.33 .

Caso não ocorra a fusão, então se procede ao cálculo da abrasão nuclear de acordo com 3.5 e energia de excitação de acordo com 3.27. Se não houver bárions retirados na interação, então é dito que houve espalhamento.

vi Fissão: Somente se a energia de excitação total é maior que a energia de ativação. Se este for o caso, então são tomados os seguintes passos: a)Verifica-se qual é a divisão mais assimétrica permitida com a energia de excitação disponível; b)Associa-se uma distribuição de probabilidade gaussiana com pico em $A / 2$ e largura a meia altura tal que $P\left(A_{\min }\right)=0$; c) Sorteia-se os valores de $A_{1}$ e $A_{2}$ de acordo com a probabilidade construída; d) as energias cinética e de excitação são divididas proporcionalmente entre os fragmentos

vii Cálculo da temperatura de acordo com a Primeira Lei da Termodinâmica para que sejam analisados os processos de desexcitação (emissão de fótons, neutrinos, evaporação por nêutrons, perda de energia devido a emissão de píons)

Nas figuras 3.6 e 3.7 são apresentadas as probabilidades de ocorrência dos processos de abrasão, fusão e espalhamento, conforme descritos na seção 3.2, numa colisão com prótons no meio interestelar como função da energia incidente da strangelet ${ }^{\S}$.

O espalhamento é definido como o processo no qual não há variação no número bariônico da strangelet e engloba, portanto, tanto o espalhamento Coulombiano a baixas energias quanto a situação na qual o sistema tem a possibilidade de interagir levando à abrasão de matéria da strangelet, mas que, devido à relação entre a corda máxima para interação e o livre caminho médio (dependente da probabilidade de confinamento temporário de três quarks em uma região finita em seu interior), não há bárions expulsos.

\footnotetext{
${ }^{\S}$ Nesta análise consideramos a dependência da massa da strangelet com o número bariônico conforme valores obtidos na seção 2.2.
} 


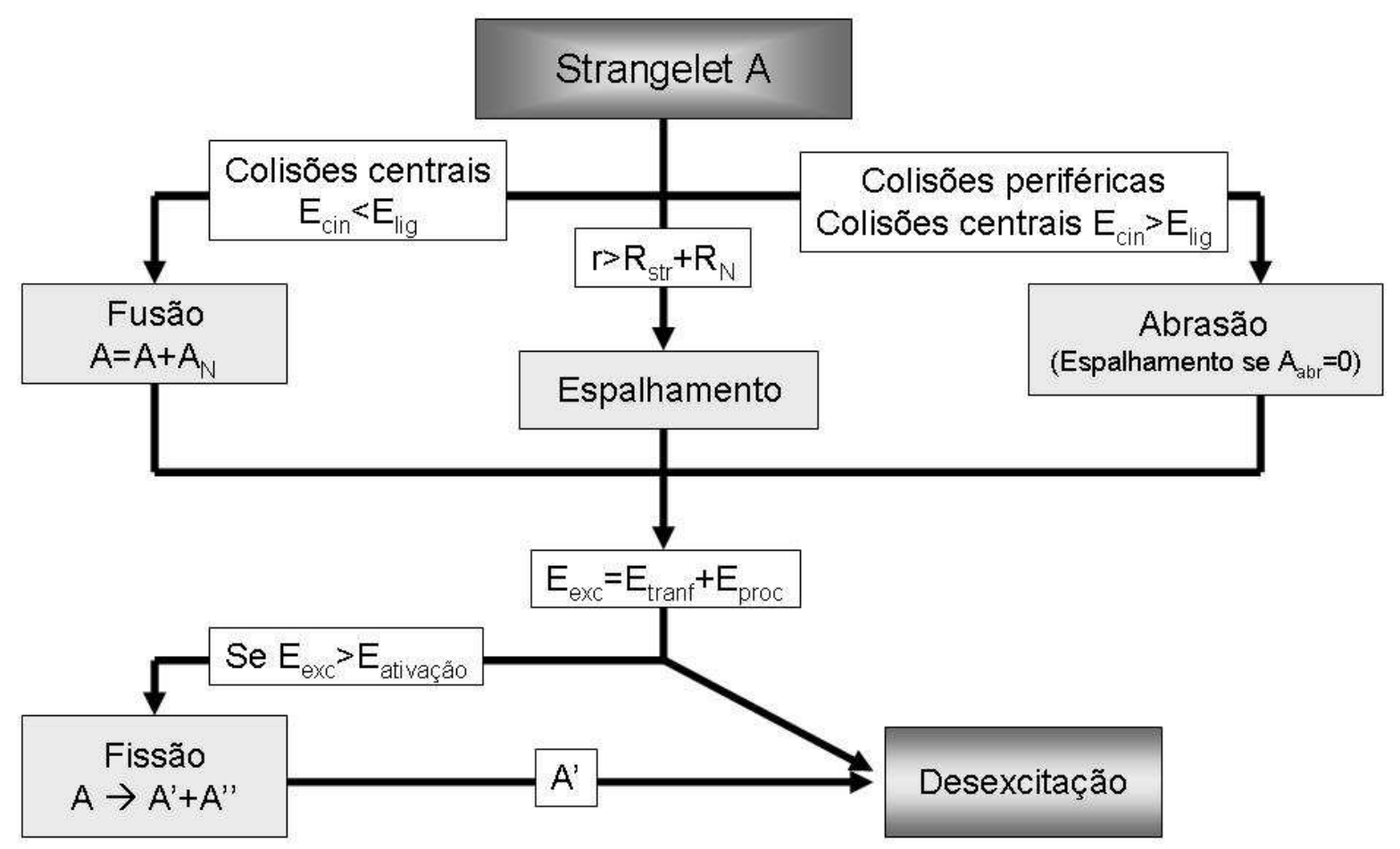

Figura 3.5: Visão esquemática do processo de avaliação da interação de uma strangelet com prótons. A partir do sorteio de um parâmetro de impacto e tendo a energia inicial da strangelet, determina-se qual processo ocorrerá (espalhamento, fusão ou abrasão). Calcula-se, então, a energia de excitação decorrente da interação, a qual é comparada à energia de ativação para a fissão. Se ocorrer fissão, acompanhamos a strangelet agora com $A^{\prime}$ durante o processo de esfriamento pelos possíveis mecanismos detalhados na seção 3.2.5, o que também é feito no caso em que não há fissão (referir ao texto para maiores detalhes). 
A fração de bárions para a strangelet é variada e está relacionada à probabilidade (até o momento incalculável) de que num dado instante haja uma certa quantidade de clusters de três quarks formados. Este valor é importante para verificar-se a importância relativa dos processos de abrasão e espalhamento.

Ainda para a matéria CFL, é possível que a existência dos pares cause um efeito de transparência para a passagem da matéria hadrônica. No entanto, a análise para verificar se isto de fato ocorre é bastante complexa e foge ao escopo desta tese.

Para energias abaixo da barreira Coulombiana, a fusão primeiramente ocorre devido ao tunelamento quântico pela barreira e, para energias que aumentam progressivamente, é produzida como resultado do aprisionamento do próton em colisões centrais. Conforme a energia aumenta, a probabilidade de colisão central na qual ocorra a deposição de toda a energia cinética do próton (no referencial da strangelet) diminui progressivamente até que a energia cinética esteja acima da máxima associada à fusão (que corresponde àquela depositada ao longo do diâmetro da strangelet), ponto no qual a probabilidade vai a zero.

Devido à diminuição da probabilidade de fusão conforme a energia é elevada, o processo de abrasão passa a ser importante. Também o livre caminho médio decresce com a energia, o que provoca que a colisão entre o próton e os pseudo-bárions dentro da strangelet seja mais provável. No entanto, se a fração de clusters é bastante baixa, o processo de abrasão passa a dominar somente em altas energias pois a passagem do próton pela strangelet não resulta em alteração do número bariônico desta última. Por exemplo, para $f=0,1$ a abrasão só passa a ser importante para energias superiores a $E / A \sim 10^{4} \mathrm{MeV}$ para $A=100$. Apesar do crescimento mais suave da carga elétrica em strangelets CFL (o que influi a determinação da distância de maior aproximação), para energias muito grandes este fator é irelevante, e por isso não há diferenças significativas entre os dois estados, resultado principalmente do livre caminho médio para interação do núcleo ordinário com os bárions formados temporariamente no interior da strangelet ser considerado o mesmo para os dois estados neste estudo. Conforme o número de clusters aumenta, a influência do processo de abrasão ganha importância com aumento da sua probabilidade e também do número de bárions extraídos. Para energias por número bariônico acima de $10^{5} \mathrm{MeV}$, a relação entre os processos de abrasão e espalhamento tende a um valor assintótico. 
Mostramos na figura 3.8 o número bariônico médio que é retirado da strangelet no processo de abrasão quando este processo torna-se relevante. Conforme a energia da strangelet aumenta, a perda de massa na colisão devido ao processo de abrasão torna-se maior, até que atinja um patamar para energia muito altas. Obviamente, este valor também é afetado pela fração $f$ de quarks que se encontram temporariamente ligados em clusters, sendo que quanto maior esta fração, maior a perda de massa da strangelet em uma dada colisão, até energias intermediárias. Havendo uma concorrência entre os processos de abrasão e fusão, a energia na qual a abrasão passa a dominar deve ser maior que àquela na qual o processo de fusão deixa de ser importante, sendo o ponto exato dependente fortemente de $f$.

É possível verificar que, na colisão de uma strangelet com outras partículas, para que haja fissão a energia de excitação deve ter valores acima das curvas mostradas na figura 3.9. O canal mais provável para a fissão das strangelets (desprezando-se qualquer possível efeito de camada) é aquele que resulta em dois fragmentos de mesmo número bariônico. Para strangelets interagindo com prótons no meio interestelar, as maiores energias transferidas nesta análise, entretanto, não se mostraram suficientes para causar a fissão de strangelets de baixa massa. Para strangelets de alta massa, a fissão também parece desfavorecida pois, apesar da diferença em energia de ligação diminuir entre a strangelet e seus fragmentos, o alto número bariônico leva as estimativas da energia de ativação para valores ainda maiores que para pequenas frações de matéria estranha.

Podemos estimar quais os processos dominantes para desexcitação de strangelets a partir das temperaturas médias atingidas pelas mesmas em uma colisão (mostradas na figura 3.10). Na figura 3.11, apresentamos o cálculo da derivada da energia de uma strangelet com relação ao seu conteúdo bariônico como função da temperatura a partir dos resultados apresentados no capítulo 2 desta tese. A linha tracejada vertical indica o limite de $939 \mathrm{MeV}$, acima do qual o decaimento da strangelet pela emissão de bárions é favorecido. Comparando estas duas figuras concluímos que o processo de evaporação de strangelets devido à elevação de temperatura durante a colisão não é relevante. Seria possível a emissão de nêutrons em instantes pré-equilíbrio nos quais a energia liberada na fusão do próton ainda não tenha sido distribuída uniformemente pelo interior da strangelet. No entanto, se este for o caso, este processo deve contribuir pouco, com a emissão de no máximo um nucleon, já que o equilíbrio térmico deve ser alcançado muito rapidamente. 

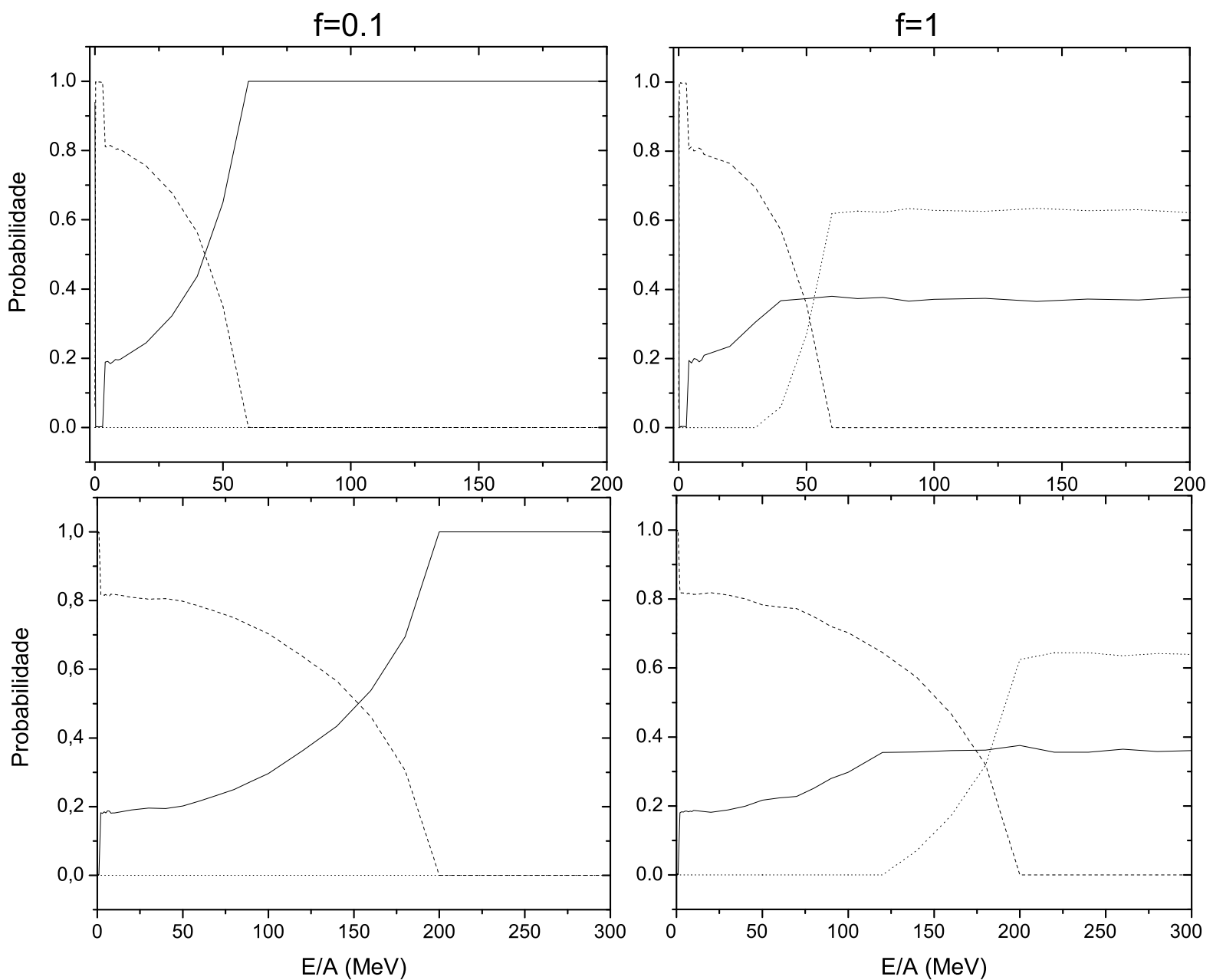

Figura 3.6: Probabilidade de ocorrência dos processos de interação hadrônica para strangelets sem emparelhamento (acima) e CFL (abaixo) com fração de clusters de bárions de 0,1 (à esquerda) e 1 (à direita) para $A=100$ no meio interestelar. As curvas cheia, tracejada e pontilhada são para os processos de espalhamento, fusão e abrasão, respectivamente. 

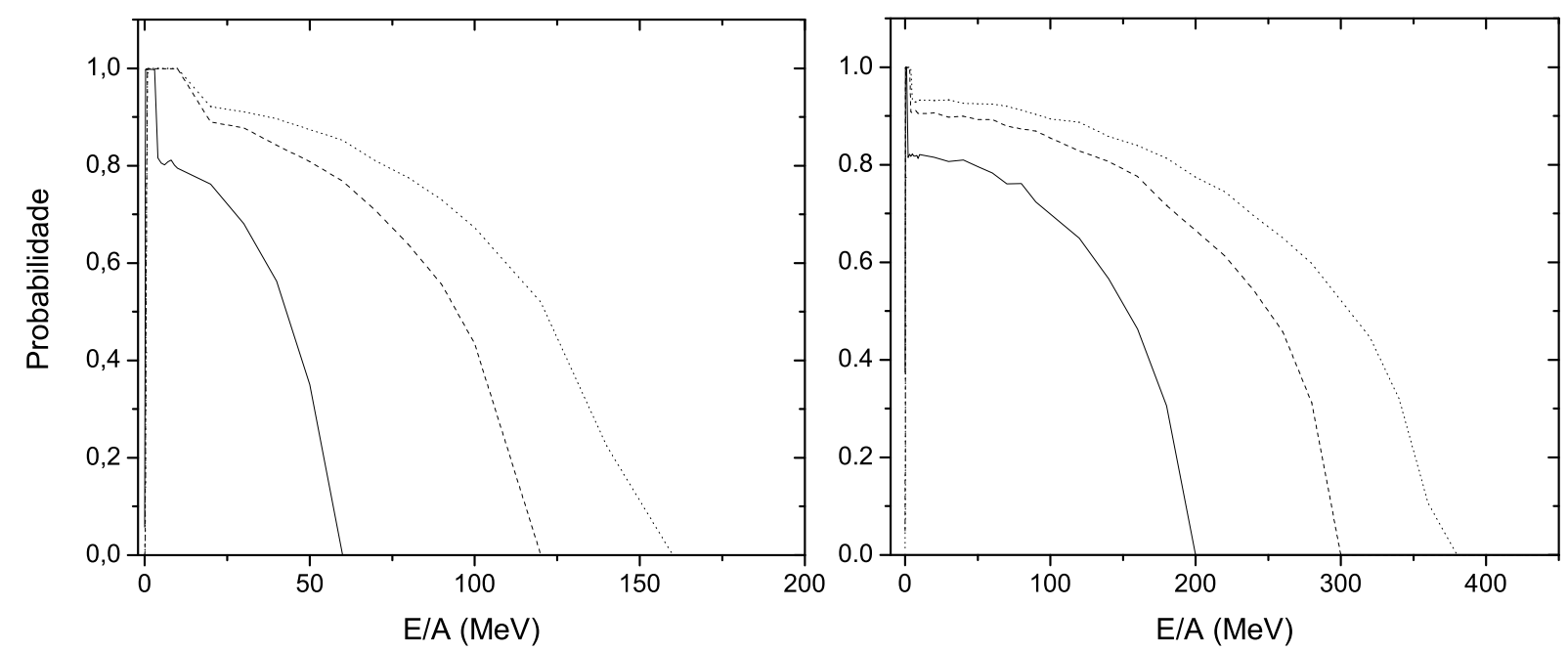

Figura 3.7: Probabilidade de fusão como função da energia incidente para strangelets sem emparelhamento (à esquerda) e CFL (à direita) no meio interestelar com fração de clusters de bárions de 0,3. As curvas cheia, tracejada e pontilhada representam $A=100, A=1000$ e $A=3000$, respectivamente.
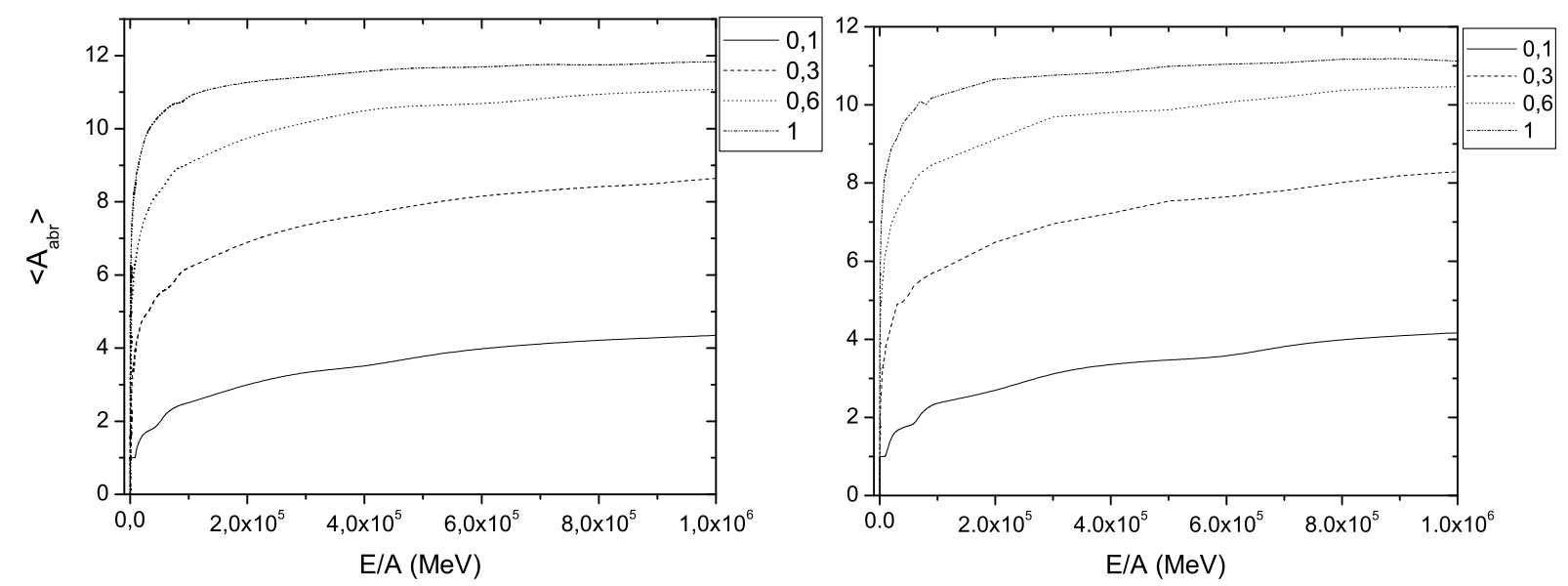

Figura 3.8: Quantidade de matéria retirada da strangelet no processo de abrasão em média como função da energia para strangelets sem emparelhamento (à esquerda) e CFL (à direita) no meio interestelar, para $A=1000 \mathrm{e}$ fração $f$ de clusters de bárions conforme indicado. 

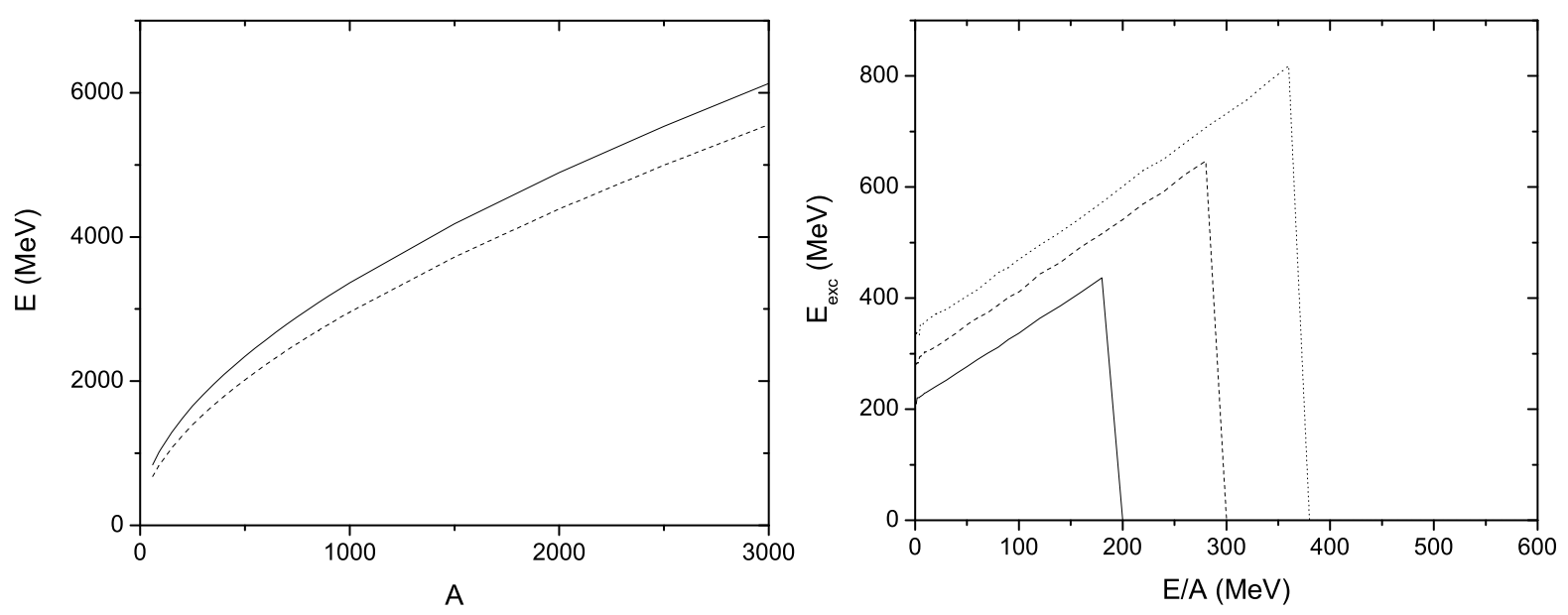

Figura 3.9: À esquerda, energia de ativação para a fissão de strangelets sem emparelhamento (linha cheia) e CFL (linha tracejada) como função de $A$. Verifica-se que a energia depositada deve ser maior que alguns $\mathrm{GeV}$ para que seja possível fissão de sistemas de número bariônico pequeno. Conforme aumenta-se $A$, a energia de ativação cresce pois, apesar da diferença entre as massas dos fragmentos e da strangelet que originou a fissão diminuir, a energia total cresce devido $A$ elevado. À direita, a energia de excitação adquirida por uma strangelet CFL na fusão desta com um próton no meio interestelar como função de $E / A$ da strangelet. As curvas cheia, tracejada e pontilhada representam $A=100,1000$ e 3000, respectivamente. Verifica-se que não é possível fissão nestes casos.

Também, o esfriamento por neutrinos não deve ser o principal mecanismo de perda de energia, já que as temperaturas associadas às colisões de strangelets e prótons são de até alguns $\mathrm{MeV}$, ou seja, bem antes da emissão de neutrinos dominar sobre a de fótons. Esta situação é oposta ao caso do esfriamento de estrelas estranhas, onde a emissão de neutrinos domina a de fótons já nas temperaturas estimadas para as colisões. Isso é devido à diferença de origem dos processos: enquanto que a emissão de neutrinos é um processo volumétrico, a emissão de fótons está associada à superfície do objeto. Para as estrelas, o enorme volume quando comparado à extensão da superfície garante que o esfriamento por neutrinos seja um processo relevante em temperaturas maiores que centenas de $\mathrm{KeV}$. No caso de strangelets de número bariônico de algumas centenas a alguns milhares, o volume reduzido e a superfície extensa garantem que a emissão de neutrinos só será relevante para temperaturas bastante elevadas, nas quais a matéria estranha sequer será estável. As temperaturas atingidas também não são suficientes para a emissão de píons. Logo, conclímos que o modo de desexcitação dominante é a emissão de fótons.

Vimos que a interação de strangelets com a matéria no meio interestelar deve afetar de ma- 

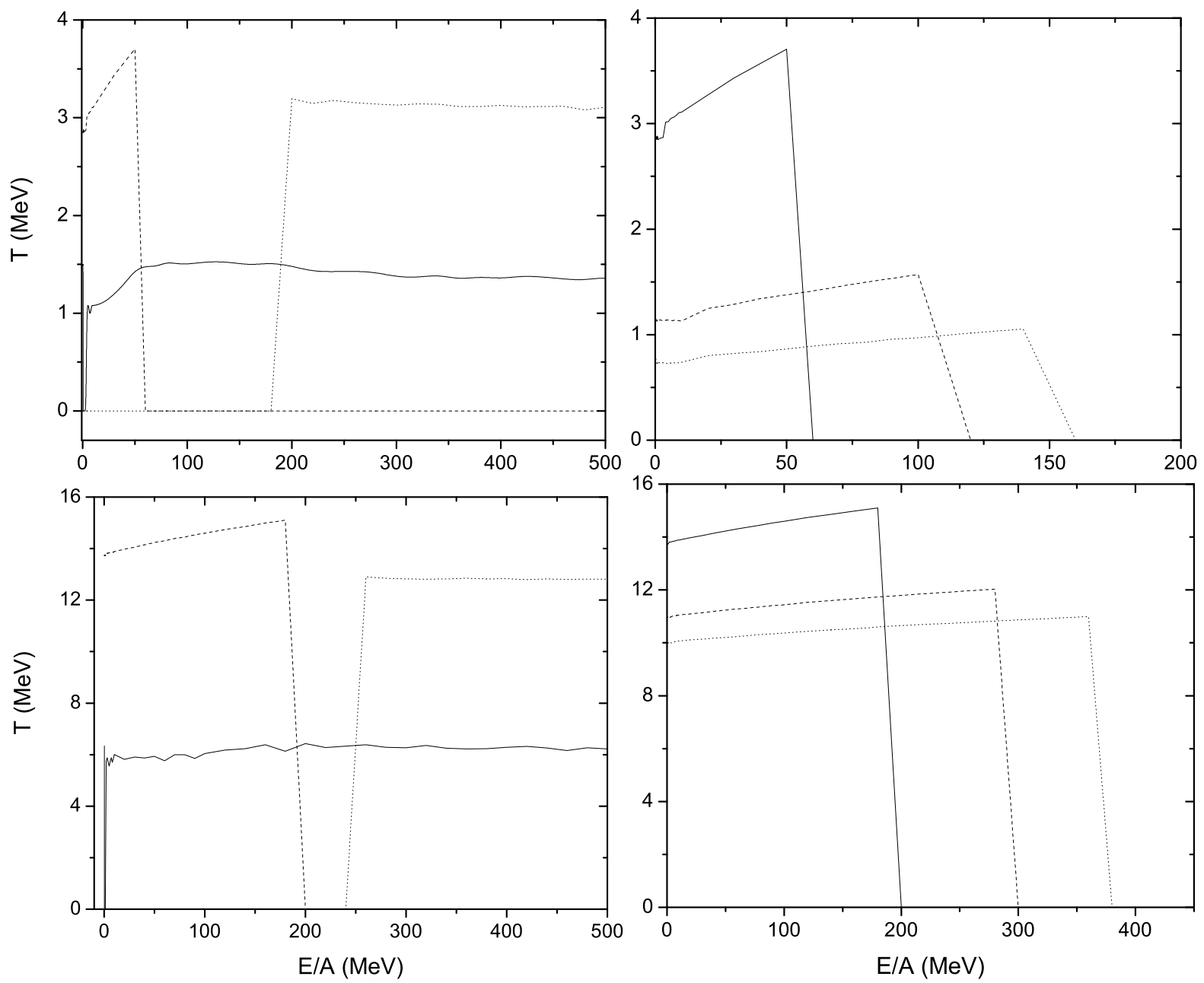

Figura 3.10: Temperatura após interação hadrônica no meio interestelar para strangelets sem emparelhamento (acima) e CFL (abaixo). À esquerda, para $A=100$ e fração $f$ de clusters de bárions de 0,3 , sendo as curvas cheia, tracejada e pontilhada para os processos de espalhamento, fusão e abrasão, respectivamente. À direita, temperatura média resultante do processo de fusão sendo as curvas cheia, tracejada e pontilhada para $A=100, A=1000 \mathrm{e}$ $A=3000$, respectivamente. 

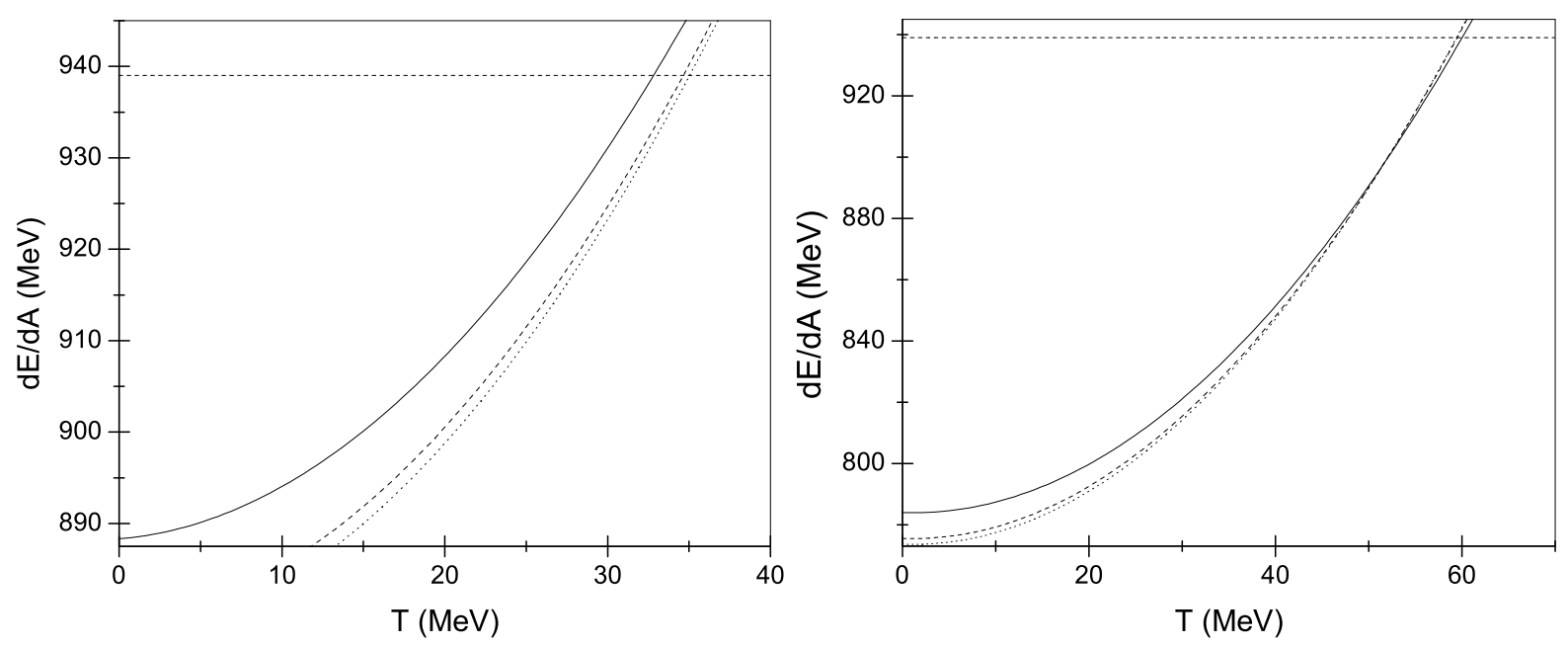

Figura 3.11: Temperatura necessária para que haja emissão de nêutrons por strangelets sem emparelhamento (à esquerda) e CFL (à direita). As curvas cheia, tracejada e pontilhada são para $A=100, A=1000$ e $A=3000$, respectivamente. Quando as curvas cruzam a linha tracejada vertical em $939 \mathrm{MeV}$, o processo de emissão de nêutrons pela strangelet é favorecido.

neira significativa o seu estado de ionização. No entanto, o número bariônico dessas partículas deve ser alterado de maneira muito mais suave devido ao elevado valor do livre caminho médio para interação, resultado da baixa densidade de núcleos na Galáxia.

Para as análises de espalação utilizamos o modelo de abrasão nuclear, por ser este um modelo fortemente dependente de parâmetros geométricos, deixando a análise, assim, mais independente de medidas experimentais, inexistentes para este problema. Este modelo, obviamente, não descreve todas as nuances verificadas em experimentos de colisão de matéria nuclear ordinária, mas é qualitativamente aceitável e assim esperamos que os resultados aqui apresentados representem a tendência dos cálculos de strangelets. Verificamos uma grande diferenca entre considerar-se a fração esperada de clusters de bárions entre $f=0,1$ e 1 . Obviamente, $f=1$ não representa a realidade, já que neste caso poderíamos considerar a strangelet como formada basicamente por um gás de partículas $\Lambda$, o que não é condizente com a hipótese de estabilidade da matéria estranha [104]. Isto nos leva a crer que análises como a apresentada por Madsen [55], que adotam a espalação com parâmetros nucleares como mecanismo para o reprocessamento de strangelets no meio interestelar, devem estar superestimadas no que diz respeito à mudança no número bariônico. Também, o processo de fusão deve ser considerado como um processo importante em baixas energias. 
Concluímos que, apesar de o reprocessamento em massa do espectro de injeção inicial proveniente das fontes ser pequeno devido à baixa densidade do meio interestelar, as estimativas do fluxo de strangelets até agora apresentadas na literatura devem ser aprimoradas incorporando os resultados obtidos nesta Tese para que se possam prever os canais mais prováveis para sua detecção. 


\section{Capítulo 4}

\section{A possível detecção de strangelets por experimentos terrestres}

O fluxo de strangelets, após sofrer certo grau de reprocessamento por interações com a matéria do meio interestelar, fatalmente atingiria as imediações da Terra. Desta forma, diversos experimentos poderiam detectar de maneira direta a presença desta componente exótica entre os raios cósmicos. Diferentes métodos de detecção têm sido propostos, entre eles os que pressupõem um efeito mensurável da interação de strangelets com materiais terrestres $[67,68,69,70]$.

Neste capítulo, serão discutidos dois sítios para a procura desses exóticos, já bastante estudados para o caso dos raios cósmicos hadrônicos: o aprisionamento dessas partículas pelo campo geomagnético e sua interação com componentes atmosféricos que podem gerar assinaturas a serem detectadas por experimentos em solo.

\subsection{Strangelets na magnetosfera terrestre}

O físico sueco, Carl Stömer, motivado pela necessidade de explicar o fenômeno da aurora boreal, começou a trabalhar no problema do movimento de partículas carregadas num campo dipolar. Henri Poincaré mostrou que se uma partícula carregada cruza uma linha de campo magnético num dado ângulo, ela procederá num movimento espiral em torno dessa linha de campo (em particular, se este ângulo é um ângulo reto, o movimento será circular). Störmer 
derivou a primeira análise matemática detalhada das trajetórias que íons fariam no campo geomagnético (este trabalho encontra-se revisado e ampliado em [105]). Ele demonstrou que para um campo dipolar a partícula com trajetória espiral chegaria a um ponto em que o movimento sofreria uma inversão em seu sentido devido à convergência das linhas de campo perto dos pólos. Ele também encontrou uma solução para o campo dipolar que descreve um caso especial de um cone com simetria axial que não permite o acesso ao seu interior a partículas que possuem rigidez menor que um dado valor, chamado de "cone proibido". O cutoff geomagnético é, então, a coordenada que descreve este cone e, conseqüentemente, a mínima rigidez permitida para o acesso a uma dada região da magnetosfera, ou seja, descreve o efeito de blindagem existente.

Quase cinquenta anos se passaram após a publicação dos primeiros artigos de Störmer nesta área até que Fermi [106] derivou uma aproximação para o acesso de partículas carregadas a uma certa região da magnetosfera, dada por $R=(A / Q)\left(E^{2}+1.863 E\right)^{1 / 2}>15 / L^{2}$, sendo $R, A$, $Q$ e $E$ a rigidez (em $\mathrm{GV}$ ), número de massa, carga iônica efetiva e energia cinética da partícula (em GeV/nuc), respectivamente *.

Uma vez na região dominada pelo campo magnético terrestre, e considerando que partículas podem ser capturadas de modo a realizarem movimentos quase-periódicos, devemos descrever as propriedades dinâmicas da população aprisionada. O estudo do movimento de partículas ionizadas na magnetosfera terrestre pode ser feita através da teoria de Störmer para um campo magnético dipolar. Esta análise geralmente utiliza-se da latitude geomagnética e do parâmetro $L$, que é a distância equatorial de uma dada linha de campo ao eixo de dipolo, medido em unidades do raio terrestre $R_{T}$, ou seja, $L=r_{e q} / R_{T}$ (ver figura 4.2).

O campo geomagnético não é um dipolo puro. A maioria dos modelos utilizados para estudá-lo incluem cerca de cinquenta termos para descrever o potencial elétrico a partir do qual o campo magnético pode ser obtido como uma soma de funções de Legendre multiplicadas por coeficientes oscilatórios na variável azimutal. Como o campo potencial tem uma dependência de $r^{-(n+1)}$, a importância de termos de elevada ordem decresce rapidamente com a distância radial à superfície da Terra. Assim, o termo $n=1$, ou seja, o termo dipolar, é o mais baixo termo

*Devido ao decaimento do campo geomagnético nas últimas seis décadas, o coeficiente que acompanha o fator $L^{-2}$ não é mais aquele derivado por Fermi (veja [107]). 
e também o dominante, e as características gerais da radiação aprisionada na geomagnetosfera podem ser analisadas sem grandes perdas com base num campo dipolar.

Em sistemas mecânicos com movimento periódico, a integral de ação para cada coordenada periódica deve ser uma constante do movimento,

$$
J_{i}=\oint p_{i} d q_{i}
$$

onde $p_{i}$ e $q_{i}$ são o momento canônico e a coordenada generalizada, respectivamente. A integração se faz sobre um ciclo completo da coordenada $q_{i}$.

Mas se o sistema sofrer alguma perturbação, na qual as forças variem lentamente em comparação com os períodos relevantes do movimento, de modo que este passe a ser "quase periódico", então, como conseqüência, a integral de ação torna-se um invariante adiabático. Em outras palavras, a existência de invariantes adiabáticos significa que seus valores são constantes contanto que as forças atuando sobre o movimento sejam alteradas infinitamente devagar.

Em dinâmica, constantes do movimento são geralmente obtidas na formulação canônica: se a Hamiltoniana é independente de dada coordenada, seu momento conjugado é um invariante. Por analogia, espera-se que a expansão da Hamiltoniana em uma série assintótica deva revelar os invariantes adiabáticos contanto que em cada passo da expansão possam ser encontradas variáveis que tornem a Hamiltoniana independente de uma das coordenadas.

Em um campo genérico, a solução da equação de movimento através da expansão em séries de Taylor em torno das condições iniciais só é prática para pequenos períodos. Para estudar-se o movimento da partícula para vários períodos de giro sem recorrer a métodos numéricos, os movimentos de giração e paralelo às linhas de campo devem ser introduzidos explicitamente na expansão e desvios do movimento estritamente helicoidal são tratados como perturbações. Esta é a chamada aproximação de "centro guia" ou "adiabática". O termo centro guia vem do fato de que em um campo variando lentamente, a partícula move-se aproximadamente em um círculo cujo centro deriva lentamente através das linhas de força e se move rapidamente na direção das linhas.

Assim, quando se procede ao estudo de partículas aprisionadas em um campo magnético dipolar, geralmente se considera o movimento da partícula como a composição de três dife- 


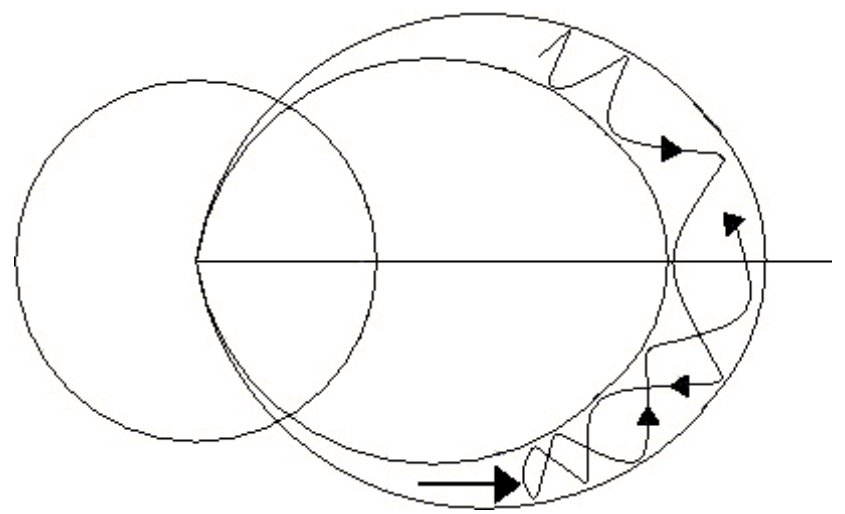

Figura 4.1: Ilustração do movimento feito por um íon aprisionado no campo geomagnético. Este pode ser decomposto em três movimentos distintos (ver texto para maiores detalhes). Esta figura ilustra o ricochete de um centro guia ao longo da linha de campo e a rotação da própria partícula em torno do centro guia. O ponto de espelho encontra-se indicado pela seta.

rentes movimentos (resultado da decomposição da força resultante que atua sobre as partículas aprisionadas em forças perpendiculares, cada qual controlando o movimento em sua direção): primeiro, supõem-se a existência de um centro-guia e o movimento de rotação da partícula ao seu redor; o movimento de ricochete do centro guia ao longo da linha de campo; e o movimento de deriva longitudinal do centro guia.

A força causada pela ação de um campo magnético sobre uma partícula em movimento é sempre perpendicular a este movimento, assim como às linhas de campo magnético. Isso resulta no padrão básico de movimento circular em torno da linha de campo, em que a força, por ser perpendicular, só altera a direção do movimento e não a energia a este associada. Devido ao padrão dipolar do campo geomagnético, o período que uma partícula leva para completar o movimento circular em torno da linha de campo guia, torna-se mais curto quando a partícula se aproxima dos pólos. Se o campo magnético na região polar é intenso o suficiente para permitir que a partícula fique presa, oscilando entre dois espelhos magnéticos (mirror points), haverá uma periodicidade associada a um movimento paralelo às linhas de campo (ver figura 4.1). Finalmente, se a deriva de linha para linha enquanto a partícula oscila entre os pontos de espelho carrega-a repetidamente em torno de uma superfície fechada, há um terceiro movimento periódico.

Partículas aprisionadas de modo estável em campos magnéticos dipolares apresentam três 
invariantes adiabáticos, cada um correspondendo a um movimento periódico diferente.

O primeiro invariante adiabático: momento magnético $\mu$

O movimento periódico em questão é o movimento ciclotrônico da partícula. O primeiro invariante adiabático é obtido através da integração de $\vec{P}$, o momento canônico da partícula, ao longo de uma órbita ciclotrônica, onde $d \vec{l}$ é um elemento do caminho da partícula em torno desta órbita:

$$
J_{1}=\oint(\vec{p}+q \vec{A}) \cdot d \vec{l}=\frac{\pi p_{\perp}^{2}}{q B}
$$

onde $q$ é a carga da partícula, $B$, o campo magnético e $\vec{A}$, o potencial vetor.

No entanto, ao invés de adotar-se a expressão dada na integral acima, o primeiro invariante adiabático é usualmente tomado como $p_{\perp}^{2} / 2 m_{0} B$, onde $m_{0}$ é a massa de repouso da partícula, que difere de $J_{1}$ apenas por alguns fatores constantes. A quantidade

$$
\mu=\frac{p_{\perp}^{2}}{2 m_{0} B}
$$

é chamada de momento magnético.

A adiabaticidade é resultado de que a órbita é circular. Na verdade, o raio ciclotrônico decresce com a aceleração de modo que o raio circular é apenas uma aproximação, válida para pequenas mudanças no campo magnético durante uma única revolução.

Se a freqüência de oscilação do campo magnético não é muito menor que a frequiência ciclotrônica da partícula, a invariância de $\mu$ pode ser violada.

A invariância de $\mu$ é válida não apenas para campos magnéticos variando no tempo, mas também para partículas que se movem em regiões de campo magnético diferente, seja seguindo uma dada linha de campo dipolar, ou derivando por diferentes linhas de campo.

O segundo invariante adiabático: invariante longitudinal J

O segundo invariante adiabático está relacionado ao movimento de oscilação de uma partícula 
confinada entre dois espelhos magnéticos. Se a deriva longitudinal é pequena durante um ricochete, a variável de ação associada a este movimento é um invariante.

Neste caso, a integral de ação é

$$
J_{2}=\oint(\vec{p}+q \vec{A}) \cdot d \vec{s}
$$

onde $d \vec{s}$ é o elemento de comprimento ao longo de uma linha de campo. O segundo termo da integral é nulo, então

$$
J_{2}=\oint \vec{p} \cdot d \vec{s}=\oint p_{\|} d s=\text { constante }
$$

O segundo invariante adiabático é geralmente chamado de invariante longitudinal e designado por $J$ ao invés de $J_{2}$. O principal uso do segundo invariante adiabático é para definir as trajetórias e superfícies resultantes dos movimentos de ricochete e deriva da partícula.

\section{O terceiro invariante adiabático: fluxo magnético $\Phi$}

O terceiro movimento periódico de uma única partícula no campo magnético terrestre é o movimento de deriva longitudinal em torno do planeta Terra. Em um campo estático, a conservação do primeiro e segundo invariantes adiabáticos garante que a partícula retornará a sua linha de campo original e, conseqüentemente, especifica a linha de campo ocupada pela partícula em cada longitude. Em um campo magnético que varia lentamente, $\mu$ e $J$ são ainda conservados, mas $p$ pode mudar de uma maneira que depende dos detalhes da trajetória e das variações do campo. Assim, uma constante de movimento adicional é necessária para determinar trajetórias em campos magnéticos que variam lentamente.

$$
J_{3}=\oint(\vec{p}+q \vec{A}) \cdot d \vec{l}=q \Phi
$$

onde $d \vec{l}$ é o incremento na trajetória de deriva longitudinal, geralmente tomado no equador. A quantidade $\Phi$ é o fluxo magnético através da superfície delimitada pela órbita da partícula em torno da Terra. 
Como as oscilações norte-sul são ao longo das linhas de campo, o valor de $\Phi$ não depende da latitude de $d \vec{l}$ desde que a trajetória de deriva envolva a Terra na camada que contém a trajetória do centro guia. Por esta razão, o terceiro invariante adiabático é geralmente chamado de invariante de fluxo e denotado por $\Phi$, omitindo a carga $q$. Para uma partícula em uma distância equatorial $R_{0}$, sendo $B_{0}$ o valor do campo magnético neste ponto, o terceiro invariante é

$$
\Phi=2 \pi B_{0} \frac{R_{T}^{3}}{R_{0}}
$$

Partículas carregadas com energia da ordem de MeV na região interna da magnetosfera $(L \ll 10)$ rotacionam com uma freqüência muito maior do que a variação típica do campo geomagnético (o qual varia com escalas de tempo da ordem de, no máximo, poucos minutos). Sob essas condições, o momento magnético é um invariante adiabático. Desta forma, partículas com momentos magnéticos altos o suficiente ficam aprisionadas nas linhas de campo dipolar do campo geomagnético, com pontos de inversão do movimento (espelhos) localizados próximos aos pólos terrestres.

Nas análises de aprisionamento na magnetosfera, o ponto de espelho é em geral tomado como a latitude geomagnética do ponto no qual ocorre a inversão do movimento. Ele é então localizado onde a projeção do vetor velocidade da partícula ao longo das linhas de campo magnético é nulo, e assim a partícula sofre inversão do seu movimento na direção paralela ao campo. Ele tem uma relação direta, portanto, com o ângulo de pitch, $\alpha$, definido como o ângulo que o vetor velocidade da partícula faz com as linhas de campo magnético num dado ponto (ver figura 4.2). Isso significa que $\alpha=90^{\circ}$ no ponto de reflexão da partícula. É comum estudar o movimento da partícula aprisionada na geomagnetosfera através da análise do seu ângulo de pitch equatorial, que é o ângulo de pitch de uma partícula no equador geomagnético. Todas as partículas com espelhos em latitudes que correspondem ao interior do planeta são obviamente perdidas, o que significa que íons com $\left|\alpha_{e q}\right|<\alpha_{E}$ ou $\left|\pi-\alpha_{e q}\right|<\alpha_{E}$ encontram-se dentro do cone de perda, onde $\alpha_{e q}$ é o ângulo de pitch equatorial e $\alpha_{E}$ é o ângulo de pitch equatorial que uma dada partícula deve ter para que seu ponto de espelho se localize sobre a superfície terrestre. 

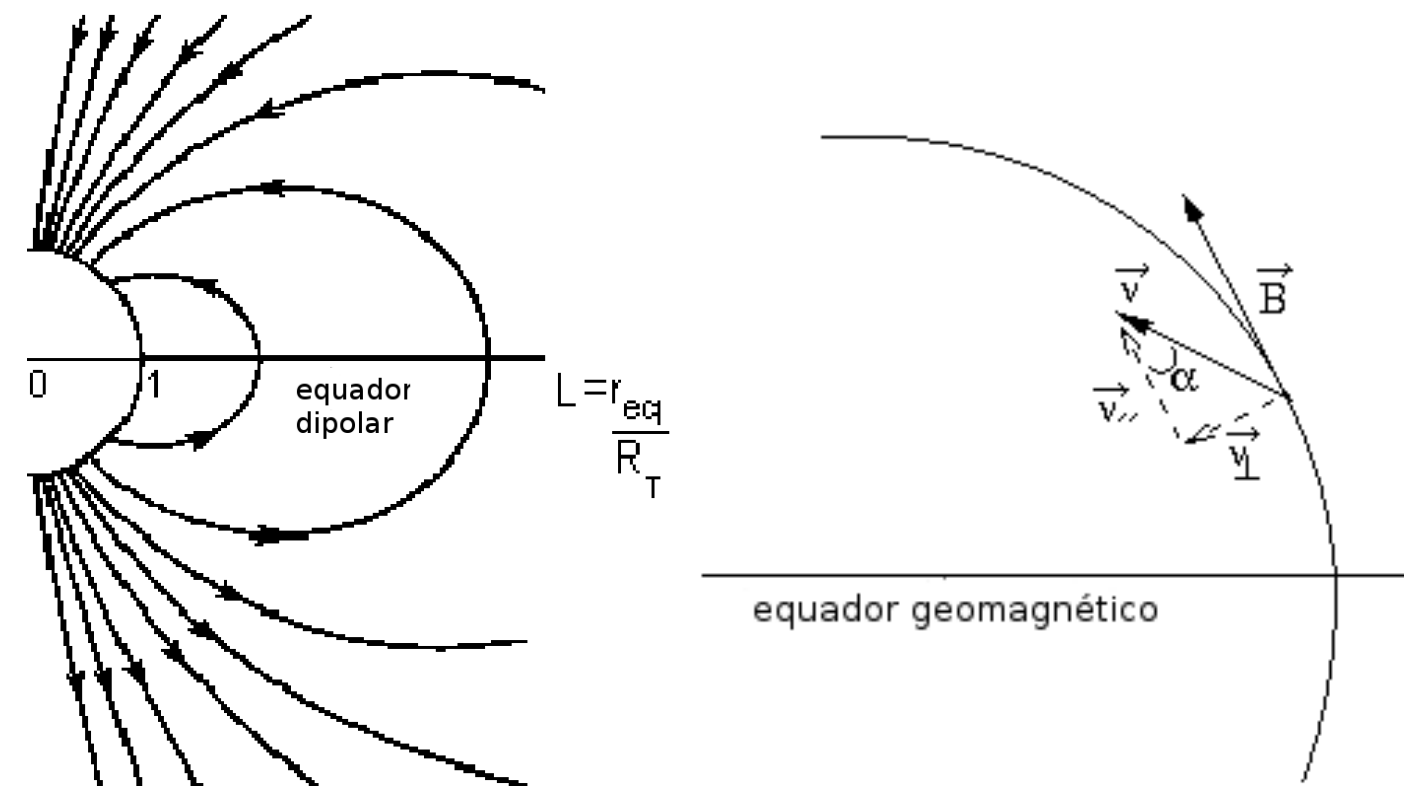

Figura 4.2: À esquerda, visão esquemática das linhas dipolares e o significado do parâmetro $L$, onde $r_{e q}$ é a distância radial do centro do dipolo a uma dada linha de campo no equador geomagnético e $R_{T}$, o raio da Terra. À direita, representação gráfica do ângulo de pitch, onde $\vec{v}$ é a velocidade da partícula e suas projeções nas direções paralela e perpendicular com respeito ao vetor de campo magnético $\vec{B}$.

\subsubsection{O cone de perda atmosférico}

Conforme as partículas espiralam ao longo do campo geomagnético e chegam próximas à superfície terrestre, a intensidade do campo magnético aumenta, o que causa a diminuição da componente paralela ao campo da velocidade da partícula (com um aumento correspondente na componente perpendicular), como detalhado anteriormente. A medida que a componente paralela da velocidade vai à zero, o ângulo de pitch vai a $90^{\circ}$. Ocorre, então, a inversão na direção do movimento da partícula (localização do ponto de espelho) de modo que esta continua a se mover ao longo das linhas de campo mas em direção ao hemisfério oposto.

É possível, então, compreender que se uma partícula penetra a magnetosfera com ângulo de pitch tal que seu ponto de espelho esteja localizado abaixo da superfície do planeta, ela será perdida antes de completar um ciclo completo de movimento de ricochete. Mas também a localização do ponto de espelho pode ser em uma altitude tal que a atmosfera é densa o suficiente para que partículas carregadas interajam com partículas atmosféricas. Neste caso, a partícula será fatalmente absorvida pela atmosfera ao invés de ser continuamente refletida entre espelhos magnéticos. Partículas perdidas desta forma devem ter ângulos de pitch no equador 
dentro de um ângulo sólido determinado. O conjunto de velocidades $\vec{v}$ no equador das partículas que serão perdidas desta forma formam um cone que se estende de zero grau a um ângulo de pitch crítico. Este cone é chamado de cone de perda.

Para avaliar a posição efetiva do cone de perda para strangelets (e, conseqüentemente, para determinar em que regiões a atmosfera é tênue o suficiente de modo que a interação de strangelets com seus componentes seja pouco provável), consideramos que as colisões ocorrem majoritariamente com a molécula de nitrogênio $\left(N_{2}\right)$. A probabilidade de interação das partículas aprisionadas que penetram a atmosfera no seu caminho ao longo das linhas de campo (perdas por colisão) pode ser tomada como

$$
P(s)=1-e^{-s / \Lambda(s)}
$$

num certo ponto $s$, já que cada processo é independente probabilisticamente, sendo $\Lambda$ o livre caminho médio da partícula. Para generalizar a expressão apresentada anteriormente, é necessário integrar sobre o caminho da partícula. Adotando o critério de que todas as strangelets que colidem com moléculas da atmosfera são fatalmente removidas do fluxo aprisionado (sejam estas interações Coulombianas, que alteram o ângulo de pitch da partícula, ou interações inelásticas, como as descritas na seção 3.2, que alteram as propriedades da strangelet em si), expressamos a probabilidade de escape como

$$
P_{e s c}=1-e^{-\int_{s} \sigma\left[n\left(s^{\prime}\right)+s^{\prime} \frac{d n}{d s^{\prime}}\right]}
$$

onde $d s=L R_{E} \cos \lambda \sqrt{1+3 \sin ^{2} \lambda} d \lambda$ é o arco ao longo de uma dada linha de campo, $\lambda$ é a latitude geomagnética, $\sigma$ é a seção de choque da strangelet e $n(s)$ é a densidade de partículas na atmosfera em um dado ponto $s$ do caminho da strangelet. Como strangelets são hadrons, podemos tomar sua seção de choque de interação como sendo geométrica $\left(\propto A^{2 / 3}\right)$.

O cone de perda calculado para strangelets, tomando-se um perfil exponencial da densidade atmosférica, é mostrado na figura 4.3 para diferentes valores de $L$, comparando-se os valores obtidos através do cálculo das perdas colisionais com moléculas na atmosfera com a não 


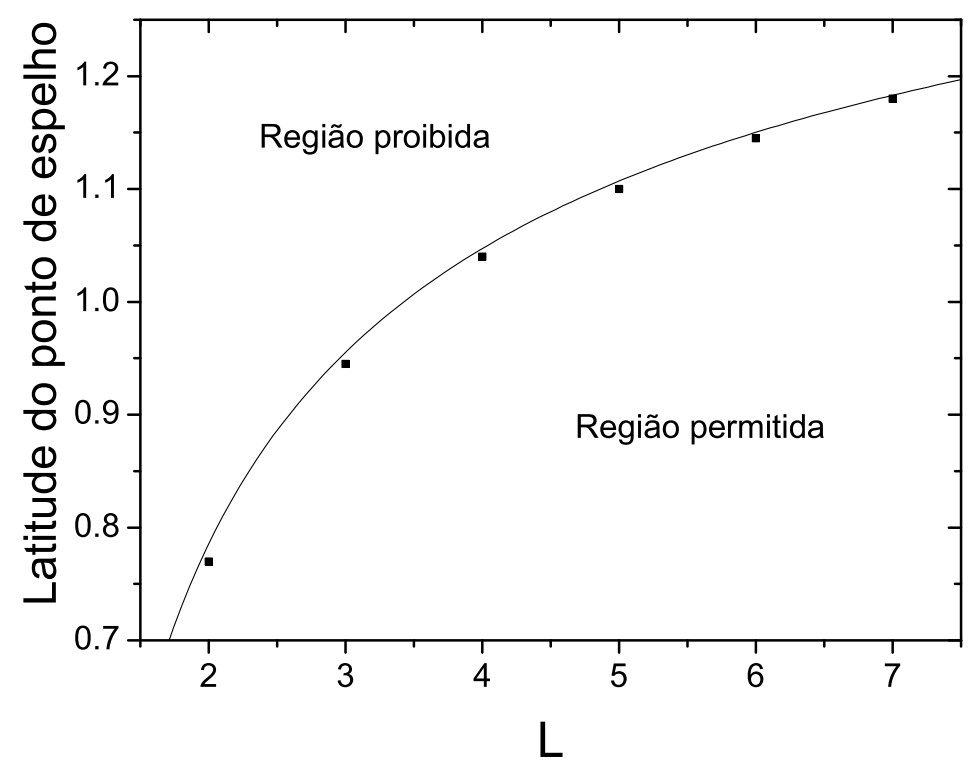

Figura 4.3: Cone de perda para strangelets no campo geomagnético. Se estas possuem pontos de espelho localizados em latitudes geomagnéticas, $\lambda_{\text {mag }}$, menores que as calculadas como resultado da análise da perda por colisão com partículas atmosféricas (representadas pelos pontos no gráfico), são fatalmente removidas da população aprisionada (maiores detalhes no texto). A linha cheia representa a latitude magnética que se posiciona sobre a superfície terrestre na aproximação de campo dipolar.

existência de um espelho magnético devido à superfície terrestre. Como esperado, quanto menor o ângulo de pitch equatorial (ou seja, quanto maior a projeção paralela do vetor velocidade em relação às linhas de campo no equador), mais fácil é removê-la do fluxo aprisionado.

\subsubsection{Condições de captura}

Para que uma partícula penetre uma certa região da magnetosfera, sua rigidez deve ser maior do que aquela associada ao cutoff geomagnético. Tomando-se uma expressão mais apropriada do que a derivada por Fermi, a condição que a partícula deve preencher para ter acesso a uma dada região da magnetosfera pode ser escrita como [108]

$$
R_{\text {partícula }}>\frac{59.6 \cos ^{4} \lambda}{L^{2}\left[1+\left(1-\cos \gamma \cos ^{3} \lambda\right)^{1 / 2}\right]^{2}} \quad \mathrm{GV},
$$


onde $\lambda$ é a latitude e $\gamma$ a direção de chegada da partícula (leste - oeste) ${ }^{\dagger}$.

A condição para movimento triplamente adiabático é que a intensidade do campo magnético deve variar lentamente ao longo de uma órbita ciclotrônica, impondo uma energia máxima para que haja aprisionamento estável. Assim, a condição que deve ser imposta para o raio ciclotrônico da partícula no equador geomagnético é dada por

$$
\left.R_{C}\right|_{\text {equador }}=\left.\frac{p_{\perp}}{q B} \ll \frac{B}{\left|\nabla_{\perp} B\right|}\right|_{\text {equador }},
$$

onde $p_{\perp}$ e $q$ são o momento perpendicular às linhas de campo e a carga elétrica efetiva do íon, respectivamente, e $B$, a intensidade do campo magnético.

As figuras 4.4 e 4.5 mostram os vínculos dados pelas equações 4.9 e 4.10 para strangelets normais e CFL, respectivamente, para $L=2$. As figuras mostram também o número bariônico mínimo requerido para a estabilidade de strangelets [45]. A existência de um número bariônico mínimo é previsto em todos os modelos de SQM porque a energia necessária para produzir esses sistemas aumenta conforme seu número bariônico decresce, até que a energia por número bariônico atinja um valor acima do qual a matéria estranha se torna instável. O valor adotado foi $A_{\min }=30$ (mostrado com a linha vertical) e pode ser trivialmente alterado para outras figuras, já que o limite exato é incerto devido às incertezas intrínsecas aos parâmetros da matéria estranha utilizados nos cálculos de estrutura. Strangelets de elevado número bariônico, apesar de poderem preencher os requisitos necessários ao aprisionamento estável na magnetosfera, estatisticamente não são prováveis para constituir uma população detectável devido a um decréscimo substancial do fluxo dessas partículas no meio interestelar com o aumento do número bariônico.

O limite superior em energia para strangelets penetrando o campo geomagnético (4.10) foi tomado em nossos cálculos com um nível de confiança de 10\% de acordo com as observações existentes para as distribuições dos raios cósmicos anômalos para diferentes camadas identificadas por $L$ [109], e consideramos $E_{\perp} \sim E$, o que significa que estamos, na verdade, su-

\footnotetext{
${ }^{\dagger}$ A assimetria leste-oeste na direção de chegada de raios cósmicos de baixas energias está relacionada à inclinação do campo geomagnético em relação ao norte geográfico.
} 

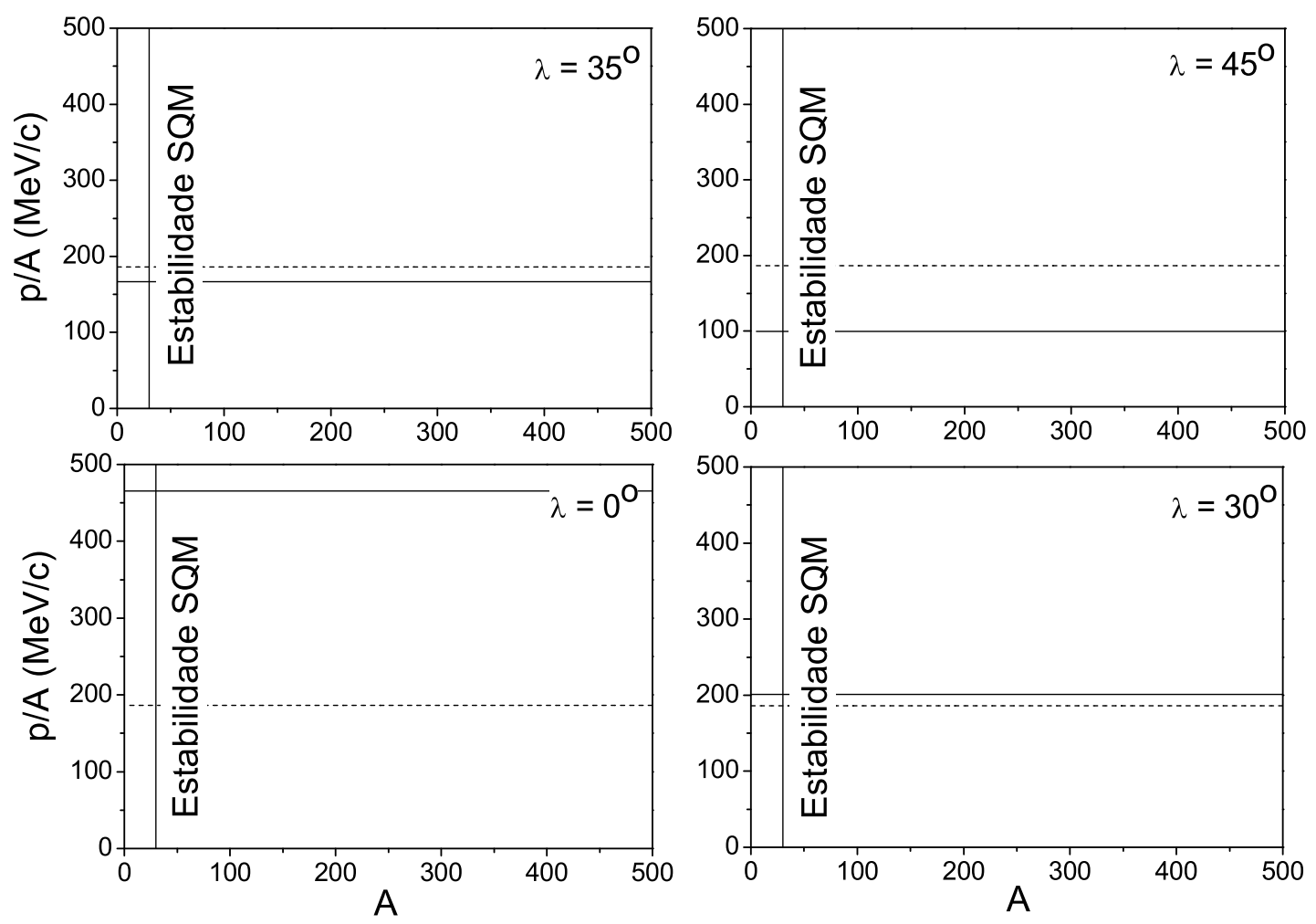

Figura 4.4: Curvas correspondentes às restrições (4.9), representada pela linha cheia, e (4.10), representada pela linha tracejada, em $L=2$ no plano número bariônico versus momento para strangelets normais incidentes do leste $(\gamma=\pi)$ para diferentes latitudes de incidência (lembrando que as linhas de campo para $L=2$ penetram a superfície terrestre em $\lambda=45^{\circ}$ no modelo dipolar). A linha cheia vertical representa o mínimo número bariônico para o qual strangelets são estáveis. 

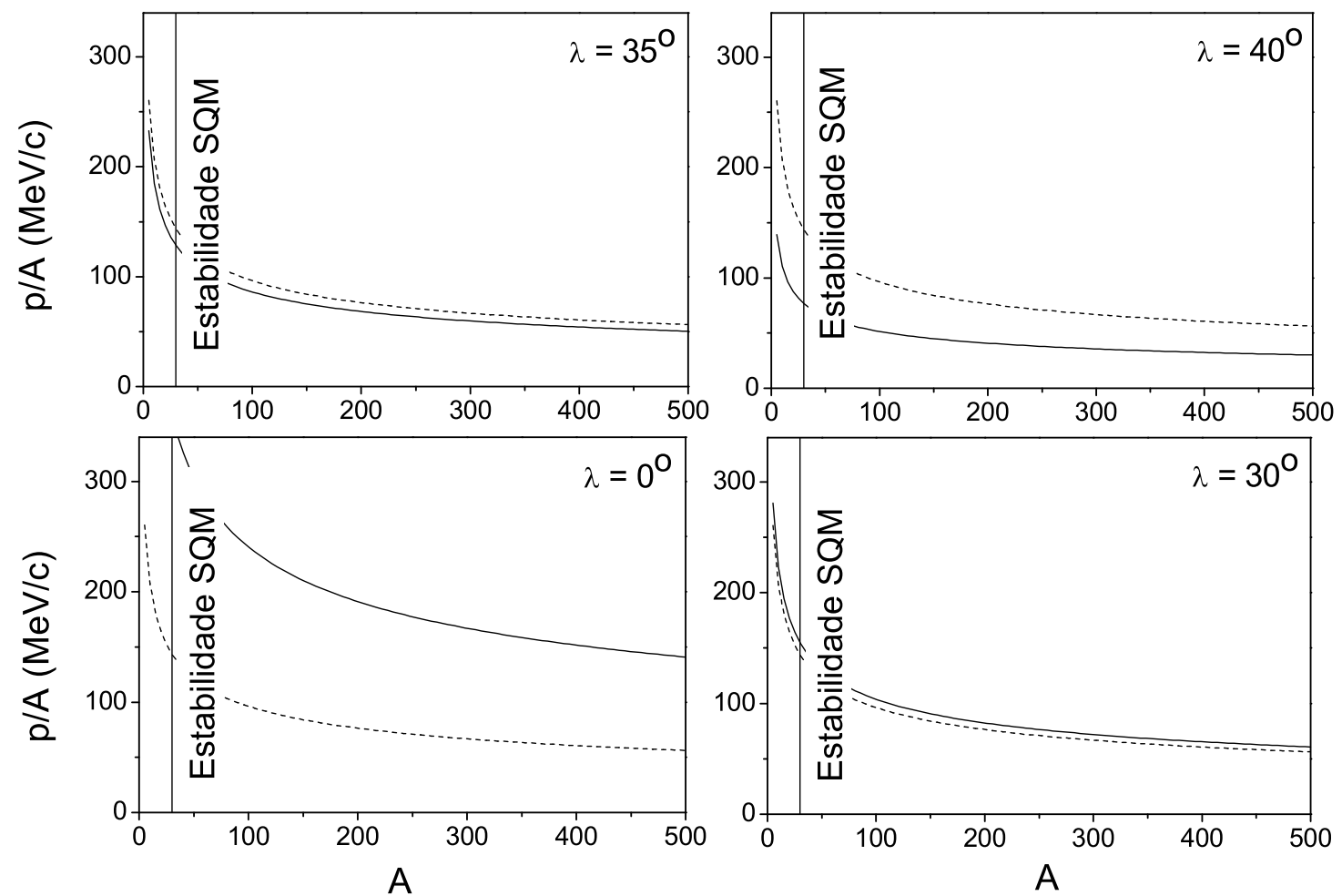

Figura 4.5: O mesmo que a figura 4.4 para strangelets CFL.

bestimando o número de partículas que podem ser aprisionadas de forma estável no campo geomagnético. Obviamente, a curva correspondente ao cutoff geomagnético deve encontrar-se sob àquela correspondente ao critério de movimento triplamente adiabático para que o aprisionamento estável ocorra. Este não é o caso para strangelets penetrando a magnetosfera em baixas latitudes geomagnéticas, mas há uma pequena "janela" a partir de latitudes um pouco acima de trinta graus em $L=2$ para que strangelets provenientes do meio interestelar preencham as condições de captura e se acumulem nas regiões caracterizadas por um dado $L^{\ddagger}$. Apesar do intervalo em latitudes ser reduzido, ainda é possível o acúmulo de partículas em limites interessantes, como será mostrado a seguir.

O cálculo quando feito para strangelets CFL mostra curvas para aprisionamento estável com formas diferentes daquelas para strangelets normais. Isso ocorre devido à forte dependência da carga elétrica $Z$ com $A$ para strangelets normais $(Z \propto A)$ resultando em valores constantes quando se considera o momento dessas partículas por número bariônico, enquanto que para

\footnotetext{
${ }^{\ddagger}$ Esta janela existe para todas as regiões tal que o campo geomagnético ainda possa ser representado pelo modelo dipolar, apenas o intervalo em latitudes para aprisionamento estável mudará dependendo do $L$ em questão.
} 
strangelets CFL a carga depende muito fracamente de $A$, levando a uma dependência do momento por número bariônico de $p / A \sim A^{-0.9}$.

Apesar de termos verificado que strangelets podem de fato ser aprisionadas no campo magnético terrestre, devemos avaliar a possibilidade de manutenção desta população para verificar se é possível que haja um aumento do fluxo quando comparado ao ISM. Para isso, devemos considerar alguns mecanismos de perda para essas partículas.

Além da já mencionada perda por colisões com moléculas na atmosfera, consideramos a deriva para dentro, resultado de flutuações assimétricas do campo geomagnético, como o mecanismo dominante responsável pela diminuição da população de strangelets aprisionadas.

Não consideramos nesse trabalho diretamente a difusão em ângulo de pitch. Devido a sua alta massa, strangelets são menos suscetíveis a serem espalhadas de maneira significativa, ou seja, terem seu ângulo de pitch mudado de maneira apreciável por colisões. O resultado final de colisões múltiplas com partículas atmosféricas seria a de reduzir a energia cinética das strangelets a valores de agitação térmica com pequenas mudanças no seu ângulo de pitch. Como já consideramos que estas partículas com pontos de inversão do movimento que se encontram dentro do limite da escala de altura da atmosfera (derivada dos resultados obtidos na seção 4.1.1) seriam fatalmente removidas do fluxo aprisionado, estamos efetivamente substituindo a equação de difusão na variável $\cos \left(\alpha_{e q}\right)$ por um termo de perda constante (um função "ralo") diretamente relacionada, mas não formalmente associada, à difusão em ângulo de pitch.

A difusão radial deve proceder através de flutuações no terceiro invariante adiabático $\Phi$, proporcional a $L^{-1}$, devido a variações nos campos elétrico ou magnético que sejam mais rápidos que a frequiência de deriva da partícula. Como os períodos ciclotrônico e de ricochete são bem menores que o de deriva, é menos provável que sejam afetados o primeiro e o segundo invariantes adiabáticos devido a essas variações de campo.

Guiados pelos cálculos e observações existentes para o aprisionamento dos raios cósmicos anômalos (de aqui em diante chamados de ACR, da sigla em inglês anomalous cosmic rays), consideramos difusão no terceiro invariante adiabático devido a flutuações assimétricas no campo geomagnético, causado prioritariamente pela pressão do vento solar (compressão repentina e relaxação lenta do campo geomagnético).

O coeficiente de difusão $D_{L L}$ é determinado teoricamente tomando-se dois procedimentos 
consecutivos [110]. Primeiro, deve-se avaliar o deslocamento radial sofrido por uma partícula sob influência da perturbação sofrida pelo campo, fruto de um modelo idealizado das perturbações reais pelas quais passa o campo geomagnético. O passo seguinte é feito para que se obtenha o coeficiente de difusão como função apenas das características estatísticas das perturbações. Isso consiste em elevar-se o deslocamento ao quadrado e se tomar a média sobre inúmeras perturbações ocorrendo randomicamente no tempo e sobre todas as possíveis latitudes iniciais da partícula.

Assim, o coeficiente de difusão devido a flutuações do campo geomagnético para partículas aprisionadas no equador [110] pode ser expresso por

$$
D_{L L}^{M}=\frac{\pi^{2}}{2}\left(\frac{5}{7}\right)^{2} \frac{R_{E}^{2} L^{10}}{B_{0}^{2}} \nu_{d r i f t}^{2} P_{A}\left(\nu_{d r i f t}\right)
$$

onde $P_{A}(\nu)$ é a densidade espectral de potência, PSD (da sigla em inglês power spectral density), da variação do campo avaliado na freqüência de deriva. Para partículas fora do equador geomagnético, o coeficiente de difusão apresenta um decaimento exponencial com a latitude magnética.

É sabido que a complexa geometria e as inomogeneidades do campo geomagnético fazem as análises quantitativas ambíguas já para o caso dos núcleos. Os valores medidos para o coeficiente de difusão e sua dependência com $L$ variam com a atividade magnética global, e as perturbações magnéticas variam apreciavelmente com o tempo. Consideramos a dependência da PSD em $\nu^{-2}$ por simplicidade [110]. A perda de informações mais detalhadas que estão associadas a essa aproximação, é que o coeficiente de difusão torna-se independente da energia da partícula que penetra o campo geomagnético. Nesse caso, o coeficiente de difusão apresenta uma forte dependência com o parâmetro de McIlwain $\left(D_{L L} \propto L^{10}\right) \S$. Isso indica que sua influência é muito importante para partículas aprisionadas em camadas caracterizadas por elevados valores de $L$.

Valores típicos para mudanças na distribuição em populações aprisionadas variam de poucas

\footnotetext{
${ }^{\S}$ A difusão radial causada por variações randômicas no potencial do campo elétrico apresentam uma dependência mais suave no parâmetro de McIlwain, sendo que o coeficiente de difusão resultante nesses casos comporta-se como $D_{L L} \propto L^{6}[111]$.
} 
horas em $L=6$ a centenas de dias em $L=2$. Assim, se strangelets são de fato capturadas pelo campo geomagnético, sua densidade deve ser maior para valores baixos de $L$, o que pode resultar num aumento substancial de sua densidade quando comparada àquela que se espera no ISM.

Outros mecanismos de perda são de menor importância em escalas de tempo curtas, mas apresentam influência em longos períodos, o que pode resultar numa diminuição no tempo de residência de partículas aprisionadas. Estes incluem deriva resultante de interações ressonantes entre partículas e campos elétricos, especialmente na frequiência de pulsação ou região VLF (da sigla em inglês, very low frequency). Esses fenômenos são fortemente afetados pela atividade do vento solar e, portanto, difíceis de prever.

\subsubsection{A população aprisionada}

A evolução temporal de partículas que sofrem inúmeras pequenas perturbações randômicas em seus movimentos é feita através da teoria de difusão. Por exemplo, na difusão de um gás, o movimento das próprias partículas desse gás é um movimento difusivo (ou seja, se não houvesse difusão, não haveria deslocamento). No entanto, o conceito de difusão a ser empregado nesta análise é diferente daquele ao qual é usualmente associado. No caso de partículas aprisionadas no campo geomagnético, o movimento principal não é difusivo, mas sim composto por aqueles associados ao movimento adiabático descrito a partir da existência de um centro-guia (giro, ricochete e deriva longitudinal). Considera-se difusão apenas o movimento gerado a partir da alteração de um dos invariantes adiabáticos, ou seja, a priori a partícula pode permanecer aprisionada e se movimentando na magnetosfera sem sofrer difusão.

Assim, a equação de difusão foi empregada para estudar-se o fluxo aprisionado de strangelets

$$
\frac{\partial f(\mu, J, L)}{\partial t}=\frac{\partial}{\partial L}\left[\frac{D_{L L}}{L^{2}} \frac{\partial}{\partial L}\left(L^{2} f(\mu, J, L)\right)\right]
$$

onde $f$ é a função de distribuição, $D_{L L}$ é dado pela equação (4.11) e $\mu$ e $J$ são os invariantes adiabáticos momento magnético e invariante longitudinal, respectivamente. Devido ao fato de 
que a população aprisionada pode sofrer movimento adiabático de modo coletivo sem alteração de seus invariantes adiabáticos, a escolha das coordenadas $\mu, J$ e $\phi$ são as escolhas naturais, já que no caso em que não há quebra de adiabaticidade, a funcão $f(\mu, J, \phi)$ permanece inalterada. Uma simples mudança de coordenadas leva à substituição de $\phi$ por $L$, uma variável mais diretamente relacionada aos observáveis.

A relação entre a função de distribuição e o fluxo pode ser dado por $j(E, \alpha)=p^{2} L^{2} f(\mu, J, L)$. Uma população estacionária requer $\partial f / \partial t=0$, ou seja, que o termo de fonte e de perda sejam instantaneamente balanceados.

Adotamos uma injeção constante de strangelets provenientes do ISM em $L=6$ (a posição do máximo da função de distribuição é altamente insensível ao parâmetro $L$ escolhido para esta condição de contorno, desde que esteja longe do máximo) e derivamos a função de distribuição entre esse $L$ externo e $L \approx 1.05$, onde esta deve ser nula (este valor de $L$ corresponde à altura da atmosfera para interação com strangelets). A forma da função de distribuição é mostrada na figura 4.6. Não estamos considerando difusão em ângulo de pitch devido a interação das partículas com ondas eletromagnéticas causadas por variações de campo que alteram o primeiro invariante adiabático, como já mencionado anteriormente.

Os cálculos foram feitos com dois valores para o fluxo proveniente do ISM que devem atingir a magnetosfera exterior.

O primeiro, a que chamaremos de "padrão", é aquele que adota a dependência padrão dos raios cósmicos para o fluxo diferencial $E^{-2.5}$. O fluxo total de strangelets no ISM que atinge a Terra, conforme estimativas dadas por Madsen [55], tendo como mecanismo de injeção a coalescência de sistemas binários de estrelas estranhas, é dado pela equação 1.5.

Desta forma, o fluxo total é modulado com uma dependência de $E^{-2.5}$ com os vínculos de energia mínima e máxima que respeitam os valores $R_{\min }=5 \mathrm{MVA} / Z$ e $R_{\max }=10^{6} \mathrm{GV}$ [55].

O segundo cálculo, o qual será chamado de "detalhado", considera uma caracterização mais minuciosa do fluxo diferencial, no qual para a região de interesse deste trabalho (rigidezes da ordem de poucos GV), o fluxo de strangelets de fato aumenta com uma dependência de $R^{1.8}$. Este fluxo foi obtido através de um ajuste do fluxo mostrado na referência [55].

Em ambos os casos, o fluxo que penetra a região da magnetosfera em $L_{\max }$ deve preencher as restrições impostas ao aprisionamento estável em ângulo de pitch e latitude geomagnética de 


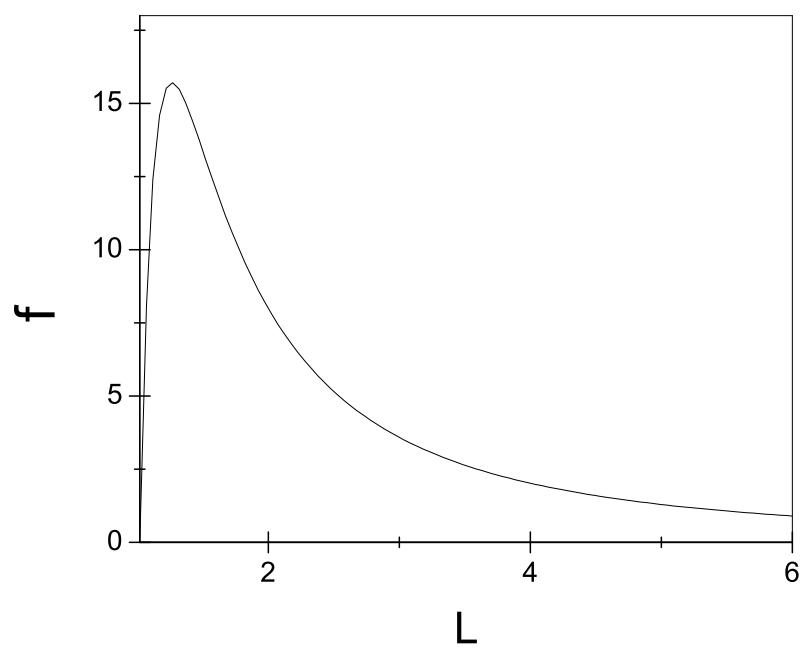

Figura 4.6: A função de distribuição (em unidades arbitrárias) para strangelets aprisionadas no campo geomagnético como função de $L$ é obtida como a solução da equação diferencial 4.12 com condições de contorno $f\left(L_{\text {ext }}\right)$ dada pelo fluxo incidente (referir ao texto para detalhes) e $f\left(L_{\min }\right)=0$ (correspondente à escala de altura da atmosfera para interações com as partículas que a compõem). A posição do pico (em torno de $L=1.3$ ) é bastante insensível a mudanças na relação $A / Z$ (strangelets normais e CFL) ou a mudanças na energia ou número bariônico das strangelets.

incidência, restrições que podem ser escritas como

$$
F_{\text {in }}=\int_{\lambda_{\min }}^{\lambda_{\max }} d \lambda P(\lambda) \int_{\alpha_{\text {loss cone }}}^{\pi / 2} d \alpha_{e q} P\left(\alpha_{e q}\right) \times F
$$

Os fatores de eficiência, $P(\lambda)$ e $P\left(\alpha_{e q}\right)$ podem ser facilmente identificados: $P(\lambda)$ nos dá a fração de área da seção esférica que permite o aprisionamento, conforme discutido anteriormente

$$
P(\lambda)=\frac{2 L^{2}(-\cos \lambda) \int_{0}^{2 \pi} d \phi}{2 L^{2} \int_{0}^{\pi / 2} \cos \theta \int_{0}^{2 \pi} d \phi}
$$

onde o fator 2 vem da simetria no ângulo $\theta$ para os dois hemisférios (norte, sul). $P\left(\alpha_{e q}\right)$ limita o número de partículas que penetram uma dada região da magnetosfera com um ângulo de pitch apropriado para evitar o cone de perda, como já discutido na seção 4.1.1. Também consideramos um fluxo isotrópico de partículas que atinge a magnetosfera exterior já que não há nenhuma justificativa teórica até o momento que aponte qualquer anisotropia na direção de chegada de 


\begin{tabular}{|l|l|l|}
\hline & $L=1.3$ & $L=2$ \\
\hline Normal & $1.28 \times 10^{-15}$ & $4.34 \times 10^{-17}$ \\
\hline CFL & $3.95 \times 10^{-14}$ & $1.34 \times 10^{-15}$ \\
\hline
\end{tabular}

Tabela 4.1: Fluxo médio de partículas em unidades de part $\mathrm{cm}^{-2} \mathrm{~s}^{-1} \mathrm{sr}^{-1}(\mathrm{MeV} / \mathrm{A})^{-1}$ para uma população estacionária de strangelets em $L=1.3$ e $L=2$ calculado com o fluxo "padrão".

\begin{tabular}{|l|l|l|}
\hline & $L=1.3$ & $L=2$ \\
\hline Normal & $3.83 \times 10^{-14}$ & $1.3 \times 10^{-15}$ \\
\hline CFL & $1.64 \times 10^{-13}$ & $5.55 \times 10^{-15}$ \\
\hline
\end{tabular}

Tabela 4.2: Fluxo médio de partículas em unidades de part $\mathrm{cm}^{-2} \mathrm{~s}^{-1} \mathrm{sr}^{-1}(\mathrm{MeV} / \mathrm{A})^{-1}$ para uma população estacionária de strangelets em $L=1.3$ e $L=2$ calculado com o fluxo "detalhado".

strangelets. Isso significa que consideramos $j_{0}\left(\cos \alpha_{e q}\right)=$ constante uma hipótese razoável. Assim,

$$
P\left(\alpha_{e q}\right)=4 \frac{\alpha_{e q}}{\int_{0}^{\pi / 2} \alpha_{e q} d \alpha_{e q}},
$$

onde o fator quatro vem da simetria na condição de uma dada partícula pertencer ao cone de perda: $\left|\alpha_{e q}\right|<\alpha_{\text {loss cone }} \mathrm{e}\left|\pi-\alpha_{e q}\right|<\alpha_{\text {loss cone. }}$.

Resolvendo a equação diferencial (4.12) e obtendo o correspondente fluxo para dentro (na direção - $\hat{\mathrm{e}}_{r}$ ) para todo $L$, é possível determinar a densidade média de partículas em cada camada e, conseqüentemente, o fluxo aprisionado de strangelets.

Os resultados encontram-se resumidos nas tabelas 4.1 e 4.2 para $L=2$ (localização do cinturão dos ACR) e $L=1.3$ (localização do máximo da função de distribuição para strangelets) para o exemplo de strangelets com número bariônico $A=100$ e energia correspondente a $R=1$ GV.

A posição do pico da função de distribuição no campo geomagnético (em torno de $L=1.3$ ) 
é bastante robusto, e não parece mudar apreciavelmente com a mudança na relação $A / Z$ (strangelets CFL e normais), ou com uma mudança na energia ou número bariônico das strangelets. Isso parece ser conseqüência de havermos adotado a PSD como sendo proporcional a $\nu^{-2}$, o que leva a um coeficiente de difusão independente da energia da partícula (ver equação 4.11). Assim, ao modificar-se a energia das strangelets, suas propriedades de difusão mantêm-se inalteradas.

Observamos que a população aprisionada é sutilmente mais favorecida se a matéria estranha encontra-se no estado CFL, sendo que as diferenças entre os fluxos aprisionados para as duas espécies (CFL e normais) aumenta com o decréscimo do expoente da energia no fluxo diferencial incidente. Isto ocorre devido à dependência do fluxo interestelar com o número bariônico das strangelets (ver equação 1.5). Como o intervalo em rigidez para aprisionamento estável é o mesmo para os dois estados, já que depende apenas das características geométricas do campo geomagnético, a diferença no número de partículas aprisionadas depende fortemente da diferença no fluxo incidente. Esta dependência do fluxo integrado no número bariônico pode ser expressa como $F_{I S M} \propto(0.125)^{-1.2} A^{-1.667}$ e $F_{I S M} \propto(0.3)^{-1.2} A^{-1.267}$ para strangelets normais e CFL, respectivamente. Desta maneira, o fluxo das strangelets CFL é menor que as daquelas sem emparelhamento, mas apenas para baixos valores do número bariônico $(A \lesssim 13)$, ou seja, para um região na qual se acredita que strangelets não são estáveis. Na região de estabilidade, o fluxo de strangelets CFL é sempre maior que o de strangelets normais, o que resulta numa densidade aprisionada maior. Assim, a diferença menos significativa vista para strangelets com e sem emparelhamento para o fluxo detalhado em relação ao fluxo padrão é explicado pela menor diferença no fluxo incidente devido a sua dependência mais suave no número atômico (o fluxo padrão tem a dependência de $E^{-2.5}$, o que significa que para uma análise em termos de rigidez, dependerá do número atômico da partícula, já que $R=\sqrt{(} 2 m E) c / Z e$ e $Z$ é função de $A$; no entanto, o fluxo detalhado já tem a sua dependência extraída diretamente em termos da rigidez, $\left.R^{1.8}\right)$.

Considerações adicionais são relevantes ao destino da população de strangelets aprisionada. A forte influência do vento solar sobre o fluxo de ACRs que atingem a Terra já é bem conhecida. O fluxo do ACR mais abundante, o oxigênio, mostra uma importante variação em sua intensidade com o ciclo solar, tendo o seu fluxo interestelar de 8-27 MeV/nucleon diminuído em até 
duas ordens de magnitude durante períodos de máxima atividade solar [112]. Durante o mínimo solar, o fluxo aprisionado na magnetosfera terrestre é da ordem de $5 \times 10^{-4}$ partículas $\mathrm{cm}^{-2} \mathrm{sr}^{-1}$ $\mathrm{s}^{-1}(\mathrm{MeV} / \text { nucleon })^{-1}$, o que corresponde a um fator de aumento de aproximadamente 15 [113], este valor experimental sendo abaixo daquele esperado a partir de considerações teóricas (maior que 25 [112]). O oxigênio corresponde a aproximadamente $80 \%$ da população dos ACRs aprisionados, enquanto que as razões para a abundância de $C / O, N / O$ e $N e / O$ são de $<0.005$, $\sim 0.10-0.15$ e $\sim 0.02-0.03$, respectivamente.

Com os resultados obtidos nesse estudo, o fluxo aprisionado de strangelets em $L<2$ seria da ordem de $10^{-14}-10^{-15}$ partículas $\mathrm{cm}^{-2} \mathrm{sr}^{-1} \mathrm{~s}^{-1}(\mathrm{MeV} / \mathrm{A})^{-1}$ em rigidez de $R=1 \mathrm{GV}$ para strangelets de número bariônico $A=100$. Isto representa um fator de incremento para o fluxo aprisionado no regime de população estacionária quando comparado ao fluxo interestelar na mesma energia e número bariônico $A$ de ordem 10 e $10^{2}$ para strangelets aprisionadas em $L=2$ e $L=1.3$, respectivamente, sendo os valores para strangelets CFL aproximadamente o dobro daqueles obtidos para strangelets normais ( $q \sim 5.5$ e 11, e $q \sim 162$ e 314 para CFL e normais em $L=2$ e $L=1.3$, respectivamente). Este simples cálculo mostra que o fluxo de strangelets pode ser tão alto quanto um fator 10000 abaixo daquele esperado para o carbono durante períodos de máxima atividade solar. Apesar de não havermos considerado a modulação solar em nossa análise, esta agiria significantemente apenas sobre aquelas de baixa energia [55], ou seja, na região de interesse para este estudo. Desta forma, a influência deve ser importante, similar àquela detectada para o densidade de oxigênio aprisionado.

A vantagem de uma procura por strangelets aprisionadas na magnetosfera terrestre feita durante períodos de máxima atividade solar, seja para identificá-los como uma importante componente dos cinturões de radiação ou apenas penetrando a atmosfera em direção à superfície, sem sofrer grande modificação de sua trajetória devido ao campo geomagnético, seria a redução da componente dos ACRs. Apesar da influência da atividade solar não ter sido considerada neste estudo, a baixa incidência de partículas quando comparada a períodos de elevada atividade solar poderia reduzir o tempo morto dos detectores e possivelmente permitir uma identificação mais clara dos primários.

O modelo proposto e amplamente aceito para o mecanismo responsável pelo aprisionamento dos ACRs [114] considera que a elevada razão massa/carga dessas partículas que se encontram 
ionizadas uma única vez, as permite penetrar profundamente na magnetosfera. Os ACRs seguindo trajetórias com espelhos magnéticos numa baixa altitude interagem com partículas na atmosfera superior, perdendo um ou todos seus elétrons restantes. Desta forma, o raio ciclotrônico da partícula é reduzido por um fator $1 / Z$, e o íon pode ser aprisionado estavelmente. Nossos resultados foram obtidos considerando-se strangelets totalmente ionizadas, e que, portanto, já devem ter exatamente as características requeridas para o aprisionamento quando atingem a magnetosfera. No entanto, uma pequena fração de strangelets deve atingir a atmosfera terrestre com uma carga efetiva algo abaixo do seu número atômico e sofrer um processo de interação semelhante ao dos ACRs. Finalmente, há também a possibilidade de que haja aprisionamento quase-estável de íons com energias altas o suficiente para que não obedeçam a condição (4.10), mas não tão altas para que deixem de sofrer deflexão significativa na sua direção de incidência quando da sua entrada na magnetosfera. Esses dois mecanismos adicionais poderiam contribuir para um aumento no número de strangelets aprisionadas.

Quando consideramos $\epsilon_{0}=930 \mathrm{MeV}$ (veja seção 3.1), estamos superestimando o valor da massa da strangelet (para um dado conjunto de parâmetros escolhido) por desprezar as contribuições de superfície, curvatura e efeitos de camada [45, 79] à energia dessas partículas. Dependendo da escolha dos parâmetros que caracterizam a matéria estranha, este valor assintótico pode ser tão baixo quanto $850 \mathrm{MeV}$ para strangelets normais e ainda menos para a matéria com emparelhamento [90], dependendo, adicionalmente, do valor adotado para o gap $\Delta$. Como o valor usual para determinar-se os limites de estabilidade para a SQM é que a massa total deve estar abaixo de $930 \mathrm{MeV}$, e o interesse aqui é estudar strangelets estáveis, (não há razão em fazer esta análise se a matéria estranha não é estável), o resultado da influência deste fator em nossa análise é superestimar a massa da strangelet. Tendo uma massa maior, a inércia dessas partículas é maior, e a deflexão causada pelo campo magnético na trajetória da partícula, menor, resultando num raio de giro em torno do centro guia, maior. Isso significa que a condição de movimento adiabático (que o campo magnético varie muito lentamente ao longo de uma órbita ciclotrônica) seria mais difícil de ser atingida em nossos cálculos do que se o valor de $\epsilon_{0}$ adotado fosse menor. O efeito qualitativo disto, é, portanto, o de subestimar o número de partículas aprisionadas, levando nossas estimativas a serem mais conservadoras.

Também as escolhas para os valores da massa do quark $s$, constante de sacola e constante de 
emparelhamento (para a matéria CFL) apresentam influência nos cálculos para a população aprisionada. As "janelas" para aprisionamento estável (figuras 4.4 e 4.5) mostram sua dependência com o número atômico apenas quando consideramos os outros parâmetros que caracterizam estas partículas fixos (o gráfico é apresentado em função de $p$ e $A$ ). Quanto menor o $Z$, menor a deflexão na trajetória da partícula devido à ação do campo magnético. Se o número atômico é muito pequeno, os efeitos serão similares àqueles descritos anteriormente para o caso de uma elevada massa: é mais provável que a partícula seja aprisionada em uma órbita instável com um tempo de residência reduzido quando comparado àquele de uma partícula que obedece os critérios de adiabaticidade. Nas referências $[79,90]$, notamos que mudar os valores de $m_{s}$ causa alterações na região de interesse de número bariônico da seguinte maneira: quando $m_{s} \rightarrow 0$, o número atômico da strangelet é muito menor do que o adotado em nossos cálculos, sendo que estes estariam, então, superestimados; para $m_{s} \rightarrow 300 \mathrm{MeV}$, a carga elétrica atinge um valor de saturação acima do adotado neste estudo (apesar do trabalho apresentado em [79] não levar em conta o efeito de blindagem da carga, verificamos que o comportamento quando se considera este efeito é qualitativamente o mesmo que o demonstrado em [79]), o que resultaria em mais strangelets aprisionadas; no entanto, é mais provável que o valor da massa do quark strange esteja na faixa de $100 \leq m_{s} \leq 200 \mathrm{MeV}$, de modo que os valores apresentados aqui seriam modificados de maneira menos significante devido à influência deste parâmetro. No que compete ao valor adotado para a constante de sacola, sua influência parece ser pequena, o mesmo para a constante de acoplamento para a matéria CFL.

\subsection{Strangelets na atmosfera terrestre}

A densidade média de partículas na atmosfera terrestre é de pelo menos quinze ordens de grandeza maior do que a encontrada no meio interestelar, de modo que os raios cósmicos passam por uma espessa camada de ar antes de atingirem a superfície terrestre. Se no ISM o reprocessamento do espectro de massa de strangelets deve ser de importância reduzida, na atmosfera este é inevitável, ao menos para strangelets que penetrem profundamente a atmosfera.

A interação de núcleos ordinários com partículas na atmosfera já há muito é objeto de estudo. Quando um raio cósmico (chamado de primário) colide com um núcleo na atmosfera, 
resulta uma reação nuclear que produz inúmeros secundários (ver figura 4.7). Devido às elevadas energias dos primários, a maioria dos secundários, apesar de apresentarem presumivelmente uma distribuição isotrópica, ou quase isotrópica no referencial do centro de massa, são propagados no referencial do laboratório em um pequeno ângulo sólido em direção à superfície da Terra, aproximadamente ao longo da direção de chegada do raio cósmico. A região central em torno deste eixo é chamada de núcleo do chuveiro.

As interações de primários e secundários pode acontecer repetidamente, de modo que o número total de partículas aumenta como uma avalanche. Este processo continua até que a energia dos secundários seja tal que a energia de excitação dos núcleos e espalhamento elástico passam a predominar sobre a geração múltipla.

No que diz respeito aos secundários, três componentes distintas são usualmente identificadas: a componente mesônica (muons), componente nucleônica (basicamente prótons e nêutrons) e uma componente leve (formada por elétrons e fótons).

Desintegrações nucleares subseqüentes são produzidas por estas partículas axiais dando origem a mais mésons e nucleons, constituindo a cascata nuclear. Na interação inicial, bem como nas subseqüentes, os píons neutros decaem em gamas de alta energia que por sua vez iniciam as cascatas fóton-eletrônica.

Os píons carregados da colisão nucleon-nucleon original são caracterizados por suas altas energias. A competição entre a interação e o decaimento espontâneo (em muons), que depende da energia do píon, proporciona a possibilidade de colisões inelásticas de píons carregados com núcleos do ar, produzindo uma cascata meson-nucleon.

Partículas de matéria estranha poderiam sofrer colisões com partículas na atmosfera, produzindo chuveiros que eventualmente poderiam ser detectados por experimentos em solo.

Ao longo dos anos surgiram na literatura tentativas de explicar-se os eventos Centauro, Price, ET, entre outros, em termos da origem exótica dos primários que os originaram. Há duas explicações propostas para o processo a que estariam sujeitas as strangelets e que as permitiriam alcançar tão profundamente a atmosfera.

Foi sugerido que strangelets de elevado número bariônico perdem massa em interações sucessivas com núcleos ordinários desde que atingem o topo da atmosfera durante a sua propagação em direção à superfície terrestre. Quando o seu número bariônico atinge um valor para o qual 


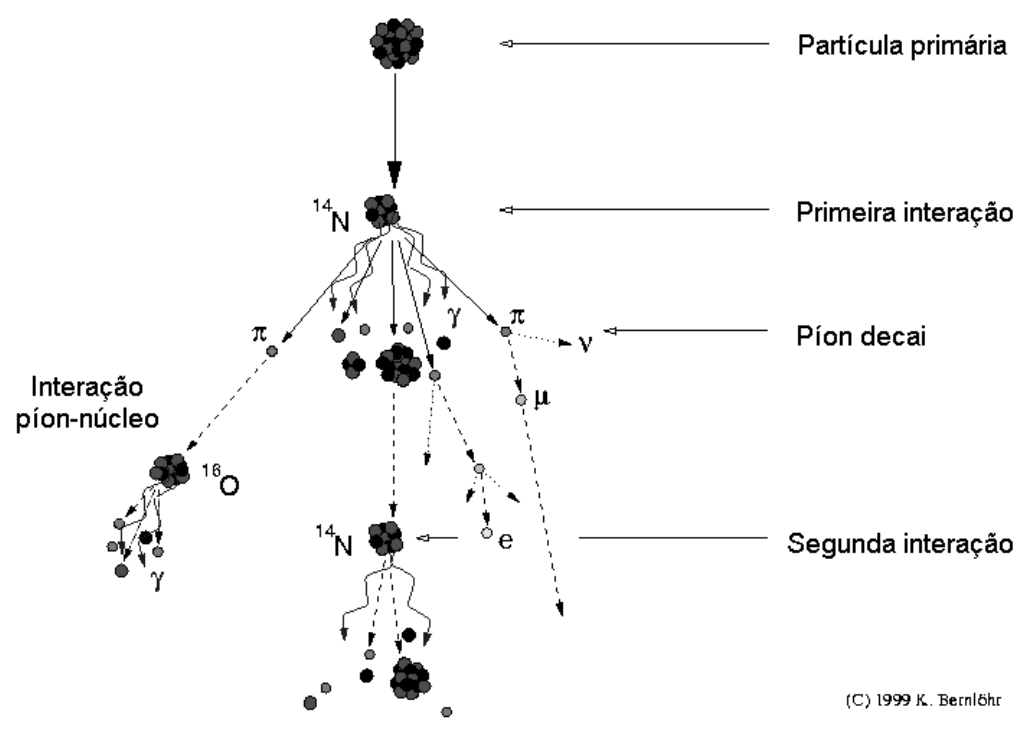

Figura 4.7: Exemplo esquemático da geração de um chuveiro atmosférico pela interação de um núcleo ordinário. O primário interage com uma partícula da atmosfera (sendo mais provável a colisão com o nitrogênio) gerando secundários que irão originar cascatas mesônicas, nucleônicas e leves (referir ao texto para maiores detalhes).

sua massa passa a ser menor do que a mínima permitida para estabilidade, elas então decaem, dando origem a uma série de hadrons. Desta forma, seria possível conciliar o livre caminho médio pequeno (da mesma ordem que o de núcleos ordinários) e a alta penetração na atmosfera [115].

Por outro lado, as críticas surgidas a este cenário são de que, enquanto núcleos ordinários tendem a fragmentar-se nas colisões, strangelets poderiam tornar-se mais ligadas através da absorção de matéria. Também, como vimos na seção 4.1, a carga elétrica não nula das strangelets permite que sua trajetória seja afetada pelo campo magnético terrestre, o que pode levar ao aumento do caminho percorrido por esta partícula antes que atinja uma dada altitude. Se assim ocorrer, então o número de interações que a strangelet pode sofrer com núcleos atmosféricos para que chegue a uma dada altura seria maior, o que provavelmente resultaria em sua total evaporação antes de atingir a altura desejada.

Desta forma, postulou-se o cenário de strangelets com número bariônico algo acima do limite crítico, $A_{\text {crit }}$, quando atingem a atmosfera superior e então aumentam sua massa, ao 
invés de diminuí-la, através de sucessivas reações de fusão com átomos da atmosfera [116]. Os autores propõem que esta situação poderia prevalecer contanto que a velocidade de propagação da strangelet pela atmosfera não seja tão alta a ponto de a energia de excitação exceder a energia de ligação em uma colisão com núcleos na atmosfera. Segundo suas estimativas, quando a massa inicial da strangelet é maior do que $A \gtrsim 40$, o limite superior para a velocidade é de 0,7c. Não é considerada a hipótese de fragmentação por processo de fissão de strangelets.

Enquanto ainda há controvérsias no tratamento deste fenômeno por diferentes autores, uma análise mais completa se faz necessária para prover uma resposta definitiva sobre qual o processo de interação dominante que poderia levar a um evento com caraterísticas do tipo Centauro. Entre as características mais incomuns, está a ausência de píons neutros (o que sugere um primário com alto $Z$ ) e a média de momento transversal dos secundários muito maior do que o valor típico de uma fragmentação nuclear.

\subsubsection{Análise dos processos de interação hadrônica}

Utilizamos o mesmo procedimento empreendido na seção 3.3 para avaliar a importância relativa dos processos de abrasão, fusão, fissão e espalhamento para a interação de strangelets na atmosfera terrestre.

O principal componente atmosférico é a molécula de nitrogênio, de modo que foi considerada a interação de strangelets com estas partículas. Não consideraremos aqui a possibilidade de fusão parcial.

É possível verificar que o processo de fusão é apenas favorecido para energias da strangelet mais baixas quando comparadas ao ISM devido à diferença das massas de repouso entre o próton e o nitrogênio (ver figura 4.9). Esta probabilidade aumenta com $A$ devido ao aumento do raio da strangelet, o que leva a uma maior distância percorrida em colisões centrais para o depósito da energia cinética do núcleo com o qual a strangelet interage (no referencial desta última). Os diferentes pontos nos quais a probabilidade de fusão passa a ser nula reflete a diferença na energia de ligação para a matéria estranha com e sem emparelhamento, maior para o primeiro caso.

A probabilidade de abrasão é baixa para energias pequenas devido à competição com o pro- 

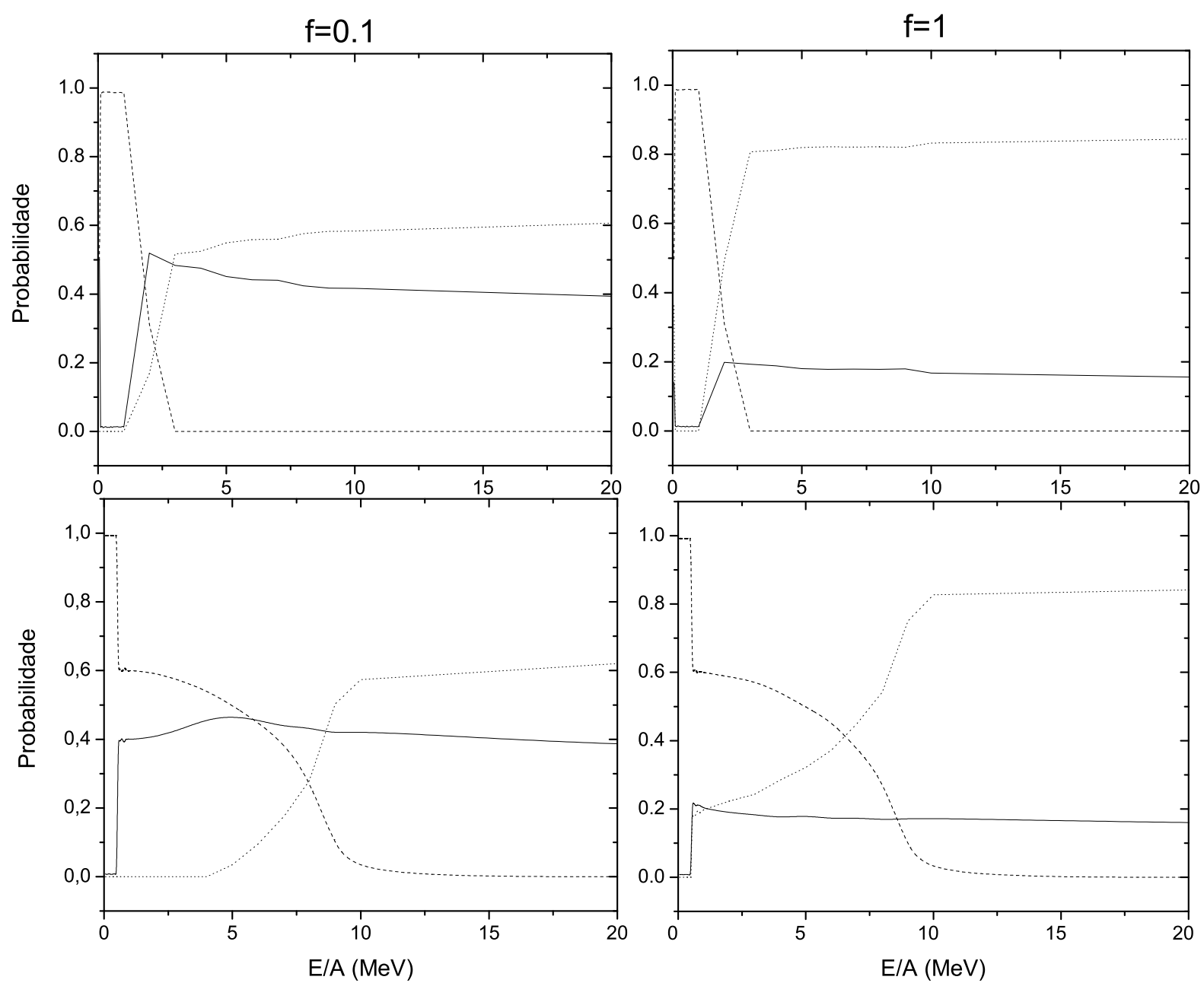

Figura 4.8: Probabilidade de ocorrência dos processos de interação hadrônica para strangelets sem emparelhamento (acima) e CFL (abaixo) de $A=100$ e fração de clusters de bárions de 0,1 (à esquerda) e 1 (à direita) com nitrogênio atmosférico. As curvas cheia, tracejada e pontilhada são para os processos de espalhamento, fusão e abrasão, respectivamente. 

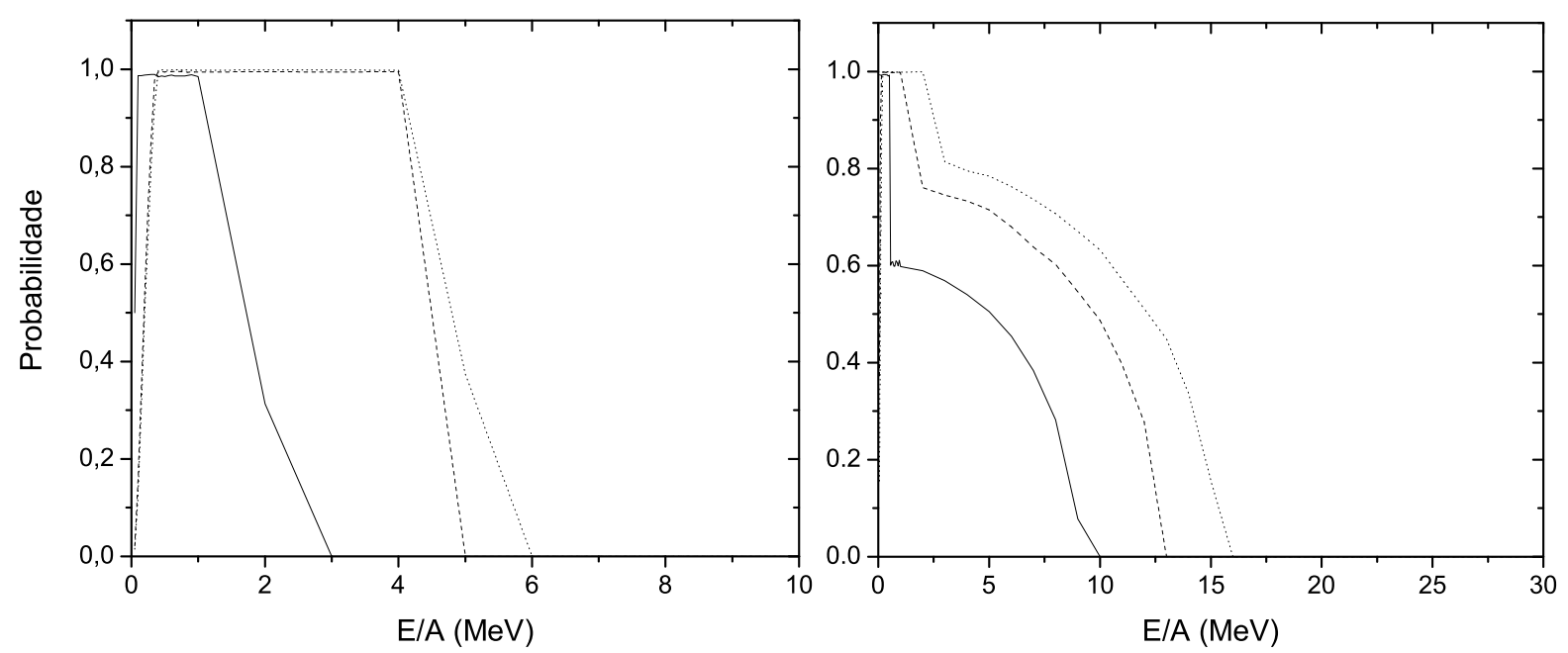

Figura 4.9: Probabilidade de fusão como função da energia incidente para strangelets sem emparelhamento (à esquerda) e CFL (à direita) com nitrogênio na atmosfera com fração de clusters de bárions de 0,3 . As curvas cheia, tracejada e pontilhada representam $A=100, A=1000$ e $A=3000$, respectivamente.
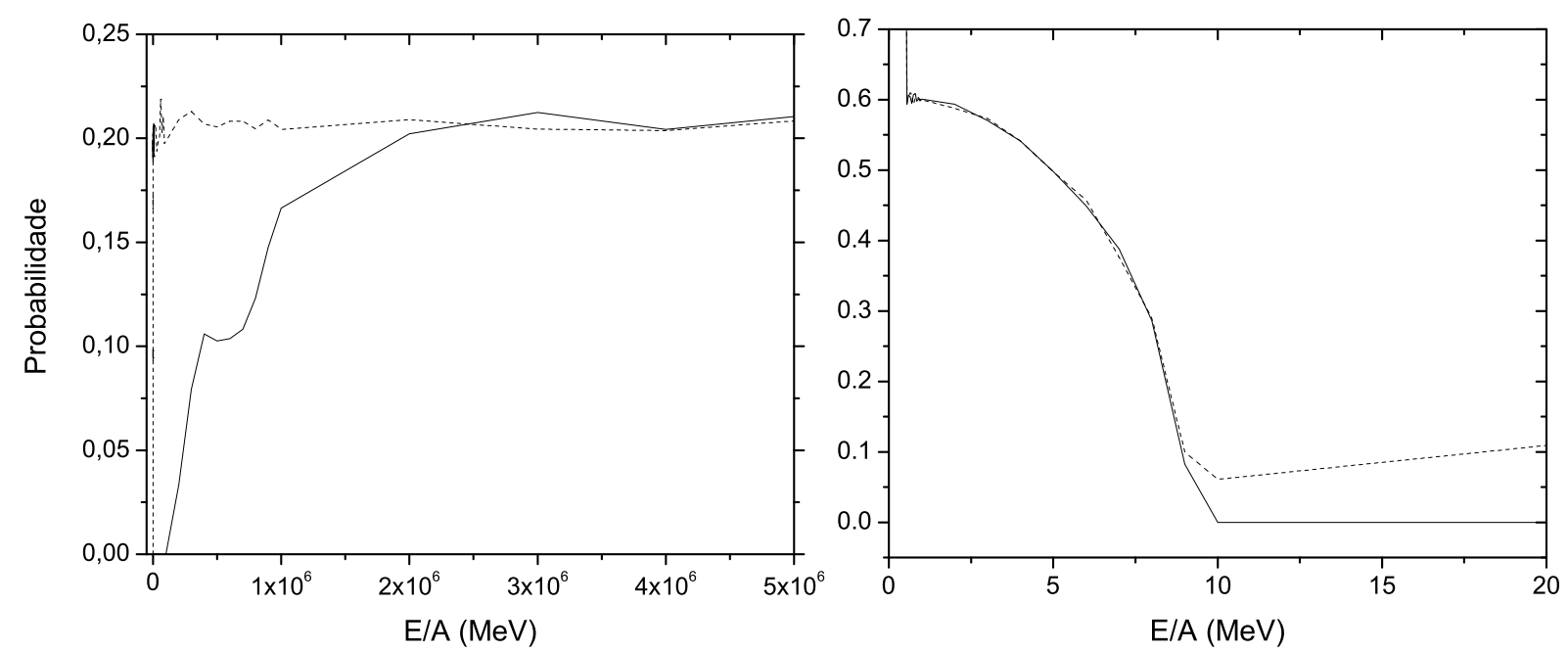

Figura 4.10: Probabilidade de fissão como função da energia incidente para strangelets de número bariônico $A=100$ sem emparelhamento (à esquerda) e CFL (à direita) a partir de interações com nitrogênio. A fração de clusters de bárions de 0,1 e 1 é representada pelas linhas cheia e tracejada, respectivamente. 
cesso de fusão e aumenta com energias maiores, pois, reduzindo-se a importância do desvio Coulombiano, o espalhamento torna-se pequeno. Estas observações são fracamente dependentes de $A$.

A proporção relativa entre os processos de abrasão e espalhamento aumenta com a energia e tende assintoticamente a um valor constante (e próximo de 1) para strangelets relativísticas devido à dependência do livre caminho médio de interação nucleon-nucleon com a energia. Esta observação independe de $A$ e das diferentes frações de clusters formados temporariamente na strangelet.

A média de energia de excitação nas colisões após cada processo é de até $\sim 800 \mathrm{MeV}$ para a abrasão (depende muito fracamente de $A$ e independe do estado da matéria estranha com as considerações feitas neste trabalho) e até $\sim 1,3 \mathrm{GeV}$ e $\sim 3 \mathrm{GeV}$ para strangelets sem emparelhamento e CFL, respectivamente, após a fusão completa da strangelet com o nitrogênio. Estes valores justificam a observação de fissão induzida para strangelets CFL de baixa massa (ver figura 4.10). Para baixas energias, a fissão ocorre devido à liberação de energia resultante da fusão (as duas curvas de probabilidade podem ser superpostas, ver figuras 4.9 e 4.10). Para energias maiores, a probabilidade de fissão, tanto para strangelets com e sem emparelhamento de quarks, é devido ao ganho de energia de excitação pela deformação da strangelet quando da abrasão de um grande número de massa. Apesar de a média de energia total no processo de abrasão ser menor que a energia de ativação, uma fração destes eventos têm capacidade de elevar a energia do sistema à níveis no qual a fissão é favorecida. Neste caso, a probabilidade é menor quando a fração de pseudo-bárions é menor devido à diminuição na quantidade de matéria retirada e, conseqüentemente, menor distorção da strangelet. Este resultado, no entanto, deve ser visto com cuidado pois o modelo de abrasão, tendo sido criado para a descrição da matéria nuclear ordinária, certamente não previa situações nas quais a diminuição na quantidade de número bariônico de uma partícula poder chegar a valores da ordem de $10^{2}$, o que pode render energias de excitação superestimadas.

Não é verificada a probabilidade de fissão de strangelets de alta massa já que as energias resultantes do processo de colisão entre strangelets e o nitrogênio não são suficientes para suprir o aumento da energia de ativação para fissão destes exóticos (ver figura 3.9).

A média de material que sofre abrasão é maior na atmosfera do que no meio interestelar 

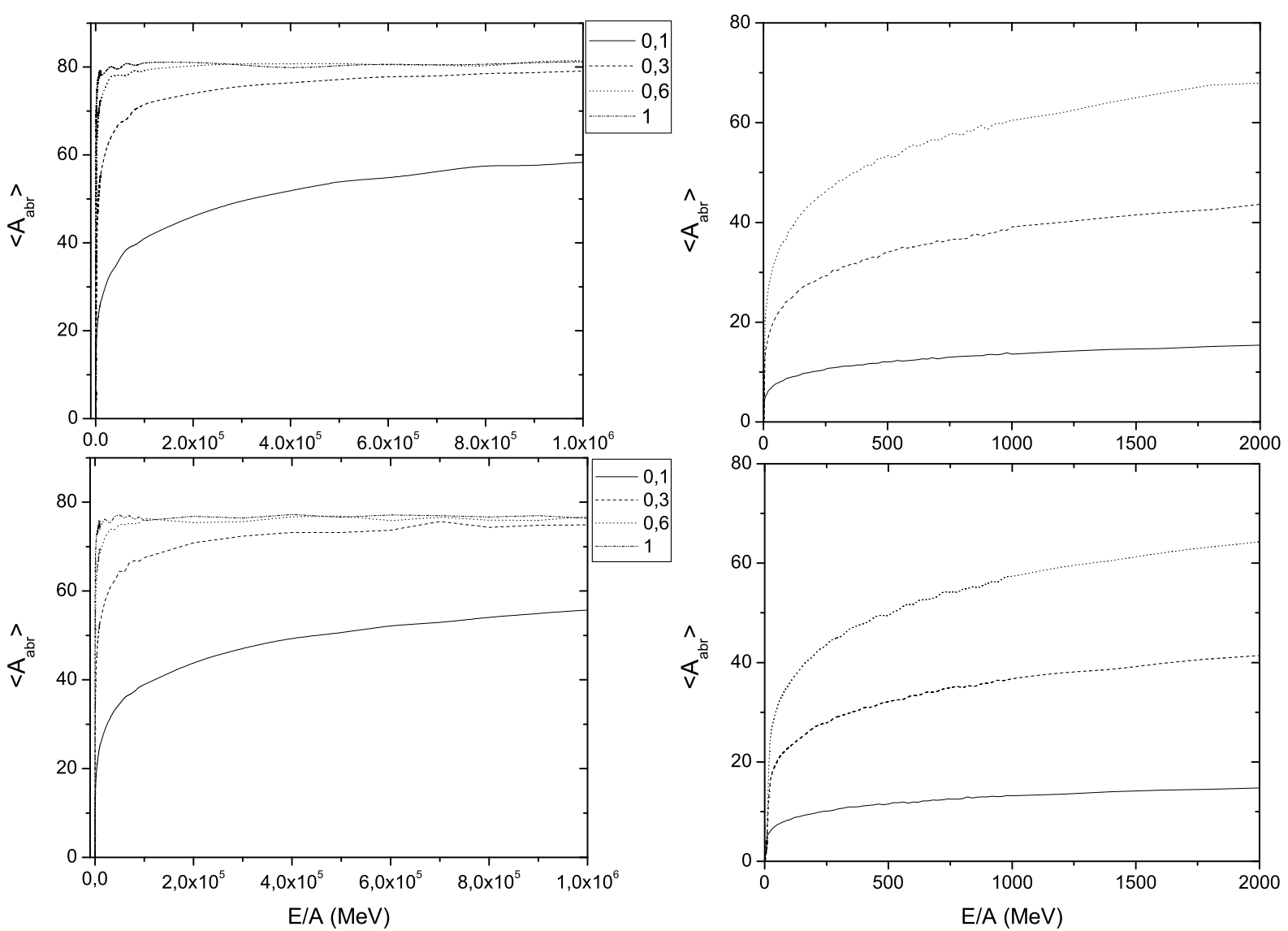

Figura 4.11: Quantidade de matéria que sofre abrasão em média como função da energia para strangelets sem emparelhamento (acima) e CFL (abaixo) na atmosfera. À esquerda, para $A=1000$ e fração $f$ de clusters de bárions conforme indicado. À direita, matéria que sofre abrasão para $f=0,3$ sendo as curvas cheia, tracejada e pontilhada para $A=100, A=1000$ e $A=3000$, respectivamente. 

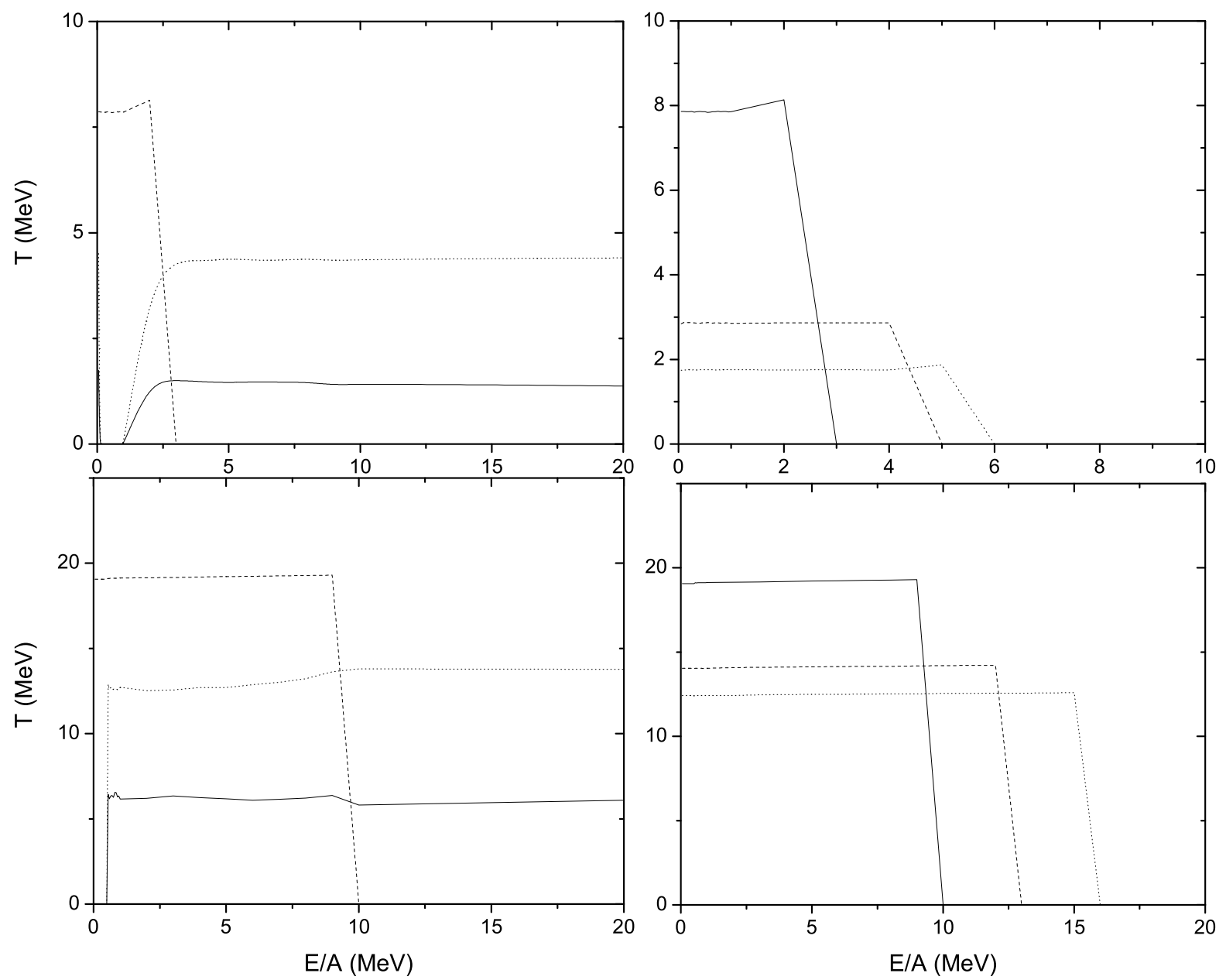

Figura 4.12: Temperatura após interação hadrônica na atmosfera para strangelets sem emparelhamento (acima) e CFL (abaixo). À esquerda, para $A=100$ e fração de clusters de bárions de 0,3, sendo as curvas cheia, tracejada e pontilhada para os processos de espalhamento, fusão e abrasão, respectivamente. À direita, temperatura média para o processo de fusão sendo as curvas cheia, tracejada e pontilhada para $A=100, A=1000$ e $A=3000$, respectivamente.

pois a área de interação entre o alvo e o projétil é substancialmente maior (ver figura 4.11). Esta aumenta com a fração de clusters de bárions $f$ mas apresenta diferença significativa apenas para $f=0,1$ em altas energias devido à diferença no livre caminho médio. Em energias mais baixas, a diferença em $A_{a b r}$ com a mudança em $f$ é mais pronunciada. Estas conclusões mantêm-se para diferentes números bariônicos de strangelets e também é fracamente dependente de seu estado de emparelhamento de quarks (CFL ou não).

Verifica-se que as temperaturas em processos de fusão (apresentadas na figura 4.12) são maiores do que aquelas correspondentes à fusão no meio interestelar pois, com a fusão com- 
pleta, é liberada uma grande quantidade de energia de excitação por cada nucleon proveniente do nitrogênio. Isto possibilita a fissão de strangelets CFL de baixo número bariônico. As temperaturas obtidas após o processo de fusão são menores que $\sim 6 \mathrm{MeV}$ para strangelets sem emparelhamento e para fusão seguida de fissão, atingem até $\sim 18 \mathrm{MeV}$ para strangelets CFL. No caso de strangelets sem emparelhamento e CFL com $A>1000$, as temperaturas, que dependem fortemente do conteúdo bariônico, resultantes do processo de fusão (e que não há fissão) são menores que $\sim 3 \mathrm{MeV}$ e $\sim 14 \mathrm{MeV}$, respectivamente.

Os valores de temperaturas aqui obtidos indicam que o canal de desexcitação mais provável para strangelets interagindo na atmosfera terrestre é a emissão de fótons. Para as mais altas temperaturas atingidas, também é possível a emissão de píons, no entanto com uma contribuição bem menos efetiva que a desexcitação por gamas. Apesar das altas temperaturas, ainda não é atingido o estágio de emissão de nêutrons após o equilíbrio térmico. No entanto, como já mencionamos anteriormente, pode haver emissão de partículas localmente antes que o equilíbrio aconteça.

\subsubsection{Considerações sobre chuveiros atmosféricos}

Strangelets que penetram profundamente na atmosfera podem desencadear reações quando da colisão com partículas do ar, levando, assim, à geração de um chuveiro. Não vamos considerar a possibilidade de formação de matéria estranha (possivelmente meta-estável devido às altas temperaturas), em colisões de raios cósmicos ordinários com partículas na atmosfera.

Para a avaliação dos possíveis destinos de strangelets penetrando a atmosfera terrestre a partir dos resultados encontrados na seção anterior, precisamos verificar a rigidez para o cutoff geomagnético e compará-la à rigidez das partículas. Os valores de rigidez são mostrados nas figuras 4.13 e 4.14 .

Deste modo, strangelets com energias cinéticas por unidade de número bariônico menor do que centenas de $\mathrm{MeV}$ a alguns $\mathrm{GeV}$ sofrerão diminuição no fluxo que penetra a atmosfera devido ao cutoff geomagnético. Também, se a rigidez estiver acima do cutoff local mas $E / A$ tiver valor da ordem de algumas dezenas a poucas centenas de $\mathrm{MeV}$, dependendo da massa da strangelet, é mais provável que ela seja aprisionada pelas linhas de campo magnético, conforme 


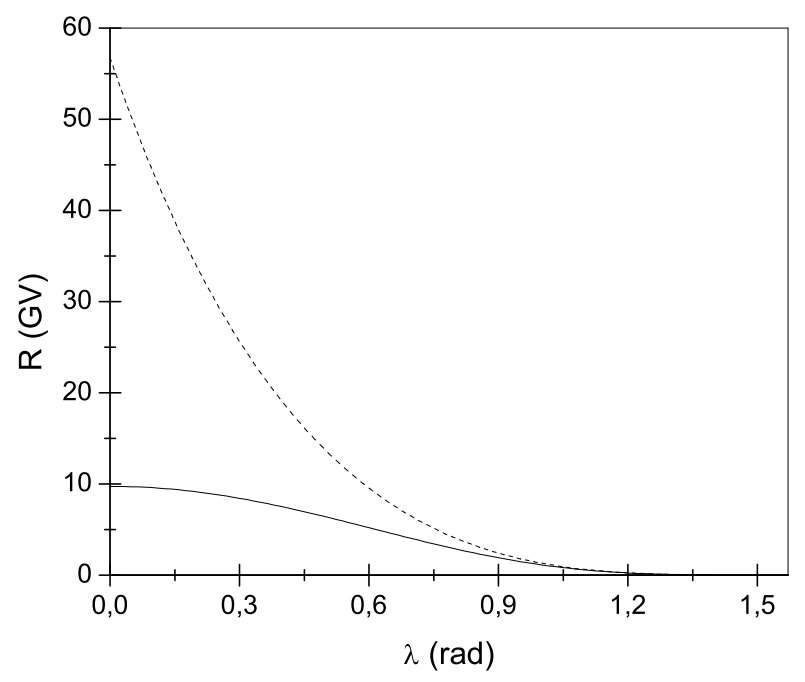

Figura 4.13: Rigidez de cutoff geomagnético como função da latitude magnética em $L=1,05$, posição aproximada da escala de altura da atmosfera. A curva cheia representa o cutoff para direção de chegada do leste e a tracejada, do oeste. Partículas com valores de rigidez menores do que aqueles do cutoff são impedidas de penetrar a dada região da magnetosfera.

discutido na seção 4.1, se o ângulo de pitch é favorável. Desta forma, a possibilidade de geração de chuveiros atmosféricos por strangelets de baixas energias é bastante reduzido. Também, a probabilidade de que o processo de fusão seja aquele que permite penetração de strangelets até baixas altitudes parece bastante desfavorável.

Se a densidade de coluna percorrida entre colisões de strangelets com núcleos na atmosfera é da ordem de $30 \mathrm{~g} / \mathrm{cm}^{2}$, apropriado para quando $R_{\text {strang }} \sim R_{a r}$ ฯ, e considerando que em uma colisão típica a perda de energia é $\Delta E / E \sim 3 \%$ [117], obtivemos uma estimativa da evolução do número bariônico de uma strangelet como função da densidade de coluna atravessada, mostrada na figura 4.15 .

Como esperado, quanto maior a energia e o número bariônico da strangelet, maior a inclinação da curva de perda de massa.

O processo de fissão é importante para strangelets de baixa massa. Apesar de menos provável que a abrasão, este processo contribui para impedir que estas partículas penetrem profundamente a atmosfera antes de atingir o mínimo $A$ para o qual a matéria estranha é estável.

O trabalho apresentado em [98], estima a possibilidade de fissão de strangelets na atmos-

\footnotetext{
"Para o caso de strangelets de elevado número bariônico, os valores obtidos para a massa final após uma dada densidade de coluna atravessada deve estar superestimado.
} 

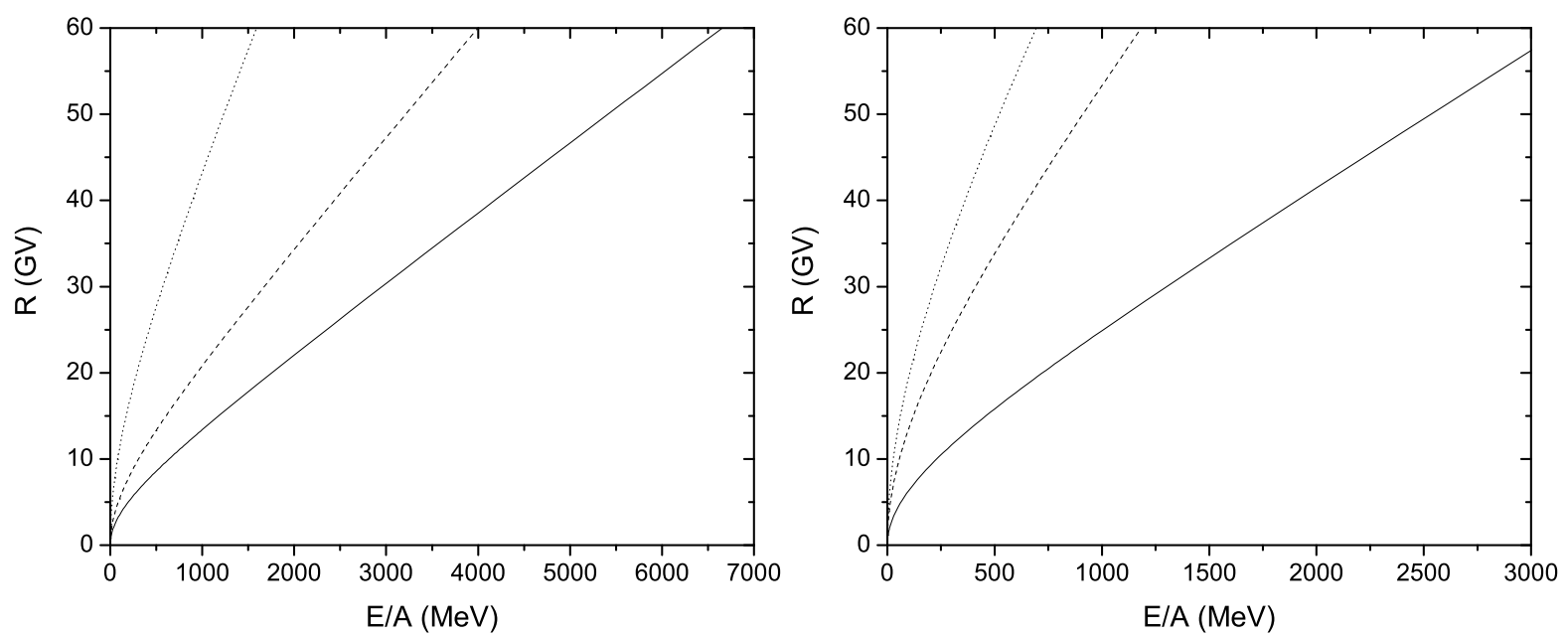

Figura 4.14: Rigidez de strangelets sem emparelhamento de quarks (à esquerda) e CFL (à direita) como função de sua energia cinética por número bariônico. As curvas cheia, tracejada e pontilhada são para $A=100, A=1000$ e $A=3000$, respectivamente.
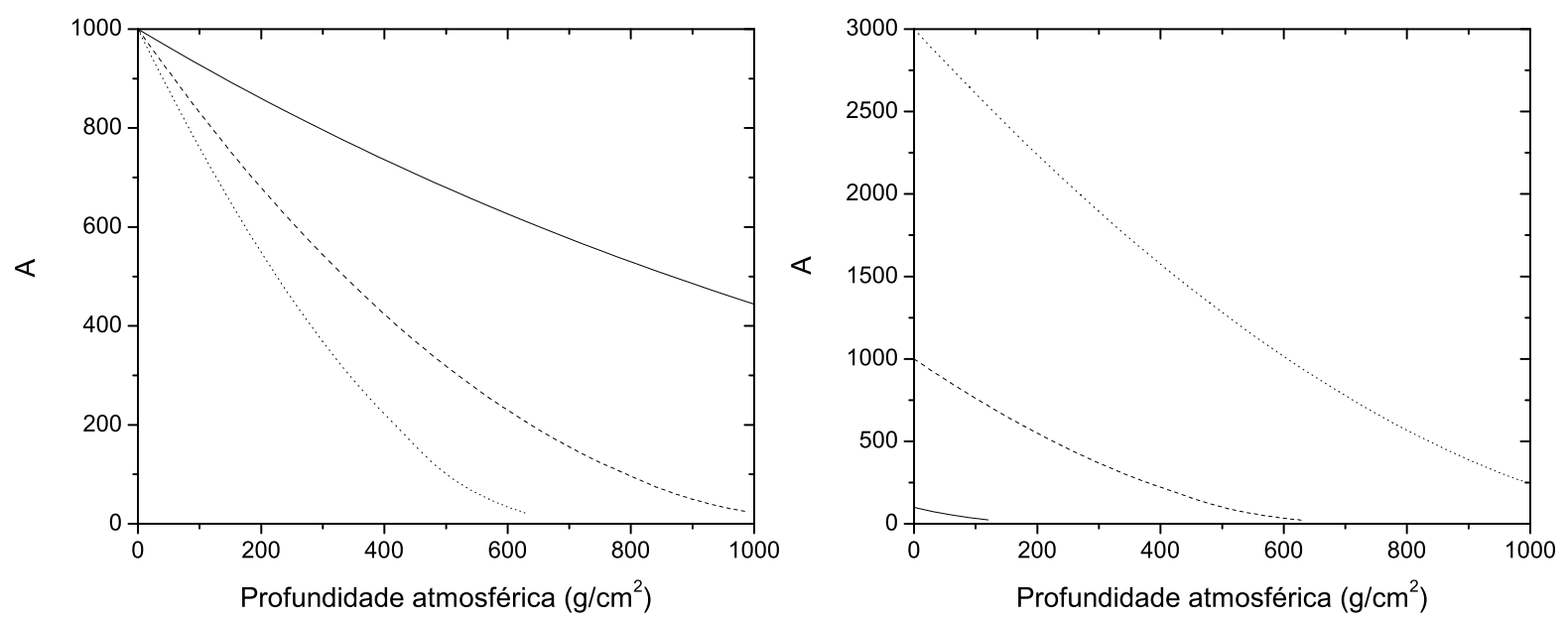

Figura 4.15: Evolução do número bariônico de uma strangelet como função da densidade de coluna atravessada na atmosfera terrestre. Estes valores mudam minimamente quando se consideram strangelets com ou sem emparelhamento de quarks com as considerações feitas nesta Tese. À direita, o número bariônico da strangelet é fixo em $A=1000$ e as curvas cheia, tracejada e pontilhada são para $E / A=100,10^{4}, 10^{6} \mathrm{MeV}$, respectivamente. À esquerda, a energia por unidade de número bariônico da strangelet é fixa em $E / A=1 \times 10^{6} \mathrm{MeV}$ e as curvas cheia, tracejada e pontilhada são para $A=100,1000,3000$, respectivamente. 
fera através de um modelo que leva em conta a contribuição da energia rotacional. Partículas com elevados valores de deformação por rotação têm probabilidade de sofrer fissão em uma colisão substancialmente maior do que quando se consideram partículas esféricas, sem deformidades. No entanto, a estimativa de espalação tomada pelos autores não provém de nenhum modelo, considerando que a strangelet vai perder a mesma massa que o núcleo de ar com o qual colide em cada colisão. Apesar disso, as nossas estimativas não parecem estar longe em valores absolutos (apesar de apresentarem concavidade opostas nas curvas de evolução de massa para strangelets) o que nos leva a crer que as curvas presentes na figura 4.15 devam ser limites superiores no que diz respeito a este ponto.

No que concerne os eventos Centauro, verificamos que este poderia ser explicado por uma strangelet de alta massa e elevada energia penetrando o topo da atmosfera e sofrendo sucessivas perdas em número bariônico até alcançar experimentos em solo. No entanto, mais análises relativas à produção de secundários são necessárias para uma conclusão mais firme.

Os resultados previstos para detectores em órbita sensíveis a strangelets de baixa massa e energia mostram que dado um tempo de integração suficiente, deve ser possível detectar estas partículas aprisionadas no campo geomagnético, contanto que haja condições para sua presença entre os primários de raios cósmicos" ${ }^{\|}$.

Para detectores em solo, também seria possível detectar-se strangelets, em especial em experimentos no topo de montanhas já que a perda de massa por interação tende a ser catastrófica para elevadas densidades de coluna atravessada. Não é descartada, pelo contrário, verificamos preliminarmente que os eventos Centauros podem ter origem em strangelets, ainda que estes resultados devam ser reanalizados em mais detalhes.

\footnotetext{
${ }^{\|}$Estes resultados encontram-se publicados em [118]
} 


\section{Capítulo 5}

\section{Conclusões}

A hipótese da estabilidade da matéria estranha de quarks (SQM) traz uma série de questionamentos sobre a nossa compreensão do comportamento da matéria hadrônica em baixas temperaturas e altas densidades bariônicas. Em especial, se esta estabilidade é de fato favorecida, então há a possibilidade de importantes implicações para a Astrofísica, com a possível conversão de estrelas de nêutrons em estrelas estranhas. Se este é o caso, então o fluxo de raios cósmicos ordinários deve conter uma "contaminação" de strangelets (porções finitas de SQM), que pode ser detectada por experimentos terrestres.

As condições de estabilidade para a matéria estranha com e sem emparelhamento de quarks à temperatura finita foram calculadas nesta Tese. Determinamos que a matéria estranha no estado CFL é mais estável que no estado sem emparelhamento de quarks, independentemente da temperatura na qual se encontra o sistema, ainda que a temperatura finita sempre desestabilize o sistema em relação ao estado fundamental. Mesmo se a temperatura do estado CFL está próxima à temperatura crítica para supercondutividade, esta ainda pode ser (meta-) estável, dentro de um certo espaço de parâmetros que caracterizam a matéria. Estes resultados têm importantes implicações para a análise da conversão de uma estrela de nêutrons em estrela estranha, para os processos de aceleração de strangelets de origem astrofísica, para as colisões de íons pesados e fragmentação em geral. Ainda que a extrapolação do modelo de gota líquida não seja indicada para a análise de strangelets de baixo número bariônico, a tendência é de que o número bariônico crítico para estabilidade de strangelets CFL seja menor do que aquele para strangelets sem emparelhamento de quarks, ainda que não tenha sido possível determiná-lo para 
os casos de elevado valor da constante de emparelhamento $\Delta$.

O espectro de fragmentação original nas fontes (o qual, até o momento, resistiu a todas as nossas tentativas de cálculo) deve sofrer pouco reprocessamento pela passagem destas strangelets pelo meio interestelar. Isto é devido ao elevado livre caminho médio para estas partículas na Galáxia. No entanto, não é garantido que este deva ser sempre atuando no sentido de diminuir as massas dessas partículas, como suposto em trabalhos anteriores (veja, por exemplo, [55]), em particular para strangelets de baixa energia por unidade de número bariônico ( $E / A \lesssim 50-350$ $\mathrm{MeV}$ ) que podem sofrer fusão. Também, foi verificado que a utilização de modelos cujos parâmetros são obtidos a partir do ajuste a dados provenientes de experimentos com núcleos ordinários pode superestimar o grau de reprocessamento de strangelets. Isto indica que análises mais cuidadosas da passagem destas partículas pelo meio interestelar devem ser feitas de modo a melhorar as estimativas do fluxo de strangelets que deve atingir a Terra.

Determinamos que strangelets com ângulos de incidência e momentos iniciais apropriados (correspondentes a rigidez de $R=1-3 \mathrm{GV}$ ) podem ser confinadas no campo magnético terrestre, levando a um aumento substancial de seu fluxo quando comparado àquele do meio interestelar (de até duas ordens de grandeza!). O ponto fundamental desta análise é que este acúmulo em regiões específicas da magnetosfera terrestre deve ocorrer, uma vez que strangelets estejam presentes em ambientes astrofísicos. Independentemente de refinamentos na estimativa do fluxo de raios cósmicos esperado na Terra (cálculos do espectro de fragmentação inicial nas fontes e reprocessamento no meio interestelar), o aumento do fluxo aprisionado em relação àquele que pode ser medido fora da magnetosfera constitui uma previsão sólida (ainda que o valor exato do máximo da distribuição ainda possa ser aprimorado). Isto resulta que a região entre $L=1.3-2$ é a mais promissora em relação à detecção de strangelets, devendo ser explorada por experimentos projetados especificamente para medir a carga e a massa dessas partículas.

Com relação à detecção de strangelets na atmosfera terrestre, é possível que strangelets penetrando profundamente na atmosfera gerem chuveiros com uma forte componente nucleônica. Claramente, esta afirmação é fortemente dependente da massa e energia iniciais destas partículas. Verificamos que o processo que deve ser responsável pela alta penetração destes exóticos deve ser a espalação de strangelets de elevado número bariônico em sucessivas interações com com- 
ponentes atmosféricos. Isto está de acordo com o que parece ter sido observado nos eventos Centauros, favorecendo, assim, a hipótese de strangelets como primários para estes eventos.

Estes cálculos fornecem subsídios para a reanálise dos dados de experimentos já existentes e planejar novos aparatos que possam explorar estas predições.

Os experimentos em solo têm a vantagem do longo tempo de exposição e praticamente não há limites para o tamanho dos detectores. As observações de raios cósmicos que sofrem colisões inelásticas com os componentes da atmosfera (gerando os chuveiros de partículas) são importantes para a caracterização do espectro proveniente do meio interestelar. No entanto, estas observações devem ser corrigidas pela influência da atmosfera terrestre.

Por outro lado, se o experimento de raios cósmicos é realizado fora da atmosfera, apesar das limitações de tamanho e peso dos detectores e do tempo de observação (menor do que algumas semanas para o caso de experimentos em naves espaciais), os efeitos de atmosfera podem ser desprezados, ajudando numa melhor identificação dos processos e primários. No entanto, intensidades fracas para os raios cósmicos (caso esperado para a intensidade do fluxo de strangelets) não podem ser medidas. Espera-se que estas limitações sejam superadas quando a Estação Espacial Internacional estiver disponível para este tipo de medidas [56].

Em análises futuras será possível utilizar as técnicas desenvolvidas nesta Tese para, por exemplo, reimplementar esta análise com a utilização de outros modelos físicos que não o modelo de sacola do MIT.

Em resumo, se a matéria estranha é de fato estável na região do diagrama de fases que deve ser ocupado pelas estrelas de nêutrons, deve haver uma certa abundância de strangelets no fluxo de raios cósmicos. Se este é o caso, a detecção de strangelets é possível (em especial na magnetosfera terrestre) e deve prover respostas diretas e seguras sobre a composição dos interiores das estrelas de nêutrons (que não existiriam como tais) e a respeito do estado fundamental das interações hadrônicas. 


\section{Apêndice A}

\section{Espectro de fragmentação da matéria}

\section{estranha}

Por sua importância em situações de laboratório e também astrofísica, a fragmentação da matéria nuclear infinita durante o esfriamento/descompressão tem sido objeto de estudo por várias décadas (para uma revisão, veja a referência [87]). Um exemplo de evento específico no qual esta fragmentação pode ocorrer e contribuir de forma significativa ao resultado final é a produção de elementos típicos de processos $r$, estudados em certo detalhe em [119], entre outros.

Quanto à pesquisa deste mesmo processo para a matéria estranha de quarks, até o momento, os detalhes da produção de strangelets e sua subseqüente aceleração são ainda temas que carecem de análises detalhadas. Seria igualmente importante verificar se os fragmentos resultantes de uma possível fragmentação poderiam decair para matéria nuclear ordinária. Os valores propostos para o fluxo de strangelets entre os raios cósmicos até agora apresentados (ver seção 1.3) são, em sua maioria, baseados largamente em suposições plausíveis mas não em cálculos detalhados.

Além disso, o espectro de energia de strangelets injetadas no meio interestelar é incerto. Portanto, considerar que um mecanismo de Fermi acelere strangelets em remanescentes de supernovas, da mesma forma que acelera raios cósmicos ordinários, pode gerar problemas, já que apenas partículas com energias não térmicas são aceleradas por choques.

Com o propósito de estimar estes espectros, estudamos alguns modelos que poderiam elu- 
cidar a física por trás da transição da matéria estranha em bulk para strangelets, cujos métodos são descritos a seguir. No entanto, ainda não foi possível estabelecer com confiança sob que condições há a fragmentação e com qual espectro de massa a SQM se apresenta e, assim, os resultados são tão somente preliminares.

\section{A.1 O modelo de multifragmentação estatística}

Entre diversas propostas, o modelo estatístico de multifragmentação (SMM, da sigla em inglês statistical multifragmentation model) desenvolveu-se recentemente [87], com a vantagem, por exemplo, de ter esclarecido aspectos relacionados à transição de fase na matéria nuclear e à multifragmentação nuclear (produção múltipla de fragmentos em regiões de energia intermediária). Anteriormente, eram feitos cálculos numéricos no ensemble canônico que exibem peculiaridades intrigantes e não havia investigações do comportamento do sistema no limite termodinâmico. Não havia prova rigorosa da existência da transição de fase da matéria nuclear e a estrutura do seu diagrama de fase mantinha-se obscura.

Após uma detalhada análise do SMM, verificamos que não resulta satisfatória a sua aplicação à fragmentação da matéria estranha no cenário da colisão de duas estrelas estranhas, pois as temperaturas envolvidas são muito baixas. Desta forma, a energia de excitação por unidade de número bariônico $\left(E_{\text {exc }} / A\right)$ não seria grande o suficiente para a ocorrência do break-up e as hipóteses envolvidas na formulação do modelo não seriam válidas (equilíbrios térmico, dinâmico e químico).

Tendo em vista que as energias envolvidas na fragmentação da matéria estranha no cenário de explosão de supernovas são uma ou duas ordens de grandeza acima daquela esperada para a colisão de estrelas estranhas, decidimos aplicar o modelo de multifragmentação estatística a este problema, até agora pouco explorado em comparação à colisão de binárias.

Baseamos nossa análise numa versão simplificada do SMM apresentado por Bugaev e colaboradores [120], na qual o sistema é estudado no ensemble grande canônico e que produz soluções analíticas quando levado ao limite termodinâmico.

O espectro de fragmentação, $P_{g}$, pode ser obtido (considerando-se equilíbrio químico entre o bulk e os fragmentos de massa $A$ ) através da derivação da pressão do gás, $p_{g}$, em relação ao 

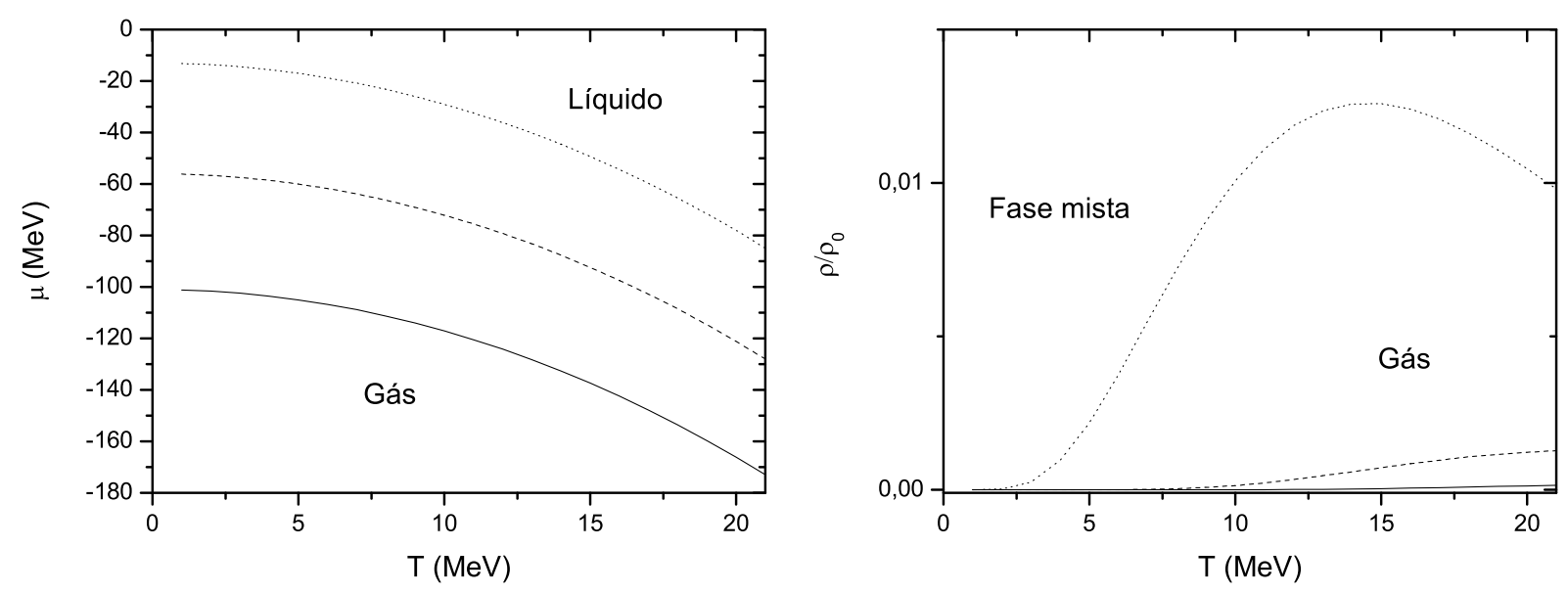

Figura A.1: Exemplo do diagrama de fases da matéria estranha nos planos $T \times \rho$ (à esquerda) e $T \times \mu$ (à direita) no modelo de multifragmentação estatística. As curvas são para $m_{s}=0$ (linha cheia), $m_{s}=150 \mathrm{MeV}$ (linha tracejada) e $m_{s}=300 \mathrm{MeV}$ (linha pontilhada). A fase líquida é representada por densidades acima de $(2-3) \rho_{0}$.

potencial químico dos fragmentos, $\mu_{a}$,

$$
\mathcal{P}_{g}(A)=\frac{\partial}{\partial \mu_{A}} p_{g}=\left(\frac{m_{0} T}{2 \pi}\right)^{3 / 2} A^{3 / 2} e^{\left[\left(\mu+W-b p_{g}\right) A-\sigma A^{2 / 3}-C A^{1 / 3}\right] / T},
$$

sendo $W, \sigma$ e $C$ a energia interna livre em bulk, de superfície e curvatura, respectivamente, do fragmento caracterizado por $A$, e $M=m_{0} A$ é a massa de repouso da strangelet. Em primeira aproximação, $m_{0}$ foi tomado como $930 \mathrm{MeV}$. O termo $b$ representa a interação de repulsão na aproximação de Van der Waals, $T$ é a temperatura do sistema e $\mu$, seu potencial químico.

Com as ferramentas do formalismo, construímos o diagrama de fases e derivamos o número atômico para o qual a distribuição de fragmentos atinge o seu máximo no estado de fase mista (consideramos que os fragmentos interagem muito fracamente após a fragmentação inicial). Os resultados encontrados estão muito longe daqueles esperados por mostrarem strangelets com valores de $A$ que são (formalmente) muito menores que 1. Ainda que se utilizem parametrizações mais completas, como as obtidas para a dependência das energias de superfície e curvatura com o número bariônico apresentadas no capítulo 2 , os valores continuam muito abaixo de $A=1$.

Alguns motivos poderiam ter causado a inconsistência verificada durante os cálculos de fragmentação. Este modelo pode não considerar um tratamento quântico adequado à matéria de quarks podendo levar a uma análise inadequada da transição de fase da matéria estranha. Outro 


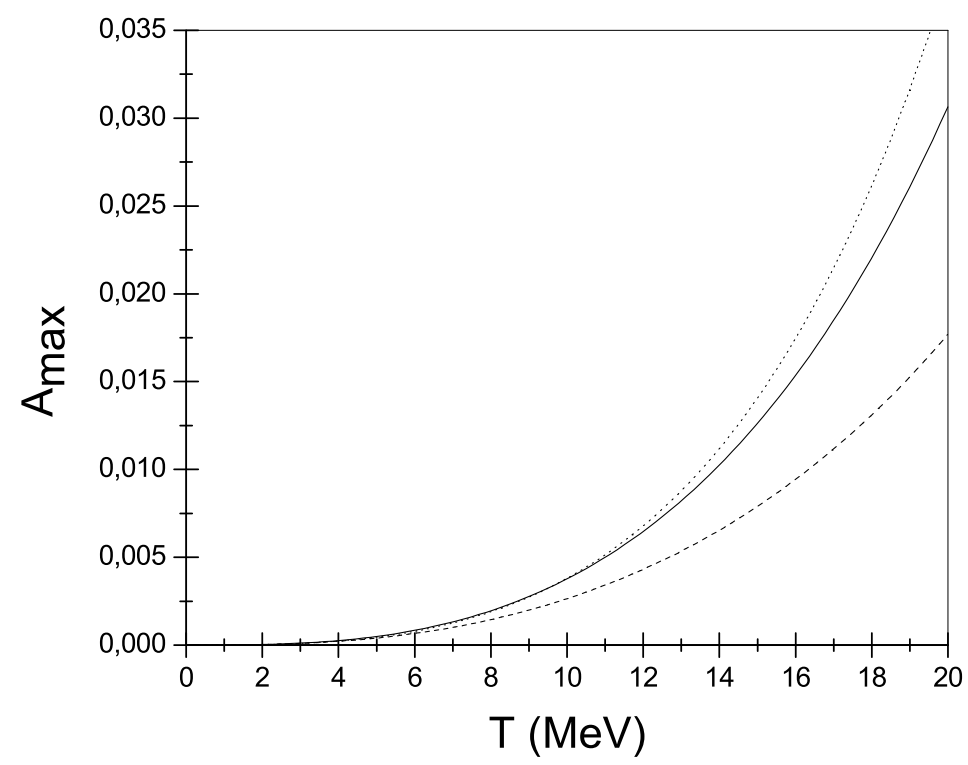

Figura A.2: Número bariônico no qual a função de distribuição de fragmentos alcança o máximo na fase mista para $m_{s}=50$ (linha cheia), $m_{s}=150 \mathrm{MeV}$ (linha tracejada) e $m_{s}=300 \mathrm{MeV}$ (linha pontilhada) para a matéria CFL com $\Delta=100 \mathrm{MeV}$.

ponto é se de fato existe equilíbrio químico entre as fases de matéria em bulk e strangelets durante todo o processo de expansão e esfriamento. Em resumo, estes resultados poderiam indicar ou que este formalismo não é válido para a análise da fragmentação da matéria estranha ou que o modelo necessita de adaptações apropriadas ao tratamento de um plasma de quarks e gluons. Esta inconsistência também poderia ser interpretada como a ausência de fragmentação da SQM em bulk sob expansão livre, um ponto que merece ser explorado em mais detalhes.

Desta forma, para tentar aferir a validade do formalismo, ainda com base no SMM, decidimos verificar se um tratamento mais adequado da influência da pressão da sacola $B$, com sua introdução direta na pressão da SQM na fase líquida, poderia resultar numa melhor aplicabilidade do modelo. Este termo de pressão do vácuo é naturalmente ausente quando se considera a fragmentação da matéria nuclear, já que ele não influi na consideração física (o modelo de sacola quando utilizado para estudar-se a matéria nuclear tem como objetivo determinar parâmetros relevantes à análise e que, portanto, já incorporam a influência do vácuo). No entanto, é possível visualizar a fragmentação da matéria estranha como um processo no qual a energia do vácuo é aproveitada para dotar strangelets de energia de superfície e curvatura, entre outros efeitos resultantes de um tamanho finito. 
Pela definição de pressão no ensemble grande canônico

$$
p(T, \mu)=T \lim _{V \rightarrow \infty} \frac{\ln \mathcal{Z}(V, T, \mu)}{V},
$$

onde $\mathcal{Z}$ é a transformada de Laplace da função de partição grande canônica. As pressões nas duas fases são obtidas a partir das singularidades da função de partição isobárica.

As pressões nas fases gasosa e líquida são dadas por

$$
\begin{aligned}
& p_{g}(T, \mu)=T\left(\frac{m T}{2 \pi}\right)^{3 / 2}\left\{z_{1} e^{\frac{\mu-b p_{g}}{T}}+\sum_{A=2}^{\infty} A^{3 / 2} e^{\left[\left(\nu-b p_{g}\right) A-\sigma A^{2 / 3}-C A^{1 / 3}\right] / T}\right\} \\
& p_{l}(T, \mu)=\frac{\nu}{b}-B
\end{aligned}
$$

onde $\nu=\mu+W$ é o potencial químico (deslocado) e $W$ é a energia interna livre volumétrica por unidade de número bariônico, $W=W_{0}+B v$. Nota-se que a pressão do gás é dada por uma equação transcendental.

A energia interna livre volumétrica também não deve ser a mesma nas duas fases, devido a sua dependência com o volume próprio associado a cada sistema:

$$
\begin{gathered}
W_{l}=W_{0}+B v_{l i q}, \\
W_{g}=W_{0}+B v_{\text {gas }} .
\end{gathered}
$$

Tomamos $b$ como o volume próprio da strangelet $(b=v=V / A)$.

A densidade de fragmentos com número bariônico $A$ é dada pela equação A.1. O argumento do termo exponencial da distribuição de massa $\left[\left(\nu-b p_{g}\right) A\right]$ fica, na fase de coexistência, onde $p_{g}=p_{l}$,

$$
\begin{aligned}
{\left[\nu-b p_{g}^{*}\right] A } & =\left[\mu_{g}+W_{g}-\nu_{l}^{*}+B b\right] A=\left[\mu_{g}+W_{g}-\mu_{l}-W_{l}+B b\right] A \\
& =\left[B\left(v_{\text {gas }}-v_{l i q}\right)+B b\right] A,
\end{aligned}
$$


onde $v$ é o volume por unidade de número bariônico.

Parametrizamos o volume excluído $b$ de modo que esta contribuição possa ser "absorvida" como uma contribuição efetiva à energia de curvatura,

$$
b=K_{1} A^{-2 / 3}+K_{2} A^{-1}
$$

com os valores obtidos a partir dos cálculos apresentados no capítulo 2 para strangelets sem emparelhamento de $K_{1}=4.7 \times 10^{-7} \mathrm{MeV}^{-3}$ e $K_{2}=2.03 \times 10^{-6} \mathrm{MeV}^{-3}$ e para strangelets CFL, $K_{1}=5.4 \times 10^{-7} \mathrm{MeV}^{-3}$ e $K_{2}=1.75 \times 10^{-6} \mathrm{MeV}^{-3}$.

Assim, a função de distribuição fica

$$
\mathcal{P}_{g}(A) \propto A^{3 / 2} e^{\left[B A\left(v_{g}-v_{l}\right)+B K_{2}-\sigma A^{2 / 3}-C_{e f f} A^{1 / 3}\right] / T},
$$

onde $C_{\text {eff }}=C-K_{1} B$.

A função de distribuição de massa apresenta, neste caso, dois picos cujas posições dependem da temperatura na qual o sistema fragmenta: um pico para valores baixos de $A(A<1 \mathrm{e}$ $A \lesssim 100$ para NSQM e CFL, respectivamente) e que não é relevante estatisticamente dado que sua intensidade é uma fração mínima do segundo, e outro para valores um pouco mais elevados (de algumas dezenas ou centenas em número bariônico).

Conforme já previsto, a menor energia de superfície e curvatura para strangelets CFL em comparação com a SQM sem emparelhamento, favorece a fragmentação desse sistema em valores mais elevados de $A$ (ver figura A.4). No entanto, este procedimento contém uma inconsistência devido às diferentes parametrizações do volume próprio que são utilizadas em $b$ e $v_{\text {strangelet }}$ (fases líquida e gasosa). Este resultado deve ser, portanto, visto como uma tendência dos dados a ser confirmada por outro(s) método(s).

Estudos anteriores indicam que a SQM deve se fragmentar em grandes pedaços de matéria [53], comparáveis a massas de asteróides. O argumento é que, contrariamente ao caso da matéria nuclear, a energia por número bariônico decresce sempre com $A$ para a matéria es- 


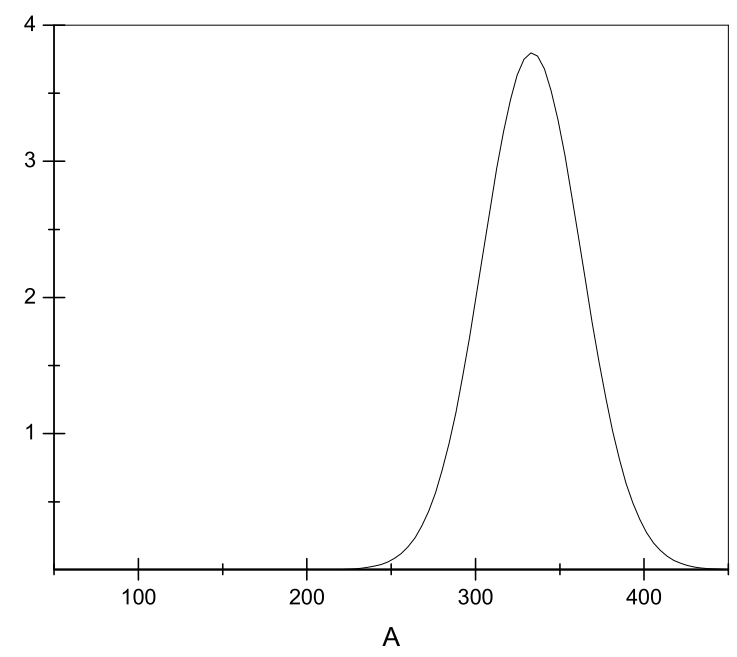

Figura A.3: Exemplo do pico relevante da função de distribuição para o modelo de mutifragmentação estatística com introdução explícita da pressão devido à constante de sacola $B$. Escala em valores arbitrários no eixo das ordenadas.
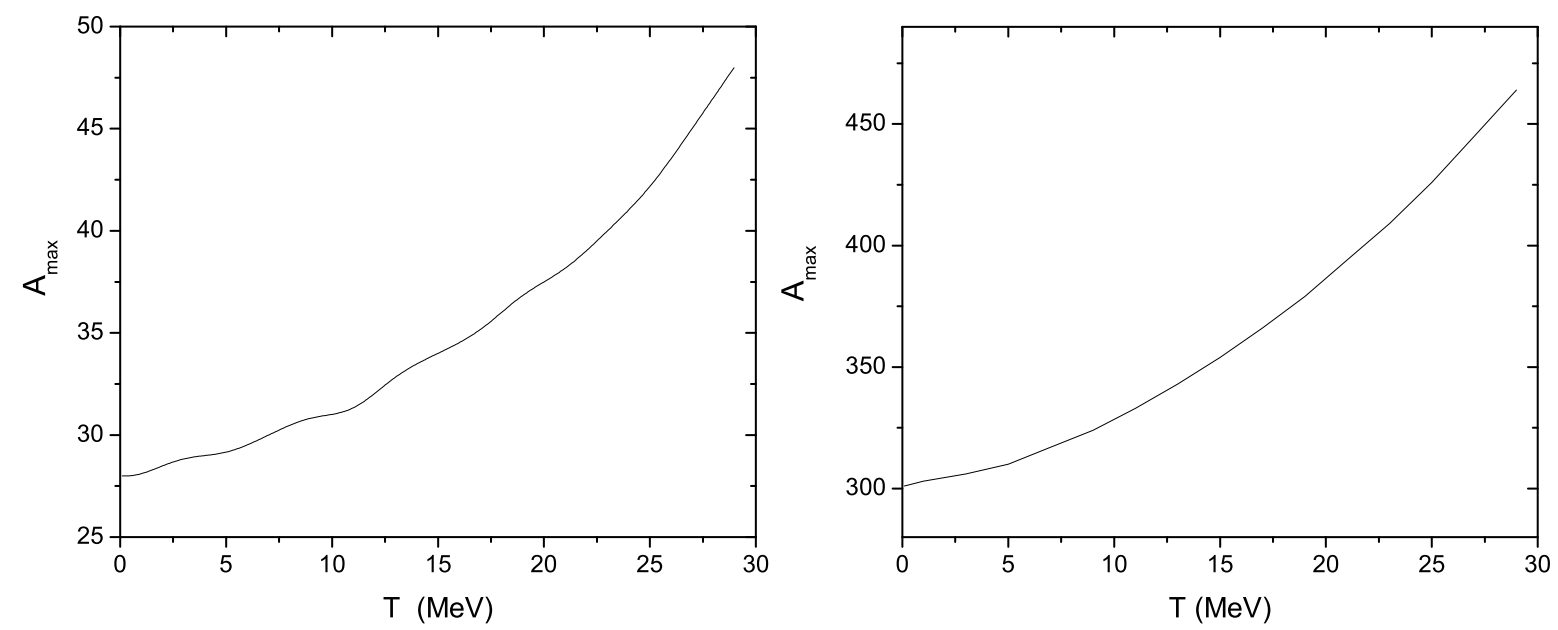

Figura A.4: Número atômico para o qual a função de distribuição dos fragmentos atinge seu máximo na fase mista para $m_{s}=150 \mathrm{MeV}$ como função da temperatura. A parametrização de $b$ foi feita de modo a contribuir para uma energia de curvatura efetiva (ver texto para maiores detalhes) devido à introdução explícita da constante de sacola na pressão da fase líquida. À esquerda, cálculo feito para strangelets sem emparelhamento e à direita, para strangelets CFL com $\Delta=100 \mathrm{MeV}$. 
tranha (veja figuras 2.3 e 2.4). Isto indica que é necessária a introdução externa de uma grande quantidade de energia para provocar a quebra de uma strangelet em dois fragmentos de massa menores, como visto nas análises de fissão apresentadas no capítulo 3 e 4 . É possível que o modelo estatístico não seja mesmo adequado ao estudo da fragmentação da matéria em um número pequeno de fragmentos, invalidando, assim a análise no ensemble grande canônico.

\section{A.2 Minimização da informação}

Um outro método para a análise da fragmentação da matéria estranha foi estudado como uma tentativa de obter-se maiores detalhes deste processo e o motivo da aparente falha da utilização do modelo de multifragmentação estatística.

O método utilizado por nós a seguir foi adaptado de uma proposta de Aichelin \& Huefner [121].

Seja a "informação" (entropia de Shannon) definida como

$$
I=\sum P(A, N) \ln P(A, N)
$$

onde $\mathrm{P}(\mathrm{A}, \mathrm{N})$ é a probabilidade (normalizada) do sistema emitir $N$ clusters de $A$ nucleons.

Para que haja conservação do número bariônico do sistema,

$$
\sum_{N, A} N P(N, A) A=A_{B}
$$

e da energia,

$$
\sum_{N, \epsilon_{A}} A P(N, A) \epsilon_{A} N=f \epsilon_{B} A_{B}
$$

onde $\epsilon_{A}$ é a energia total de um fragmento de número bariônico $A, \epsilon_{B}$ é a energia por unidade de número bariônico em bulk, $A_{B}$ é o número bariônico inicial da matéria que irá fragmentar-se e $f$ é a fração da energia associada ao neutrinos (que supomos escapam do sistema). 
Maximizando $I$ através da introdução de multiplicadores de Lagrange ( $D$ e $F$ ), o máximo aparece para

$$
P(A, N)=C^{\prime} e^{-N\left[D A+F A \epsilon_{A}\right]}
$$

$\operatorname{com} C^{\prime}(A)=1-\exp \left\{-\left[D A+F \epsilon_{A} A\right]\right\}$.

Através do sistema de equações dado pelas expressões (A.8) e (A.9) para conservação da carga e energia, pode se determinar $D$ e $F$. Foram substituídas as somas por integrais e, após extensa manipulação das expressões com aproximações nas integrais quando necessário pela falta de primitivas, análises preliminares deste sistema indicam que pode haver uma instabilidade numérica quando da resolução do mesmo, impossibilitando, assim, a avaliação do processo de fragmentação.

\section{A.3 Construção do diagrama de fases pelo critério de Gibbs}

Uma terceira abordagem para obter-se a distribuição de fragmentos foi a de construir o diagrama de fases obedecendo os critérios de Gibbs:

$$
\begin{aligned}
& T_{g a s}=T_{l i q}, \\
& \mu_{\text {gas }}=\mu_{l i q}, \\
& P_{\text {gas }}=P_{l i q} .
\end{aligned}
$$

A partir destas condições, é possível obter o ponto $(T, \mu)$ de coexistência e, derivando-se a pressão do gás em relação ao potencial químico do fragmento de massa $A$, caracterizar o espectro de fragmentação da matéria.

Verificamos que o gás de Boltzmann não é adequado à análise pois as temperaturas envolvidas na fragmentação da matéria estranha são muito baixas. Assim, recorremos a modelos válidos para temperaturas pequenas, tal como o modelo de esferas rígidas como aproximação para o conjunto de strangelets.

Para o sólido de esferas rígidas clássico [122], a equação de estado pode ser escrita como 


$$
\frac{P V}{R T}=\frac{3}{1-\rho \sigma^{3} / \sqrt{2}}
$$

onde $\rho=N_{A} / V, N_{A}$ o número de Avogadro, $V$ o volume molar, $\sigma$ o diâmetro da esfera rígida, $T$ a temperatura e $R$ a constante dos gases.

O modelo de sólido de esferas rígidas fornece a densidade de close packing ${ }^{*}, \eta_{C P}$, correspondente ao ponto no qual a expressão (A.11) diverge. Para núcleos ordinários esta corresponde a algumas vezes a densidade de saturação nuclear, $n_{0}$. No entanto, para strangelets de alta massa, $\eta_{c p}$ é pelo menos uma ordem de grandeza menor que $n_{0}$, ou seja, muito menor que a densidade na qual se deve atingir o ponto de instabilidade mecânica para a matéria estranha, que deve ser de $4 B$. O valor da densidade de close packing diminui com o aumento do diâmetro da esfera rígida, gerando a diferença entre os resultados para núcleos ordinários e strangelets de alta massa.

A descrição de strangelets é feita através do equilíbrio da pressão interna devido aos quarks com a pressão externa do modelo fenomenológico de sacolas, $B$. Para a transição da fase líquida para strangelets, se esta pode ser descrita por um close-packing, a pressão externa a que estariam submetidas estas partículas seria bastante alta, possivelmente justificando a alteração de alguns parâmetros que as caracterizam, especialmente do raio, o que afetaria diretamente as condições para que sejam feitos os cálculos.

Em resumo, as tentativas efetuadas por nós em obter o espectro de fragmentação da matéria estranha mostraram-se ambíguas e/ou inconclusivas. Se a transição é tal que se podem utilizar formalismos no ensemble grande canônico cujas soluções são levadas ao limite termodinâmico (ou se seria necessário o sorteio direto, microcanônico, de todos os canais de decaimento) ou se a transição pode ocorrer fora do equilíbrio (e, portanto, não poderiam ser aplicadas as condições de Gibbs) são ainda problemas em aberto. Este é um assunto importante que deve ser estudado mais a fundo para que se possam fazer previsões mais confiáveis para o possível fluxo de strangelets em meio aos primários de raios cósmicos, em especial porque devem prescrever o espec-

* O chamado close packing corresponde ao arranjo de infinitas esferas de modo que estas ocupem a maior fração possível de um volume tridimensional, ou seja, a configuração que permite a maior densidade média. 
tro de injeção para o caso dos eventos de supernovas, se de fato a hipótese de explosão devido à formação de matéria estranha no interior de estrelas massivas em colapso se mostrar compatível com simulações e futuras observações destes fenômenos. O espectro de injeção para o caso de coalescência num sistema de duas estrelas estranhas é muito mais complexo, devido à presença de choque e efeitos de turbulência que são difíceis de modelar. 


\section{Apêndice B}

\section{Análise do evento AMS-01: contínuo versus modelo de camadas}

Medidas coletadas pelo experimento AMS-01, um espectrômetro de massa a bordo da nave Discovery em um vôo em 1998, reportaram, entre aproximadamente quatro milhões de núcleos de hélio medidos, uma partícula com energia cinética de $2,1 \mathrm{GeV}$, relação carga-massa bastante reduzida, $Z / A=0,114 \pm 0,01$, e fluxo estimado de $5 \times 10^{-5}\left(\mathrm{~m}^{2} \mathrm{sr} \mathrm{s}\right)^{-1}$. Assim, este evento apresenta-se naturalmente como um candidato para a detecção de uma strangelet. Revisitamos aqui o problema de identificação deste exótico e apontamos que esta pode ser complicada pelos importantes efeitos de camada para strangelets de baixo número bariônico. Desta forma, uma avaliação mais cuidadosa das cargas e massas é necessária para associar este evento a uma origem exótica.

\section{B.1 Efeitos de camada}

A análise de strangelets com baixo número bariônico utilizando-se do modelo de gás de Fermi não é adequada. Nestes casos, o ideal é popular explicitamente os orbitais de quarks em uma sacola esférica.

Efeitos de camada devem ser importantes pois, quando se preenche uma sacola com quarks, a energia por número bariônico em função de $A$ muda substancialmente quando se tem uma camada fechada e leva a uma maior estabilidade do sistema, do mesmo modo como este efeito 
é observado em sistemas nucleares.

O procedimento adotado é como descrito a seguir: os níveis da sacola são primeiramente preenchidos com os quarks de massa nula menos energéticos. Estas partículas leves são adicionadas até que o nível de Fermi seja elevado o suficiente para seja energeticamente favorável a adição de quarks massivos. No entanto, com o aumento de quarks strange no sistema, chega-se ao ponto em que é favorável novamente a adição de quarks não strange à sacola. Este processo se repete até que todos os quarks tenham sido acomodados em camadas.

É interessante notar que não é obrigatório que os níveis de quarks strange e não strange sejam preenchidos alternadamente. Os níveis do quark $s$ são preenchidos em um ritmo diferente com a variação do raio daquele dos quarks leves, justamente devido a sua massa finita. Os níveis de energia podem "cruzar-se" e os níveis de quarks strange que estavam preenchidos podem ser esvaziados em favor de quarks sem massa.

Também é esperado que a cada camada fechada seja observada uma grande mudança na energia de ligação das strangelets, gerando uma região de estabilidade muito mais pronunciada quando comparada aos cálculos de contínuo e mesmo em comparação com o preenchimento de camadas para números bariônicos próximos (mínimo local). Claramente, estas regiões dependem do potencial ao qual os quarks encontram-se confinados, portanto, do modelo adotado e dos parâmetros que o caracterizam.

A carga atômica de strangelets de baixo número bariônico é uma característica importante a ser determinada para as procuras experimentais destes exóticos. Em bulk, espera-se que a matéria estranha possua um número aproximadamente igual de quarks $u, d$ e $s$. Já as cargas para strangelets pequenas devem ser determinadas por quais camadas de quarks encontram-se preenchidas, totalmente ou não. Deste modo, o procedimento de preenchimento de camadas torna a relação entre $Z$ e $A$ bastante complexa.

No trabalho de Farhi e Jaffe [15], considera-se uma Hamiltoniana incluindo as energias cinéticas dos quarks, a energia da sacola, uma energia de ponto zero fenomenológica do tipo $-Z_{0} / R$, onde $R$ é o raio da strangelet, e não são consideradas correções de ordem $\alpha_{c}$. Para sistemas com baixo número bariônico, $A \leq 6$, não é prevista a estabilidade da matéria estranha *.

\footnotetext{
*Uma possível exceção é o dihiperon, $\operatorname{com} A=S=2$.
} 
Já para strangelets de número bariônico maior que seis, cada auto-estado pode ser preenchido com $3(2 j+1)$ quarks, para cada sabor de quarks, sendo $j$ o momento angular do modo correspondente. Estes cálculos ignoraram efeitos devidos à energia Coulombiana, já que esta é pequena em strangelets. A energia total é minimizada para um $A$ fixo sujeito ao vínculo $3 A=N_{u}+N_{d}+N_{s}$, onde $N_{i}$ é o número de cada quark $i$. Os orbitais incluídos nos cálculos foram $1 s_{1 / 2}, 1 p_{3 / 2}, 1 p_{1 / 2}, 1 d_{5 / 2}, 1 d_{3 / 2}, 2 s_{1 / 2}, 1 f_{7 / 2}, 1 f_{5 / 2}, 1 g_{9 / 2}, 2 p_{3 / 2}$ e $2 p_{1 / 2}$. Para $m_{s}=150$ $\mathrm{MeV}, B^{1 / 4}=150 \mathrm{MeV}$ e $Z_{0}=2,0$, a energia por número bariônico em bulk é de $903 \mathrm{MeV}$ e a strangelet é estável apenas para $A \gtrsim 70$.

Gilson e Jaffe [16] também estudaram pequenas strangelets, modelando-as como um gás de férmions não-interagentes confinados a uma sacola. Os autovalores para a energia foram determinados preenchendo-se os níveis da sacola em seqüência, levando em conta o princípio de exclusão de Pauli. A energia para cada $A$ foi minimizada e o raio da sacola ajustado de modo que a pressão $B$ fosse balanceada pela pressão dos quarks. Foi introduzida uma energia de ponto zero fenomenológica $(-1,84 / R)$ e ignoradas as correções de Coulomb e de ordem $\alpha_{c}$.

Neste estudo foram determinadas regiões de número bariônico nas quais strangelets são meta-estáveis ainda que os parâmetros escolhidos levem à não estabilidade da matéria estranha em bulk. Portanto, strangelets absolutamente estáveis não foram possíveis dentro do espaço de parâmetros estudado e com as suposições feitas para o modelo. Camadas fechadas foram determinadas para $A=6,14,18,22 \ldots$, correspondentes a uma camada fechada estranha $s_{1 / 2}$, uma não estranha $p_{3 / 2}$, uma não estranha $p_{1 / 2}$ e uma estranha $p_{3 / 2}$, respectivamente. Foram determinadas "ilhas de meta-estabilidade" contra o decaimento por emissão de bárions para valores $930<\epsilon<1000 \mathrm{MeV}$, onde $\epsilon$ é o valor assintótico da energia por número bariônico da matéria estranha, com $m_{s}=150 \mathrm{MeV}$. Os valores obtidos para a relação $Z / A$ para $A<100$ são relativamente baixas, o preenchimento de camadas podendo inclusive alterar o sinal da carga com o aumento de $A$.

Madsen [78] derivou resultados de maneira similar àqueles de Gilson e Jaffe, sem a inclusão da correção de ponto zero. O comportamento da curva de energia por número bariônico (mostrado na figura B.1) é bem ajustado pelo modelo de gota líquida com contribuições volumétrica, de superfície e curvatura. No entanto, quanto menor o número atômico da strangelet, mais diferenças podem ser notadas. 


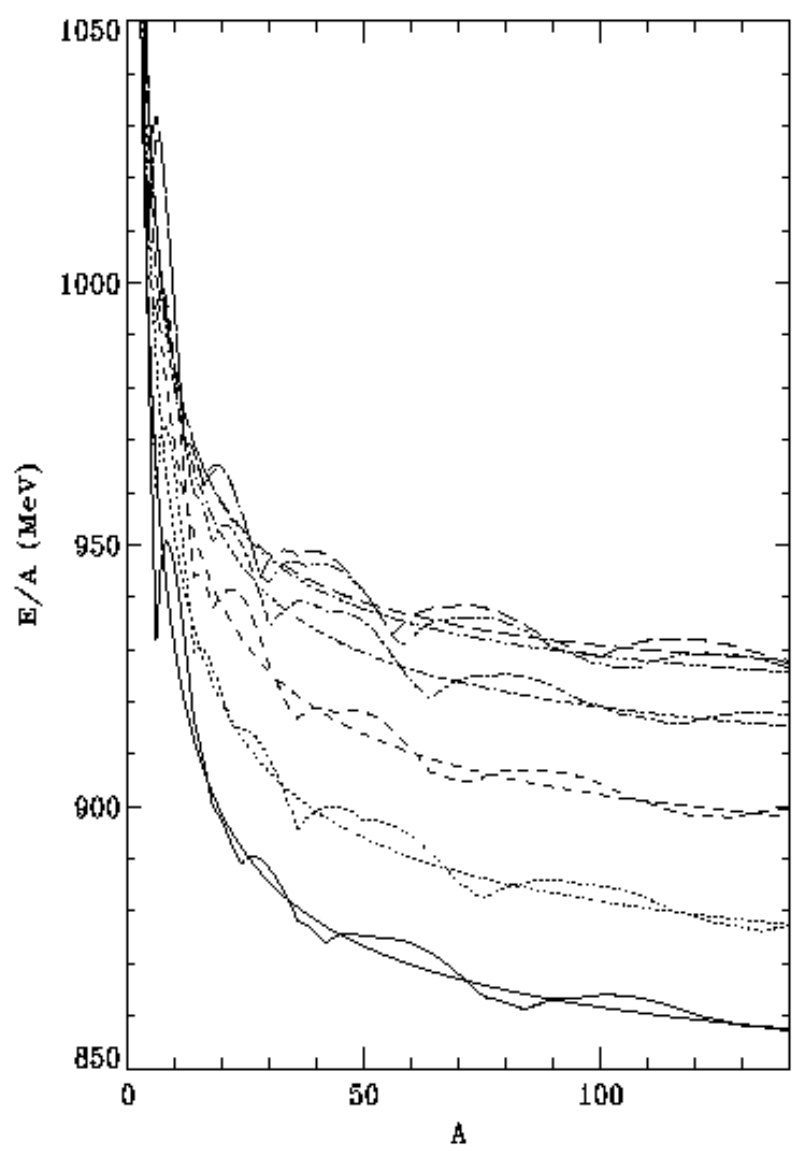

Figura B.1: Energia por número bariônico para strangelets com $B^{1 / 4}=145 \mathrm{MeV}$. Os pares de curvas com o mesmo tipo de linha comparam os modelos de camada e de gota líquida para o mesmo valor de $m_{s}$ variando entre 50 a $300 \mathrm{MeV}$, em passos de $50 \mathrm{MeV}$ (de baixo para cima). Para valores maiores de massa do quark strange, não há quarks $s$ e os resultados parecem com aqueles para $m_{s}=300 \mathrm{MeV}$. Figura reproduzida da referência [78]. 


\section{B.2 O evento AMS-01 como strangelet}

A detecção de uma partícula com $Z=2$ e relação carga-massa inferida extremamente baixa pelo experimento AMS-01 foi apresentada e discutida em [12]. Com energia cinética total de 2,1 GeV e coletado entre aproximadamente quatro milhões de núcleos de hélio, apresentou $Z / A=0,114 \pm 0,01$, sendo esta relação claramente muito menor do que esperado para núcleos ordinários.

Um conjunto de possíveis razões para uma falha de interpretação deste evento tendo, pois, origem em um núcleo comum foi analisada e descartada pela colaboração responsável pelo experimento como improvável, apesar de um único evento sempre deixar margem a dúvidas. Se o evento reportado de fato representar a realidade, certamente aparece a necessidade de uma explicação não convencional. Uma das mais promissoras, é que esta partícula com $Z=2$ não é um núcleo ordinário mas sim uma strangelet.

A carga elétrica esperada para strangelets é de

$$
\begin{aligned}
& \frac{Z}{A}=0,12\left(\frac{m_{s}}{150 M e V}\right)^{2} \\
& \frac{Z}{A}=0,3\left(\frac{m_{s}}{150 M e V}\right)^{2} \times A^{-1 / 3}
\end{aligned}
$$

para strangelets sem emparelhamento de quarks com baixo número bariônico e CFL, com $\Delta=100 \mathrm{MeV}$, respectivamente [88, 90]. Uma análise preliminar baseada unicamente na comparação destas estimativas para a relação carga-massa com o valor experimental obtido no evento mostra-se compatível com uma strangelet com ou sem emparelhamento de quarks com número bariônico no intervalo [16, 19]. Isto permite impor limites diretos à massa do quark strange que podem ser obtidos em conjunto com o valor da constante de sacola, e/ou outros parâmetros associados aos modelos de análise. Assim, seriam obtidos ajustes que parecem bastante satisfatórios às considerações envolvidas.

No entanto, antes de aceitar esta explicação, devemos analisar com cuidado as premissas a partir das quais as expressões B.1 e B.2 são obtidas.

Na sua versão menos complexa, a matéria estranha não apresenta emparelhamento de quarks 
e a carga elétrica é determinada através do cálculo das abundâncias de equilíbrio para os quarks, conforme detalhado no capítulo 2. Devido à supressão de quarks strange perto da superfície por conta de sua massa finita e muito maior que a dos quarks $u$ e $d$, a carga elétrica resultante é muito menor do que aquela observada em núcleos ordinários para o mesmo número bariônico. Strangelets de baixo $A$ devem encontrar-se cercadas por uma nuvem eletrônica, em contraste com o bulk, no qual os elétrons encontram-se misturados aos quarks.

Por outro lado, o estado CFL não permite o aparecimento de elétrons em bulk já que a interação força o emparelhamento de partículas com momento de Fermi iguais igualando, assim, as abundâncias de quarks, apesar da maior massa do quark strange (mas desde que esta não seja muito grande [123]). Mais uma vez, efeitos de superfície irão diminuir a densidade de quarks strange, levando a uma pequena carga elétrica para strangelets.

A primeira observação relevante para a análise do evento reportado pelo AMS-01 é ressaltar que as expressões B.1 e B.2 são limites para pequenos números bariônicos de um cenário contínuo. Estas expressões são extrapolações obtidas de um limite termodinâmico em bulk. Assim, o limite para números bariônicos cada vez menores deve ser tomado com cuidado e não são garantidos para o intervalo estimado a partir da relação carga-massa inferida para este evento. A maioria das investigações de estabilidade de matéria estranha que utilizam as expressões derivadas desses limites em bulk indicam que, pelo menos quando não há emparelhamento de quarks, estes valores de $A$ não devem ser estáveis.

De fato, strangelets com baixo número bariônico são melhor representadas quando se faz um estudo de um problema de poucos corpos (férmions numa cavidade esférica [124]), preenchendose os níveis de energia explicitamente $[65,16]$. Desta forma, mostrou-se que a densidade de estados vai de modo suave a um limite contínuo que é bem representada pela expansão assintótica que inclui os termos de volume, superfície e curvatura.

É a existência de uma estrutura de camadas que complica a identificação desta partícula com número atômico 2. Esta indica que $A=18$ seria o valor mais provável para o número bariônico pelas razões apontadas abaixo.

Considerando a matéria estranha sem emparelhamento de quarks, a estrutura de camadas indica que $A=18$ seria um mínimo local da energia pois neste modelo isto corresponde a uma camada fechada $p_{1 / 2}$ não-estranha. Neste caso, a carga elétrica é fixa pelo preenchimento das 
camadas e corresponde a $Z=6$. Como o nível de preenchimento é uma função da interação auto-consistente na cavidade, e outras interações que violam a simetria de isospin devem ser consideradas, esta predição de carga é válida apenas para o modelo mais simples. No entanto, esta é bastante diferente do contínuo (extrapolação para baixos valores de $A$ ) dada em B.1 e deve ser levada em conta devido à similaridade com o comportamento dos estados nucleares.

A situação é mais complexa para o caso CFL. Não há cálculos disponíveis para um estado de poucos corpos com $A=18$. O processo de preenchimento das camadas deve levar em consideração as interações não-perturbativas desde o princípio para que se possa determinar o nível de preenchimento. No entanto, a predição mais ingênua seria considerar iguais números de quarks $u, d$ e $s$, similarmente ao encontrado no limite em bulk, devido à própria natureza do estado CFL (veja uma discussão mais extensa em [19]). O que é importante aqui é que, se este é o caso, este estado pode ser inclusive neutro e, portanto, muito diferente da predição encontrada em B.2. Nota-se que os argumentos sobre a abundância de quarks perto da superfície de strangelets CFL utilizados para explicar uma carga elétrica não-nula na equação B.2, não devem ser aplicados para um sistema de poucos corpos, como aquele reportado pelo AMS-01, sem riscos, já que este comportamento é uma extrapolação do cenário contínuo. No entanto, o preenchimento explícito das camadas deve naturalmente incorporar tais efeitos. Por estas razões, e devido à falta de uma resposta baseada em cálculos mais detalhados, $A=18$ pode ser uma alternativa natural para interpretar-se o evento AMS-01. No entanto, a carga elétrica desta partícula ainda é motivo para dúvidas.

Uma última consideração que deve ser feita, é que não se espera que sistemas tão leves quanto o considerado aqui sejam estáveis pela extrapolação de bulk para modelos de strangelets. Um mínimo em massa tem sido discutido por anos, e se espera que strangelets menores do que este $A_{\min }$ sejam apenas objetos meta-estáveis (mínimo local). No entanto, um objeto metaestável seria uma causa muito improvável para o evento em questão, devendo ser este o resultado de uma interação ocorrida perto do local do experimento que produziu esta partícula. Se este evento de fato corresponde a uma strangelet, então isto indica que $A_{\min } \leq 18$ e que, portanto, importantes efeitos de camada que reduzem a massa total, certamente abaixo de $930 \mathrm{MeV} / \mathrm{A}$, estão presentes, talvez até para valores menores que o limite assintótico em bulk. Especulações desta natureza foram publicadas no passado $[125,126]$ e talvez uma reconsideração destas deve 
ser feita.

Efeitos de camadas são muito importantes para a determinação das características de strangelets, da mesma forma como são importantes para a matéria nuclear ordinária. Sabidamente, os desvios encontrados em comparação com a aproximação contínua devido aos efeitos de camada são mais pronunciados para baixo número bariônico. O comportamento da curva de energia calculada através do modelo de gota líquida é qualitativamente o mesmo dos cálculos de camada. No entanto, a energia destes sistemas é bastante afetada pelo efeito de camadas fechadas, sendo este, portanto, importante para o estudo de strangelets de baixo número atômico.

Apesar das dificuldades em modelar-se o preenchimento de camadas, os cálculos disponíveis e simples argumentos de simetria sugerem que as características derivadas para a descrição do evento AMS-01 discutido aqui não são garantidas pois modelos provenientes da extrapolação do contínuo podem ser enganosos quanto à composição e carga elétrica, entre outros parâmetros para strangelets.

Em outras palavras, apesar da aparente concordância das relações carga-massa B.1 e B.2 com o evento reportado, estas sabidamente não consideram os importantes efeitos de camada. Os modelos discretos mais simples prevêem que, na verdade, o evento AMS-01 deve ter uma carga muito maior no caso de matéria estranha sem emparelhamento de quarks e talvez carga elétrica nula para strangelets CFL. Em todo caso, e estando cientes da simplicidade destes modelos discretos, deve ser dada maior atenção a tratamentos mais completos de estados de poucos corpos antes que algo concreto possa ser dito a respeito de eventos como este. 


\section{Bibliografia}

[1] http://www.gsi.de/fair/experiments/CBM/1intro.html. Home page do experimento Compressed Baryonic Matter, GSI.

[2] K. Jansen. Int. J. Mod. Phys. E 16, 2638 (2007).

[3] S. L. Shapiro e S. A. Telkolsky. Black holes, white dwarfs and neutron stars. WilleyInterscience, New York, (1983).

[4] C. Alcock, E. Farhi e A. Olinto. Phys. Rev. Lett. 57, 2088 (1986).

[5] E. Witten. Phys. Rev. D 30, 272 (1984).

[6] A. Bodmer. Phys. Rev. D 4, 1601 (1971).

[7] S. A. Chin e A. Kerman. Phys. Rev. Lett. 43, 1292 (1979).

[8] H. Terazawa. Tokyo U. Report. , INS-336 (1979).

[9] M. Rybczynski, Z. Wlodarczyk e G. Wilk. Acta Phys. Polon. B33, 277 (2002).

[10] M. Rybczynski, Z. Wlodarczyk e G. Wilk. Int. J. Mod. Phys. A 20, 6724 (2005).

[11] T. Saito et al. Phys. Rev. Lett. 65, 2094 (1990).

[12] V. Choutko. In Proc. 28th Internat. Cosmic Ray Conf., Tsukuba, Japan, 1765. Universal Academic Press, Tokyo, (2003).

[13] A. Chodos, R. L. Jaffe, K. Johnson, C. B. Thorn e V. F. Weisskopf. Phys. Rev. D 9, 3471 (1974).

[14] http://th.physik.uni-frankfurt.de/ gerland/stoecker/ger/node16.html. 
[15] E. Farhi e L. Jaffe. Phys. Rev. D 30, 2379 (1984).

[16] E. P. Gilson e R. L. Jaffe. Phys. Rev. Lett. 71, 332 (1993).

[17] R. Rapp, T. Schaefer, E. V. Shuryak e M. Velkovsky. Ann. Phys. (N.Y.) 280, 35 (2000).

[18] M. G. Alford, K. Rajagopal, T. Schaefer e A. Schmitt. Color superconductivity in dense quark matter, arxiv:0709.4635.

[19] K. Rajagopal e F. Wilczeck. The condensed matter physics of QCD. At the frontier of particle physics/Handbook of QCD. World Scientific, (2001).

[20] M. Alford, K. Rajagopal e F. Wilczek. Nucl. Phys. B537, 433 (1999).

[21] G. Lugones e J. E. Horvath. Phys. Rev. D 66, 074017 (2002).

[22] M. Buballa. Phys. Rept. 407, 205 (2005).

[23] K. Rajagopal. Nuc. Phys. A 661, 150c (1999).

[24] F. Weber. Prog. Part. Nucl. Phys 54, 193 (2005).

[25] C. Alcock e E. Farhi. Phys. Rev. D 32, 1273 (1985).

[26] J. Madsen, H. Heiselberg e K. Riisager. Phys. Rev. D 34, 2947 (1986).

[27] C. Alcock e A. Olinto. Phys. Rev. D 39, 1233 (1989).

[28] M. L. Olesen e J. Madsen. Phys. Rev. D 47, 2313 (1993).

[29] G. Lugones e J. E. Horvath. Phys. Rev. D 69, 063509 (2004).

[30] P. Haensel, J. Zudnik e R. Schaeffer. Astron. Astrophys. 160, 121 (1986).

[31] O. G. Benvenuto, J. E. Horvath e H. Vucetich. Int. J. Mod. Phys. A 6, 4769 (1991).

[32] O. G. Benvenuto e J. E. Horvath. Phys. Rev. Lett. 63, 716 (1989).

[33] N. K. Glendenning e F. Weber. Astrophys. J. 400, 647 (1992).

[34] K. Rajagopal e F. Wilczek. Phys. Rev. Lett. 86, 3492 (2001). 
[35] W. Baade e F. Zwicky. Phys. Rev. 45, 138 (1934).

[36] J. R. Oppenheimer e G. M. Volkoff. Phys. Rev. 55, 374 (1939).

[37] F. Özel. Nature 441, 1115 (2006).

[38] M. Alford, D. Blaschke, A. Drago, T. Klahn, G. Pagliara e J. Schaffner-Bielich. Nature 445, E7 (2007).

[39] N. K. Glendenning. Compact stars, nuclear physics, particle physics, and general relativity. Springer-Verlag, New York, (2000).

[40] F. Weber. Pulsar as astrophysical laboratories for nuclear and particle physics. Cosmology and gravitation. IOP Publishing, Bristol, (1999).

[41] F. Weber. J. Phys. G: Nucl. Part. Phys. 25, R195 (1999).

[42] N. K. Glendenning. Phys. Rev. D 46, 1274 (1992).

[43] Ch. Kettner, F. Weber, M. K. Weigel e N. K. Glendenning. Phys. Rev. D 51, 1440 (1995).

[44] J. Madsen e J. M. Larsen. Phys. Rev. Lett. 90, 121102 (2003).

[45] J. Madsen. Lect. Notes in Physics 516, 162 (1999).

[46] N. K. Glendenning. Mod. Phys, Lett. A5, 2197 (1990).

[47] R. R. Caldwell e J. L. Friedman. Phys. Lett. 264B, 143 (1991).

[48] C. Alcock et al. Astrophys. J. 542, 281 (2000).

[49] V. Kalogera et al. Astrophys. J. Lett. 601, L179 (2004).

[50] W. H. Lee, W. Kluzniak e J. Nix. Acta Astronomica 51, 331 (2001).

[51] M. Prakash e J. M. Lattimer. J. Phys. G 30, S451 (2004).

[52] F. Limousin, D. Gondek-Rosinska e E. Gourgoulhon. Phys. Rev. D 71, 064012 (2005).

[53] J Madsen. J. Phys. G 28, 1737 (2002). 
[54] G. A. Medina-Tanco e J. E. Horvath. Astrophys. J. 464, 364 (1996).

[55] J. Madsen. Phys. Rev. D 71, 014026 (2005).

[56] http://ams.cern.ch. Home page do experimento Alpha Magnetic Spectrometer.

[57] A. Burrows, E. Livne andL. Dessart, C. D. Ott e J.Murphy. Ap. J. 640, 878 (2006).

[58] L. D. Landau e E. M. Lifshitz. Fluid Mechanics. Pergamon Press, (1959).

[59] O. G. Benvenuto, J. E. Horvath e H. Vucetich. Int. J. Mod. Phys. A 4, 257 (1989).

[60] O. G. Benvenuto e J. E. Horvath. Mod. Phys. Lett. A 4, 1085 (1989).

[61] M. G. Alford, K. Rajagopal, S. Reddy e A. W. Steiner. Phys. Rev. D 73, 114016 (2006).

[62] P. Jaikumar, S. Reddy e A. W. Steiner. Phys. Rev. Lett. 96, 041101 (2006).

[63] K.S. Cheng e V.V. Usov. Phys. Rev. D 74, 127303 (2006).

[64] E. Finch. J. Phys. G. 32, S251 (2006).

[65] C. Greiner, D.-H. Rischke, H. Stoecker e P. Koch. Phys. Rev. D 38, 2797 (1988).

[66] R. Klingenberg. J. Phys. G 27, 475 (2001).

[67] A. De Rujula e S L Glashow. Nature 312(5996), 734 (1984).

[68] M Bruegger et al. Nature 337(6206), 434 (1989).

[69] M. C. P. Isaac et al. Phys. Rev. Lett. 81, 2416 (1998). Erratum-ibid. 82, 2220 (1999).

[70] Z.-T. Lu et al. Nucl. Phys. A 754, 361 (2005).

[71] C. Lattes e K. Fujimoto. Phys. Repts. 65, 151 (1980).

[72] P. B. Price, E. K. Shirk, W. Z. Osborne e L. S. Pinsky. Phys. Rev. D 18, 1382 (1978).

[73] M. Ichimura et al. Nuovo Cimento A 36, 843 (1993).

[74] H. Wilczynski et al. In Proc. 24th Internat. Cosmic Ray Conf., Roma, Itália, 1. University of Rome, (1995). 
[75] S. B. Shaulov. APH N. S., Heavy Ion Physics 4, 403 (1996).

[76] J. E. Horvath e L. Paulucci. J. Phys. G 32, B13 (2006).

[77] J. Madsen e J. M. Larsen. Phys. Rev. Lett. 90, 121102 (2003).

[78] J. Madsen. Phys. Rev. D 50, 3328 (1994).

[79] Y. B. He, C. S. Gao, X. Q. Li e W. Q. Chao. Phys. Rev. C 53, 1903 (1996).

[80] M. Alford, K. Rajagopal, S. Reddy e F. Wilczek. Phys. Rev. D. 64, 074017 (2001).

[81] J. Bardeen, L. N. Cooper e J. R. Schrieffer. Physical Review 108(5), 1175 (1957).

[82] A. Schmitt, Q. Wang e D. H. Rischke. Phys. Rev. D 66, 114010 (2002).

[83] R. Balian e C. Bloch. Ann. Phys. 60, 401 (1970).

[84] T. H. Hansson e R. L. Jaffe. Ann. Phys. 151, 204 (1983).

[85] M. S. Berger e R. L. Jaffe. Phys. Rev. C 35, 213 (1987). 44, 566(E) (1991).

[86] R. Balian e C. Bloch. Ann. Phys. 64, 271 (1970).

[87] J. P. Bondorf, A. S. Botvina, A. S. Iljinov, I. N. Mishustin e K. Sneppen. Physics Reports 257, 133 (1995).

[88] H. Heiselberg. Phys. Rev. D 48, 1418 (1993).

[89] M. Alford. comunicação particular.

[90] J. Madsen. Phys. Rev. Lett. 87(17), 172003 (2001).

[91] H. S. Massey e E. H. S. Burhop. Electronic and Ionic Impact Phenomena. Oxford University Press, (1952).

[92] H. A. Bethe e E. E. Salpeter. Handbuch der Physik, volume 35. Springer-Verlag Berlin, (1957).

[93] N. Bohr. Kgl. Dansk. Vid. Selsk. 18, 8 (1948). 
[94] J. W. Wilson, L. W. Townsend e F. F. Badavi. Nucl. Instr. Meth. Phys. Res. B 18, 225 (1987).

[95] V. Koch e G. A. Miller. Phys. Rev. C 31, 602 (1985).

[96] R. Dymarz e T. Kohmura. Phys. Lett. 124B, 446 (1983).

[97] H. Vucetich e J. E. Horvath. Phys. Rev. D 57, 5959 (1998).

[98] F. Wu, R. Xu e B. Ma. J. Phys. G 33, 597 (2007).

[99] B. Banerjee, N. K. Glendenning e T. Matsui. Phys. Lett. B 127, 453 (1983).

[100] V. V. Usov. Astrophys. J. 550, L179 (2001).

[101] N. Iwamoto. Ann. Phys. 141, 1 (1982).

[102] J. E. Horvath, O. G. Benvenuto e H. Vucetich. Phys. Rev. D 44, 3797 (1991).

[103] D. Blaschke, T. Klahn e D. N. Voskresensky. Astrophys. Journal 533, 406 (2000).

[104] H. A. Bethe, G. E. Brown e J. Cooperstein. Nucl. Phys. A 462, 791 (1987).

[105] C. Stoermer. The polar aurora. Claredon Press, Oxford, (1955).

[106] E. Fermi. Nuclear Physics. U. Chicago Press, Chicago, (1950).

[107] D. F. Smart e M. A. Shea. Adv. Space Res. 14, 787 (1994).

[108] J. H. Adams, R. Silberberg e C. H. Tsao. Technical Report NRL Memorandum Report 4506, Naval Research Laboratory, Washington DC 20375-500, USA, (1981). Veja também por exemplo, [107].

[109] A. J. Tylka. In Proc. 23rd Internat. Cosmic Ray Conf., Calgary, Canada, volume 3, 436, (1993).

[110] M. Walt. Introduction to geomagnetically trapped radiation. Cambridge Press, (1994).

[111] C.-G. Falthammar. In Earth's Particles and Fields, 157-169. Ed.B.M. McCormac, Reinhold Book Co. (1968). 
[112] S. Biswas. Space Science Rev. 75, 423 (1996).

[113] V. V. Bobrovskaya et al. Cosmic Research 39, 98 (2001).

[114] J. B. Blake e L. M. Friesen. In Proc. 15th Internat. Cosmic Ray Conf., Plovdiv, Bulgaria, volume 2, 341, (1977).

[115] G. Wilk e Z. Wlodarczyk. J. Phys. G: Nucl. Part. Phys. 22, L105 (1996).

[116] S. Barnerjee et al. J. Phys. G: Nucl. Part. Phys. 25, L15 (1999). Veja também, S. Barnerjee et al., Phys. Rev. Lett. 85, 1384 (2000).

[117] J. D. Bjorken e L. McLerran. Phys. Rev. D 20, 2353 (1979).

[118] L. Paulucci, J. E. Horvath e G. A. Medina-Tanco. Phys. Rev. D 77, 043003 (2008).

[119] G. C. Jordan e B. S. Meyer. Astrophys. J. 617, L131 (2004).

[120] K. A. Bugaev, M. I. Gorenstein, I. N. Mishustin e W. Greiner. Phys. Rev. C 62(4), 44320 (2000).

[121] J. Aichelin e J. Huefner. Phys. Lett. B 136, 15 (1984).

[122] B. J. Yoon, M. S. Jhon e H. A. Scheraga. J. Chem. Phys. 96, 7005 (1992).

[123] K. Rajagopal e F. Wilczek. Phys. Rev. Lett. 86, 3492 (2001).

[124] T. A. DeGrand, R. L. Jaffe, K. Johnson e J. Kiskis. Phys. Rev. D 12, 2060 (1975).

[125] F. C. Michel. Astrophys. J. Lett. 327, L81 (1988).

[126] O. G. Benvenuto, J. E. Horvath e H. Vucetich. Phys. Rev. Lett. 64, 713 (1990). 